
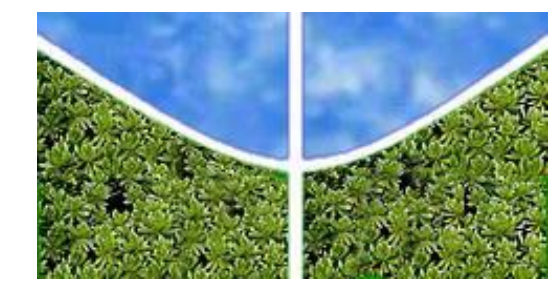

Universidade de Brasília

Instituto de Ciências Humanas

Departamento de Geografia

Programa de Pós-Graduação em Geografia - PPGEA

\title{
APLICABILIDADE DO MODELO SWAT NA SIMULAÇÃO DE VAZÃO EM BACIA HIDROGRÁFICA DO CERRADO UTILIZANDO VALORES DE PARÂMETROS REGIONALIZADOS
}

\author{
Felippe Damião Mello di Silva \\ Orientador: Dr. Roberto Arnaldo Trancoso Gomes \\ Coorientador: Dr. Jorge Enoch Furquim Werneck Lima
}

Dissertação de Mestrado

Brasília - DF, setembro de 2016 

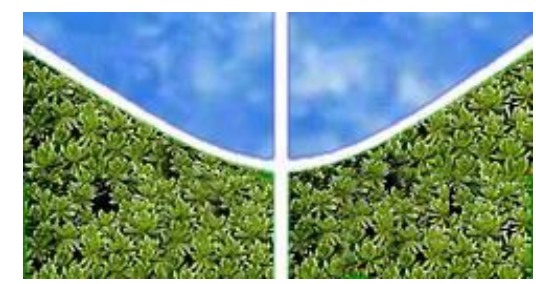

Universidade de Brasília

Instituto de Ciências Humanas

Departamento de Geografia

Programa de Pós-Graduação em Geografia - PPGEA

\section{APLICABILIDADE DO MODELO SWAT NA SIMULAÇÃO DE VAZÃO EM BACIA HIDROGRÁFICA DO CERRADO UTILIZANDO VALORES DE PARÂMETROS REGIONALIZADOS}

\section{Felippe Damião Mello di Silva}

Dissertação de Mestrado submetida ao Departamento de Geografia da Universidade de Brasília, como parte dos requisitos necessários para a obtenção do Grau de Mestre em Geografia, área de concentração Gestão Ambiental e Territorial, linha de pesquisa Análise de Sistema Naturais, opção Acadêmica.

Aprovado por:

$\overline{\text { Prof. Dr. Roberto Arnaldo Trancoso Gomes }}$ Universidade de Brasília (Orientador)
Dr. Jorge Enoch Furquim Werneck Lima Embrapa (Coorientador)
Prof. Dr. Osmar Abílio de Carvalho Júnior

Universidade de Brasília

(Examinador Interno)
Dr. Jean-Michel Martinez

Institut de recherche pour le

dèveloppement

(Examinador Externo)

Brasília - DF, setembro de 2016 
FICHA CATALOGRÁFICA

SILVA, FELIPPE DAMIÃO MELLO DI

Aplicabilidade do modelo Swat na simulação de vazão em bacia hidrográfica do Cerrado utilizando valores de parâmetros regionalizados, 90 p., 297 mm, (UnBIH-GEA-LSIE, Mestrado, 2016).

Dissertação de Mestrado - Universidade de Brasília. Departamento de Geografia.

$\begin{array}{ll}\text { 1. Modelagem hidrológica } & \text { 2. SWAT }\end{array}$

3. Análise de sensibilidade 4. Calibração

5. Verificação

\section{REFERÊNCIA BIBLIOGRÁFICA}

SILVA, Felippe Damião Mello di. Aplicabilidade do modelo Swat na simulação de vazão em bacia hidrográfica do Cerrado utilizando valores de parâmetros regionalizados. Dissertação de Mestrado, Curso de Pós-Graduação em Geografia, Universidade de Brasília, 2016, 90 p.

\section{CESSÃO DE DIREITOS}

É concedida à Universidade de Brasília permissão para reproduzir cópias desta dissertação e emprestar ou vender tais cópias somente para propósitos acadêmicos e científicos. O autor reserva outros direitos de publicação e nenhuma parte desta dissertação de mestrado pode ser reproduzida sem a autorização por escrito do autor. 


\section{DEDICATÓRIA}

Dedico este trabalho à minha família, em especial aos meus pais, Elizia Silvane Mello Pimenta e Marcos Antônio Pimenta Jr, que sempre estiveram ao meu lado em tudo e para tudo, me apoiando, aconselhando, educando e me ajudando a transpor todos os obstáculos presentes em minha jornada. 


\section{AGRADECIMENTOS}

Primeiramente a Deus que iluminou meu caminho durante esta jornada e a toda minha família, que sempre esteve ao meu lado dando carinho e apoio, sem medir esforços para que eu vencesse mais esta etapa.

Ao meu orientador Roberto Arnaldo Trancoso Gomes e ao coorientador Dr. Jorge Enoch Furquim Werneck Lima, pela confiança em minha capacidade para a conclusão deste trabalho, orientação, reflexões, discussões, incentivos acadêmicos e profissionais, ensinamentos, paciência e amizade.

À Universidade de Brasília e aos professores do Programa de Pós-Graduação em Geografia pela dedicação, ensinamentos, paciência e conhecimento que me transmitiram no decorrer do curso.

À Empresa Brasileira de Pesquisa Agropecuária (Embrapa), especialmente o Centro de Pesquisa Agropecuária do Cerrado (CPAC) que me deu suporte técnico e pela disponibilização dos dados.

À Coordenação de Aperfeiçoamento de Pessoal de Nível Superior (CAPES), pelo auxílio financeiro para o desenvolvimento das atividades do mestrado.

Aos amigos e colegas que fizeram parte e estiveram presentes nas diferentes etapas que trilhei neste período. Agradeço a amizade, parceria e cumplicidade, que serão sempre lembradas no decorrer da vida.

Agradeço aos integrantes da banca examinadora que gentilmente aceitaram o convite. 


\section{RESUMO}

A disponibilidade hídrica vem diminuindo gradativamente devido aos desordenados processos de urbanização, industrialização e expansão agrícola. Neste contexto, para a realização de uma gestão adequada dos recursos hídricos é imprescindível a utilização de bases de dados confiáveis. A aplicação de modelos vem sendo amplamente difundida com o objetivo de se reduzir o nível de incerteza e subjetividade, visto isto, esse trabalho teve como objetivo avaliar o desempenho do modelo SWAT (Soil and Water Assessment Tool) na predição da vazão na bacia hidrográfica do Rio Preto. Foram realizadas 12 simulações, onde variou-se: Modelo Digital de Elevação (MDE), quantidade de unidade de resposta hidrológica (HRU), quantidade de iterações no processo de calibração, estações climatológicas e fluviométricas. Para as simulações foram utilizadas séries mensais que se estenderam de 1981 a 2000 para o período de calibração e de 2001 a 2010 para a verificação. Para a calibração, foram utilizados 8 parâmetros, sendo que os mais influentes foram: a capacidade de água disponível no solo (SOL_AWC) e a curva número (CN2). Para avaliação dos resultados foram aplicados 3 coeficientes de análise: Nash-Sutcliffe (NSE), porcentagem BIAS (PBIAS) e a padronização do Root Mean Square Error (RSR). O modelo apresentou melhores resultados para o período de calibração em relação ao período de verificação. Em praticamente todas as simulações 0 modelo superestimou os picos e apresentou um retardo sistêmico na fase de recessão das vazões. As variáveis do balanço hídrico (precipitação, evapotranspiração, escoamentos superficial e de base) apresentaram resultados coerentes considerando as características físicas da área de estudo (bioma Cerrado), embora, o escoamento superficial tenha sido superestimado e a evapotranspiração tenha sido subestimada em relação à trabalhos semelhantes. A partir dos resultados obtidos, foi possível concluir que o modelo SWAT é passível de ser utilizado como ferramenta de auxílio na elaboração de políticas públicas com foco na gestão dos recursos naturais.

Palavras-chaves: Modelagem hidrológica; SWAT; Análise de sensibilidade; Calibração; Verificação. 


\begin{abstract}
The water availability is declining gradually due to disordered processes of urbanization, industrialization and agricultural expansion. In this context, to carry out proper management of water resources is essential to the use of reliable databases. The application of models has been widely disseminated in order to reduce the level of uncertainty and subjectivity, because this, this study aimed to evaluate the performance of the SWAT model (Soil and Water Assessment Tool) in predicting the flow in the Preto river basin. 12 simulations were performed, which was varied: Digital Elevation Model (DEM), amount of hydrologic response unit (HRU), number of iterations in the calibration process, climatological and gauged stations. For the simulations were used monthly series that extended from 1981 to 2000 for the calibration period and 2001-2010 for verification. For calibration, 8 parameters were used, and the most influential were the available water capacity in the soil (SOL_AWC) and the number curve (CN2). To evaluate the results were applied 3 analysis coefficients: Nash-Sutcliffe (NSE), percentage BIAS (PBIAS) and the standardization of the Root Mean Square Error (RSR). The model showed better results for the calibration period for verification period. In almost all the simulations the model overestimated the peaks and presented a systemic delay in the recession phase of the flow. The variables of the water balance (precipitation, evapotranspiration, surface runoff and base) showed consistent results considering the physical characteristics of the study area (Cerrado), although the runoff has been overestimated and evapotranspiration has been underestimated in relation to work like. From the results, it was concluded that the SWAT model is likely to be used as a tool in the development of public policies with a focus on natural resource management.
\end{abstract}

Keywords: Hydrologic modeling; SWAT; Sensitivity analysis; Calibration; Verification. 


\section{SUMÁRIO}

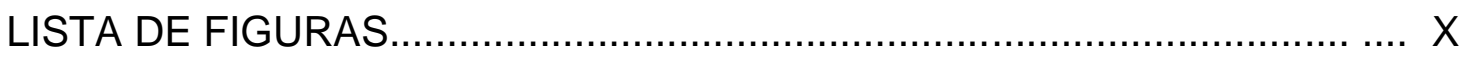

LISTA DE TABELAS.............................................................................. XII

LISTA DE ABREVIATURAS................................................................II

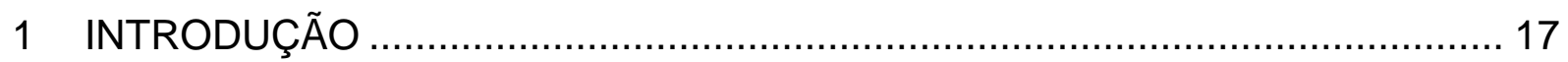

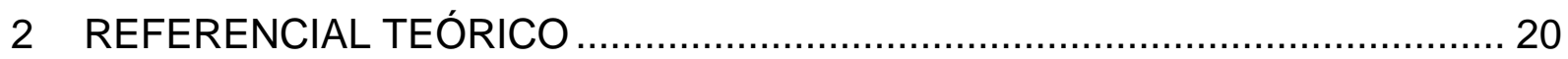

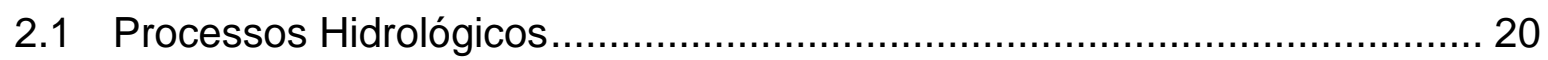

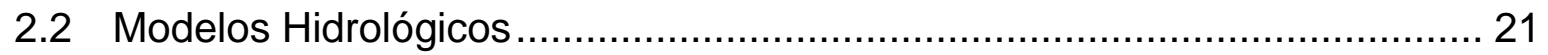

2.3 SWAT

2.4 Parâmetros de Análise de sensibilidade no SWAT ...................................... 29

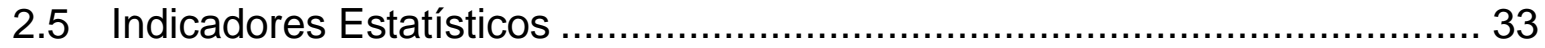

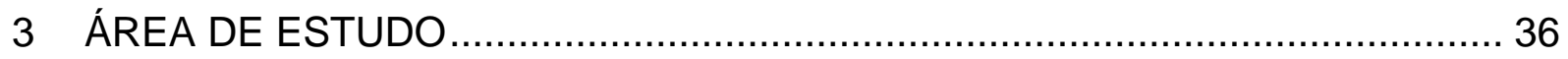

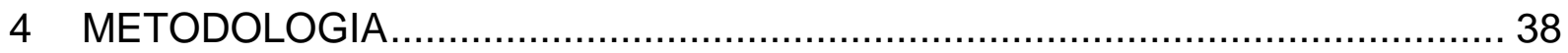

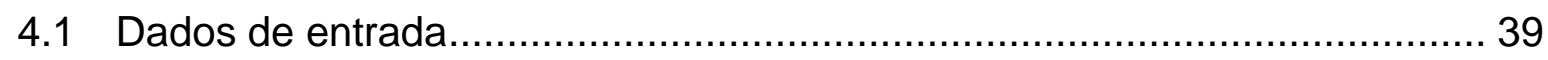

4.1.1 Tratamento do MDE ………............................................... 40

4.1.2 Mapa de Uso e Cobertura da terra ........................................... 41

4.1.3 Mapa de Tipos de Solo .......................................................... 43

4.1.4 Dados climáticos.................................................................. 45

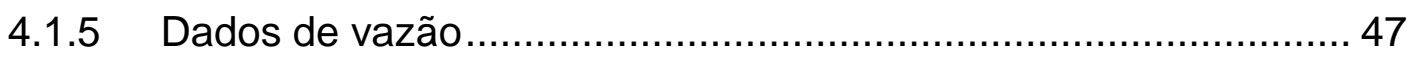

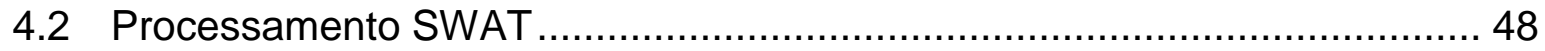

4.2.1 Simulação SWAT............................................................... 48

4.2.2 Calibração SWAT CUP ......................................................... 52

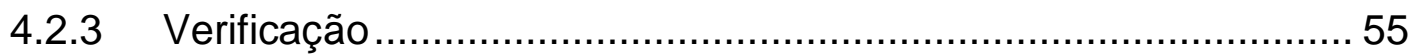

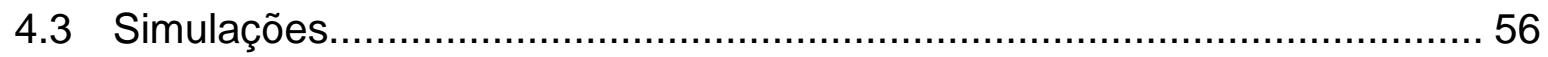

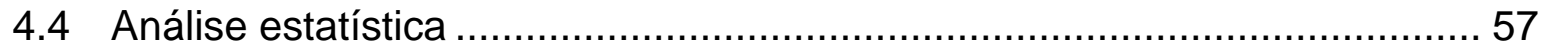

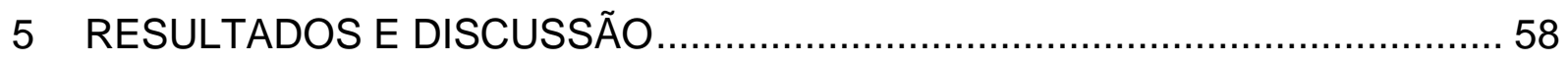

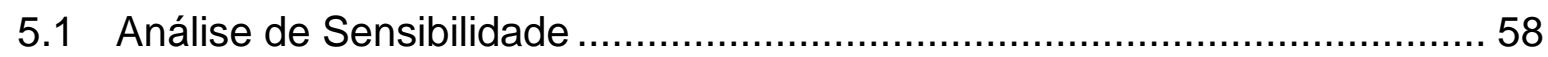




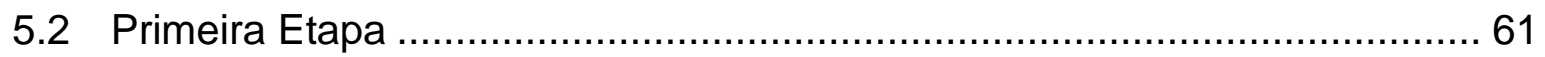

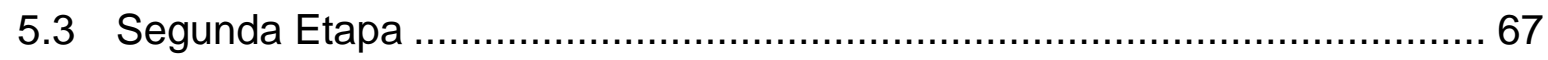

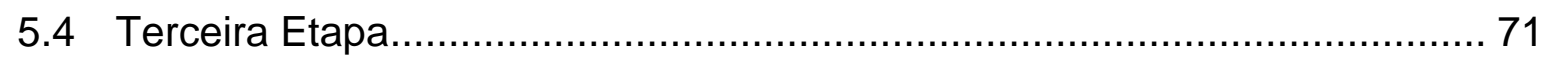

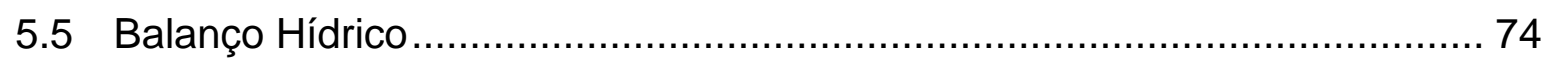

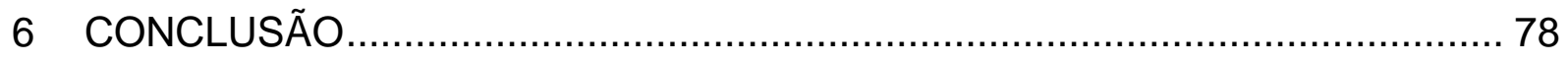

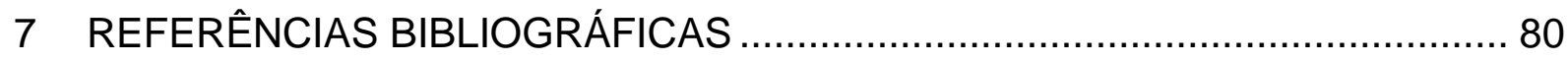




\section{LISTA DE FIGURAS}

Figura 1 - Representação do ciclo hidrológico global médio (Rebouças et al., 1999). 20

Figura 2 - Bacia hidrográfica do Rio Preto. 36

Figura 3: Esquema metodológico aplicado ao trabalho 39

Figura 4 - Mapa de Uso e Cobertura da Bacia do Rio Preto. ............................ 42

Figura 5 - Mapa de Solos da Bacia do Rio Preto. .......................................... 44

Figura 6 - Estações Climatológicas......................................................... 46

Figura 7 - Estações Fluviométricas da ANA.............................................. 47

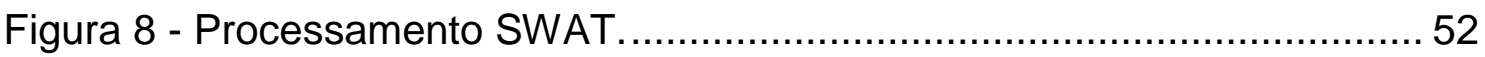

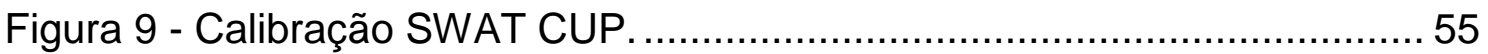

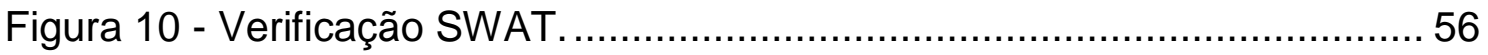

Figura 11 - Fluxo com as variáveis utilizadas em todas as simulações realizadas.

Figura 12 - Análise de sensibilidade global. ................................................ 58

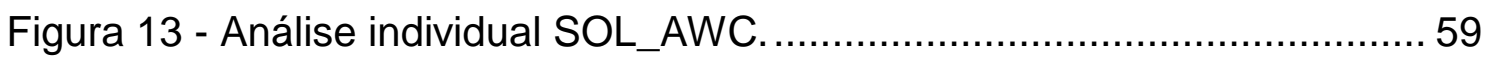

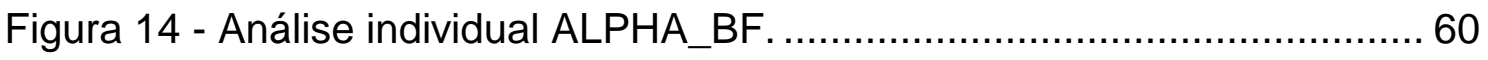

Figura 15 - Comparação entre dados de chuva com as vazões simuladas e observadas no período de calibração das combinações 1, 3, 5, 6 e 8 (Tabela 9).

Figura 16 - Comparação entre dados de chuva com as vazões simuladas e observadas no período de calibração das combinações 2, 4, 7 e 9 (Tabela 9).

Figura 17 - Comparação entre dados de chuva com as vazões simuladas e observadas no período de verificação das combinações 1, 3, 5, 6 e 8 (Tabela 9).

Figura 18 - Comparação entre dados de chuva com as vazões simuladas e observadas no período de verificação das combinações 2, 4, 7 e 9 (Tabela 9).

Figura 19 - Comparação entre dados de chuva com as vazões simuladas e observadas no período de calibração da combinação 10 (Tabela 11). 68 Figura 20 - Comparação entre dados de chuva com as vazões simuladas e observadas no período de verificação da combinação 10 (Tabela 11). 69 
Figura 21 - Comparação entre dados de chuva com as vazões simuladas e observadas no período de calibração da combinação 12 (Tabela 13) ............. 72 Figura 22 - Comparação entre dados de chuva com as vazões simuladas e observadas no período de verificação da combinação 11 e 12 (Tabela 13).... 73 


\section{LISTA DE TABELAS}

Tabela 1: Parâmetros mais sensíveis para a simulação do SWAT feitas em Bacias do Distrito Federal, bioma Cerrado (Santos, 2016)........................... 30

Tabela 2: Descrição dos principais parâmetros utilizados no Bioma Cerrado.. 31

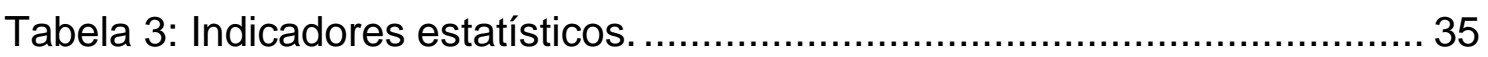

Tabela 4: Classes de Uso e Cobertura da Bacia do Rio Preto.......................... 43

Tabela 5: Classes de solos da Bacia do Rio Preto......................................... 45

Tabela 6: Parâmetros e intervalos utilizados para a modelagem da vazão no modelo SWAT para a área de estudo. ........................................................ 53

Tabela 7: Níveis de sensibilidade dos parâmetros........................................ 59

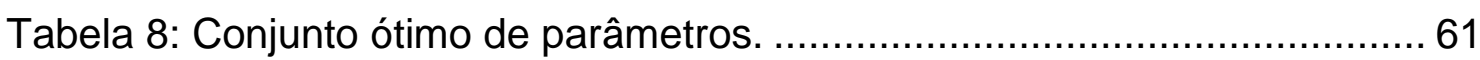

Tabela 9: Combinações geradas na primeira etapa........................................ 62

Tabela 10: Resultados estatísticos para a definição da melhor combinação de dados e procedimentos para modelar a vazão na bacia do Rio Preto com base

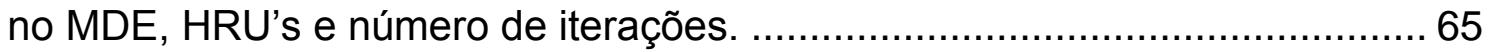

Tabela 11: Combinação gerada na segunda etapa.......................................... 68

Tabela 12: Resultados estatísticos para a definição da melhor combinação de dados e procedimentos para modelar a vazão na bacia do Rio Preto com dados climáticos de três estações climatológicas................................................... 69

Tabela 13: Combinações geradas na terceira etapa....................................... 71

Tabela 14: Resultados estatísticos das combinações da estação de referência de Porto dos Poções com parâmetros calibrados para a estação de Unaí e da estação de Porto dos Poções...................................................................... 73

Tabela 15: Parâmetros médios do ciclo hidrológico. ....................................... 75

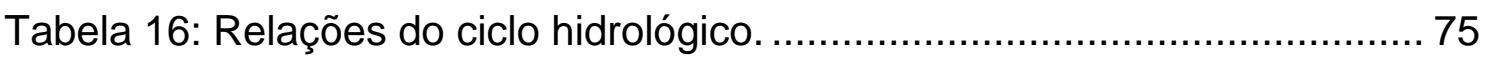

Tabela 17: Comparação entre as variáveis hidrológicas................................ 76 


\section{LISTA DE SIGLAS E ABREVIATURAS}

AGRC

Agricultural Land-Close-Grown

AGRL

Agricultural Land-Generic

ALPHA_BF

Fator alfa do fluxo de base (dias)

ANA

Agência Nacional das Águas

ARNO

Arno River Model

ARS

Serviço de Pesquisas Agrícolas

ASCE

American Society of Civil Engineers

BA

Bahia

CANMX

Capacidade máxima de armazenamento de água da cobertura formada pela vegetação

\begin{tabular}{ll} 
CERR & \multicolumn{1}{l}{ Cerrado } \\
CN & Curva Número \\
DF & Distrito Federal \\
EMBRAPA & Empresa Brasileira de Pesquisa Agropecuária \\
EPA & Agência de Proteção Ambiental \\
ESCO & Fator de compensação da evaporação do solo \\
ESRI & Enviromental Systems Research Institute \\
EUA & Estados Unidos da América \\
FF & Plintossolo Pítrico Concrecion
\end{tabular}


FRST

FX

GO

GW_DELAY

GWQMN

contribuinte (mgN/L)

HBV

HEC-HMS

System

HRU

HSPF

IBAMA

Renováveis

IBGE

INPE

MDE

MG

MMA

MMS

NASA

NGA
Forest-Mixed

Plintossolo Híplico Distréfico

Goiás

Retardo do escoamento subterrâneo

Concentração de nitrato na água subterrânea

Hydrological Simulation model

Hydrologic Engineering Center's Hydrologic Modeling

Hydrologic Simulation Program-Fortran

Instituto Brasileiro do Meio Ambiente e dos Recursos

Instituto Brasileiro de Geografia e Estatística

Instituto Nacional de Pesquisas Espaciais

Modelo Digital de Elevação

Minas Gerais

Ministério do Meio Ambiente

Modular Modeling System

National Aeronautics and Space Administration

National Geospatial-Intelligence Agency 
NNW-SSE

NSE

NWS

PAST

PBIAS

PLANPAR

Rio Paracatu

$\mathrm{RL}$

RORB

$\mathrm{RQ}$

RSR

SHE

SIG

SOL_AWC solo)

SOL_K

SOMA BRASIL

Agricultura no Brasil

SRTM

Sufi2

SWAT
Nor-Noroeste/Su-Sudeste

Nash-Sutcliffe

National Weather Service

Pasture

Porcentagem Bias

Plano Diretor de Recursos Hídricos da Bacia do
Neossolo Lítico Distrífico

Runoff Routing Model

Neossolo Quartzarcnico Hidromórfico

Root Mean Square Error

Systeme Hydrologique Europeen

Sistema de Informação Geográfica

Capacidade de água disponível (mm H2O/mm

Condutividade hidráulica saturada $(\mathrm{mm} / \mathrm{h})$

Sistema de Observação e Monitoramento da

Shuttle Radar Topography Mission

Sequential Uncertainty Fitting

Soil and Water Assessment Tool 
SWM

Stanford Watershed Model

TOPIKAPI

Topgraphic Kinematic Approximationand Integration

TOPMODEL

Physically Based Runoff Production Model

UBC

University of British Columbia

UFGO

Universidade Federal de Goiás

UFU

Universidade Federal de Uberlândia

UHE QUEIMADO

Usina Hidrelétrica De Queimado

UNB

Universidade de Brasília

URBN

Residential

URHD

Residential-High Density

URMD

Residential-Medium Density

USGS

United States Geological Survey

USDA

Departamento de Agricultura dos EUA

WATFLOOD

Waterloo Flood System

WATR

Water

WBN

Watershed Bounded Network 


\section{INTRODUÇÃO}

O Cerrado é o segundo maior bioma brasileiro com cerca de 2.000 .000 $\mathrm{Km}^{2}$, correspondendo a aproximadamente $24 \%$ do território nacional e cobrindo 11 unidades da federação (IBGE, 2004). Esse bioma possui a maior biodiversidade e heterogeneidade de paisagens entre as savanas do mundo, embora crescentemente ameaçadas pela expansão agrícola (SILVA; BATES, 2002). Esse domínio da natureza contribui com a produção e distribuição de recursos hídricos para oito das doze grandes regiões hidrográficas brasileiras: Amazônica, Tocantins - Araguaia, Atlântico Nordeste Ocidental, Parnaíba, São Francisco, Atlântico Leste, Paraná e Paraguai (LIMA; SILVA, 2007).

A água é um bem natural, finito e indispensável para a existência da vida, sendo que sua disponibilidade relativa diminui gradativamente devido ao crescimento populacional e à degradação do meio ambiente $(\mathrm{CECH}, 2009$; TUCCI, 2009). Os problemas de escassez hídrica no Brasil são decorrentes, basicamente, da combinação entre o crescimento exagerado das demandas localizadas e da degradação da qualidade das águas. Os desordenados processos de urbanização, industrialização e expansão agrícola são os principais agravantes desse quadro. O setor agrícola é o que mais demanda por água no país, especialmente a irrigação, que consome cerca de $69 \%$ das vazões efetivamente consumidas (SETTI et al., 2001; ANA, 2005).

A bacia hidrográfica do rio Preto engloba áreas dos Estados de Goiás (GO), Minas Gerais (MG) e do Distrito Federal (DF), dentre os mais diversos usos, é considerada uma bacia com uso agrícola, abrigando diversos níveis de uso do solo, desde agricultura de subsistência até culturas mecanizadas, além de diferentes tipos de sistemas de produção, podendo ser de sequeiro ou irrigado (MALDANER, 2003). Tem-se também, geração de energia elétrica na Usina Hidrelétrica de Queimado (UHE Queimado) e áreas de captação para abastecimento humano, fatores que geram uma limitação ao aumento do consumo da água na bacia (CARNEIRO et al., 2007).

A área de estudo apresenta grande diversidade de usos na bacia, fator que se mostra diretamente relacionado a conflitos entre os usuários 
(MALDANER, 2003). Tais conflitos e a devida importância econômica, social e ambiental da bacia para região, faz com que sejam fatores de grande importância os estudos que possam servir de subsídio para políticas públicas e auxílio à tomada de decisões.

Neste contexto, para a realização de uma gestão adequada dos recursos hídricos, seria importante a utilização de bases de dados medidos em campo, porém, geralmente são insuficientes ou inexistentes. Sendo assim, uma alternativa é a aplicação de modelos que possam estimar o comportamento hidrológico de uma bacia hidrográfica, gerando resultados que podem dar subsídio para o entendimento dos processos e para a tomada de decisões sobre o uso múltiplo da água na unidade de gestão.

Os estudos de avaliação ambiental utilizam modelos para predizer cenários e estimar a magnitude das alterações a serem causadas pelas atividades estabelecidas ou outras a serem desenvolvidas. $O$ uso de modelos matemáticos permite avaliar e compreender o comportamento dos processos, podendo contribuir para o planejamento do uso racional dos recursos naturais, fornecendo suporte à implementação de práticas conservacionistas e sustentáveis. Dentre os modelos disponíveis para a modelagem hidrológica de bacias hidrográficas, destaca-se o SWAT (Soil and Water Assessment Tool), um programa que trabalha como interface vinculada a um software de SIG (Sistema de Informação Geográfica) e é um modelo de base física, semidistribuído, computacionalmente eficiente e que permite simular longos períodos de séries de vazão de forma contínua. Portanto, neste trabalho é apresentada uma abordagem metodológica que visa o uso da modelagem hidrológica para estimar vazões em locais não monitorados.

O objetivo deste trabalho é avaliar a aplicabilidade do modelo SWAT na simulação de vazão em bacia hidrográfica do Cerrado utilizando parâmetros regionalizados. Tendo como objetivos específicos: determinar os parâmetros mais relevantes do modelo SWAT a serem utilizados na simulação da vazão em bacia do bioma Cerrado; avaliar as combinações de dados e procedimentos para modelar a vazão na bacia do Rio Preto com base nos seguintes fatores: tratamento ou não do Modelo Digital de Elevação (MDE); discretização das 
Unidades de Resposta Hidrológica (HRU's); e número de iterações no processo de calibração; avaliar a influência da quantidade de estações climatológicas utilizadas nos resultados da modelagem da vazão na bacia do Rio Preto; e analisar o balanço hídrico gerado nas simulações de vazão na bacia do Rio Preto, por processo hidrológico. 


\section{REFERENCIAL TEÓRICO}

\subsection{Processos Hidrológicos}

Pesquisas recentes estimaram a quantidade total de água no planeta em 1.386 milhões de $\mathrm{km}^{3}$ e que este valor tem permanecido constante ao longo dos últimos 500 milhões de anos. Contudo, a água está em constante movimento em um ciclo fechado nos diversos compartimentos, ou reservatórios, que compõem a Terra, alternando continuamente entre suas formas físicas: líquida, sólida e gasosa (REBOUÇAS; BRAGA; TUNDISI, 1999).

O ciclo hidrológico refere-se a esse fenômeno global de circulação fechada da água entre a atmosfera e a superfície terrestre. Os fluxos são essencialmente impulsionados pela distribuição não uniforme da energia solar que atinge a superfície, sendo também associados à força gravitacional e à rotação do planeta (TUCCI, 2012). A Figura 1 apresenta os principais fluxos do ciclo hidrológico.

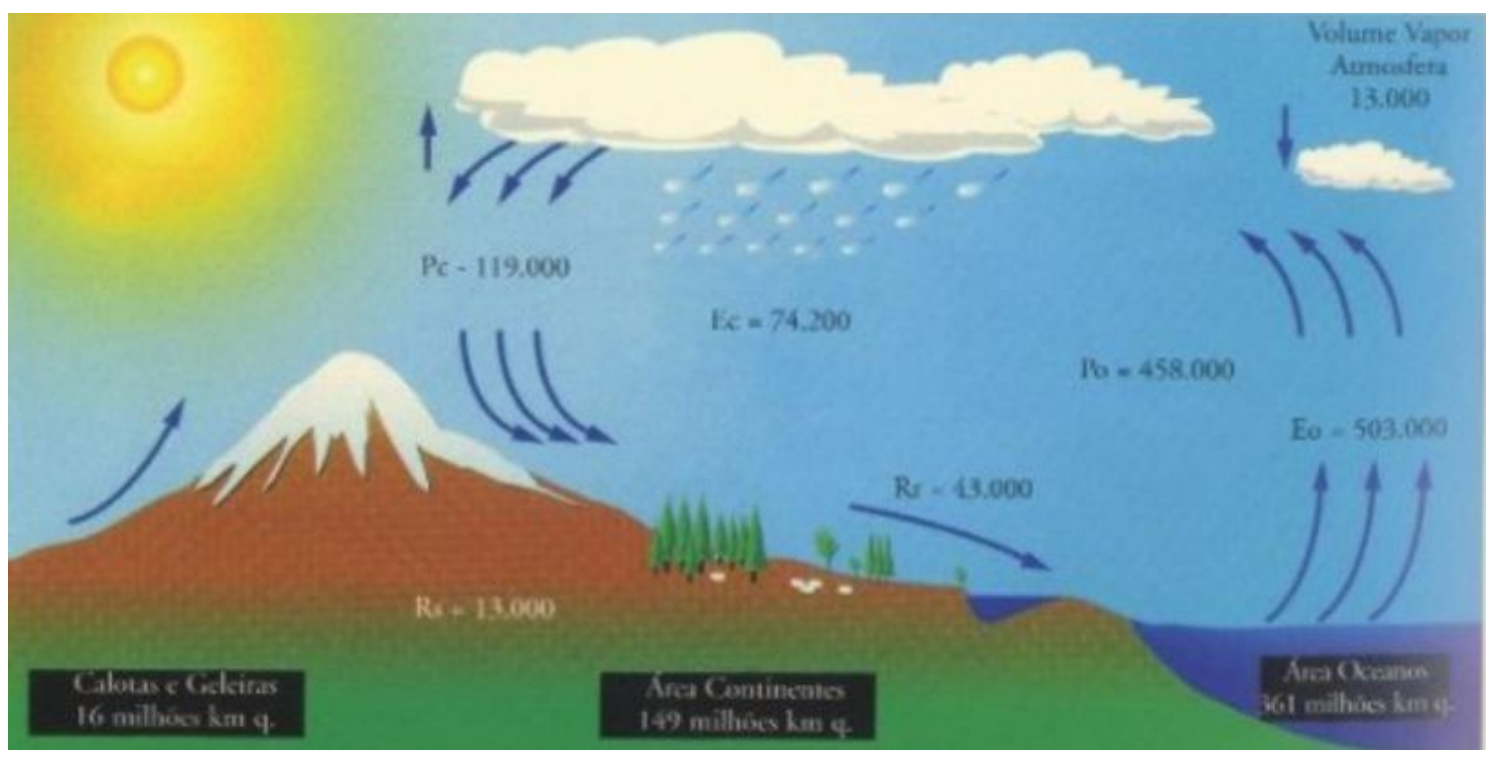

Figura 1 - Representação do ciclo hidrológico global médio (Rebouças et al., 1999). 
Usualmente, em análises do ciclo hidrológico, a unidade fundamental de estudo é a bacia hidrográfica. O conceito de bacia hidrográfica refere-se a uma região natural de captação de água precipitada, em que os diversos fluxos desenvolvidos na região são direcionados a um único ponto de saída, conhecido por exutório. Forma-se, assim, um conjunto (ou rede) de drenagem produzido pelas superfícies de captação que confluem até formarem um leito único (TUCCI, 2012).

De modo geral, os processos hidrológicos desenvolvidos nas bacias hidrográficas detêm direções de fluxo vertical e longitudinal. O primeiro é representado pela precipitação e pela evapotranspiração, enquanto que o segundo é constituído pelo escoamento ao longo dos gradientes da superfície e do subsolo (TUCCI; CLARKE, 1997).

\subsection{Modelos Hidrológicos}

Um modelo pode ser a representação de um sistema, esquema ou procedimento que em determinado tempo se inter-relaciona com uma entrada, causa ou estímulo de energia ou informação, e uma saída, efeito ou resposta de energia ou informação (DOOGE, 1973; TUCCI, 1998).

Os modelos hidrológicos surgiram com a necessidade de se obter séries hidrológicas mais longas e representativas de vazões para diferentes projetos de recursos hídricos (TUCCI, 2005). A modelagem hidrológica surgiu há mais de um século a partir do equacionamento de alguns processos hidrológicos, como por exemplo, os estudos da relação chuva-vazão que foram iniciados com o desenvolvimento do método racional por Mulvany (1850).

$\mathrm{Na}$ década de 1930, foram registrados os primeiros trabalhos com modelos hidrológicos, onde se tem: a teoria da hidrógrafa unitária (SHERMAN, 1932) e a teoria da infiltração (HORTON, 1933), os quais tinham como objetivo identificar os fatores relacionados aos processos de transformação da precipitação em escoamento e suas iterações. Em 1948, Thornthwaite e Penman 
também contribuíram para a produção de trabalhos com modelos hidrológicos através de estudos sobre modelos de evapotranspiração (FAYAL, 2008).

De acordo com Tucci (2005), até a década de 1950, havia uma tendência ao desenvolvimento de modelos hidrológicos empíricos, desconsiderando a participação dos fenômenos físicos inerentes aos processos. Normalmente, os métodos empregados na área de hidrologia eram restritos a indicadores estatísticos de processos.

Com o aumento da disponibilidade de computadores, a partir do final da década de 1950, criaram-se condições que propiciaram um acelerado processo de desenvolvimento de modelos hidrológicos baseados em conceitos físicos, sendo uma alternativa em relação aos modelos até então existentes e que utilizavam somente métodos estocásticos (TUCCI, 1998).

A simulação de praticamente toda a bacia hidrográfica por meio da integração de diferentes componentes do ciclo hidrológico foi possível somente com o início da revolução digital na década de 1960 (FERRIGO et al., 2013). O modelo SWM (Stanford Watershed Model), hoje HSPF (Hydrologic Simulation Program-Fortran), desenvolvido por Crawford e Linsley (1966) foi, provavelmente, a primeira tentativa de modelar praticamente todo o ciclo hidrológico, o qual introduziu a avaliação da distribuição espacial da infiltração.

Desde a década de 1970, tem aumentado gradualmente o desenvolvimento de modelos hidrológicos e a complexidade dos sistemas modelados, acompanhando os avanços no meio digital (FERRIGO et al., 2013). A partir destes avanços, a modelagem hidrológica tem sido desenvolvida e tem originado diversos modelos, variando de acordo com os objetivos e a escala de aplicação, desde modelos voltados para o dimensionamento de reservatórios até os que preveem alterações nas vazões de uma bacia devido a mudanças climáticas.

Segundo Engman (1996), o gerenciamento integrado dos recursos hídricos depende da disponibilidade de dados adequados para a construção e verificação de modelos representativos dos processos hidrológicos. A simulação 
hidrológica é influenciada pela heterogeneidade física da bacia hidrográfica e pelos processos envolvidos, o que tem propiciado um desenvolvimento de um grande número de modelos que se diferenciam em função dos dados utilizados, da discretização, das prioridades da representação dos processos, da escala espacial e temporal e dos objetivos a serem alcançados (TUCCI, 1998).

Um modelo hidrológico pode ser definido como uma representação dos componentes hídricos, o qual pode descrever a distribuição espacial da precipitação, as perdas por interceptação, evaporação, o movimento da água no solo causado pela infiltração, percolação, entrada e saída de água subterrânea, o escoamento superficial, subsuperficial e nos canais de escoamento, ou apenas representar parte dessas variáveis, dependendo do tipo de modelo e a que ele se dispõe, como por exemplo, modelos chuva-vazão (RENNÓ; SOARES, 2000).

Os modelos hidrológicos são classificados com base em diferentes aspectos tais como: o tipo de variáveis utilizadas na modelagem (estocásticos ou determinísticos); o tipo de relações entre essas variáveis (empíricos ou conceituais); a forma de representação dos dados (discretos ou contínuos); a existência ou não de relação espacial (concentrados ou distribuídos) e a existência de dependência temporal (estáticos ou dinâmicos) (TUCCI, 2005).

Uma das propriedades mais importantes de um modelo hidrológico talvez seja o grau de representação das variações espaciais e temporais nos parâmetros de entrada e saída, os quais podem caracterizar entre um modelo concentrado e um modelo distribuído. Nos modelos concentrados, assume-se que os parâmetros e variáveis variam somente com o tempo, enquanto que nos modelos distribuídos, os parâmetros e variáveis variam tanto no espaço quanto no tempo (SANTOS, 2002).

Os modelos distribuídos não garantem, necessariamente, melhores resultados do que alguns modelos semiconceituais concentrados, mas permite realizar com melhor embasamento a modificação das características do sistema, o que é praticamente impossível por meio dos modelos semiconceituais, devido ao excesso de empirismo e da característica concentrada de sua formulação (TUCCI, 1998). 
A discretização espacial de bacias hidrográficas possui dois tipos de abordagem: uma onde a divisão é realizada de acordo com a divisão de subbacias, que geralmente é obtida com base na drenagem e são considerados modelos semidistribuídos, e a outra, a discretização é baseada na divisão do espaço em campos contínuos, formando uma grade regular em que cada campo corresponde a uma célula, permitindo dessa forma um maior nível de detalhe (RENNÓ; SOARES, 2000).

O monitoramento e a modelagem de bacias hidrográficas, sejam elas experimentais ou representativas, fornecem informações essenciais para a compreensão de fenômenos e processos hidrológicos, além de servirem como subsídio para os sistemas de gestão de recursos hídricos (LIMA et al., 2014). Nesse contexto, diversos autores atestaram a potencialidade da utilização de modelos matemáticos associados ao uso de geotecnologias para a simulação dos processos hidrológicos em bacias hidrográficas. Correia, Ribeiro e Baptista (2015) argumenta que essa associação viabiliza o desenvolvimento de uma análise espacialmente distribuída dos fenômenos que integram a dinâmica hidrológica dentro da bacia.

Arnold e Allen (1996) ressaltam a importância de modelar os principais componentes hidrológicos para a análise de impactos quanto às mudanças na vegetação, na captação de água, no gerenciamento de reservatório e em outros. Além disso, os autores indicam que os modelos devem prover cenários realísticos e ser capazes de realizar simulações com vários componentes hidrológicos simultaneamente.

Atualmente, está disponível uma variedade de modelos específicos para simulações em bacias hidrográficas, os quais têm sido largamente utilizados em diversos países. As principais diferenças entre os modelos referem-se a sua forma de processamento, dos componentes do ciclo hidrológico e ao próprio objetivo, ou finalidade, a que o software se dispõe a cumprir (FERRIGO, 2014). Dentre alguns modelos que se destacam, temos:

HSPF (Hydrologic Simulation Program-Fortran) - é um modelo que simula o escoamento superficial e cargas não pontuais de poluentes em bacias 
hidrográficas. Necessita de uma grande quantidade de dados e informações do local para representar com precisão os processos de hidrologia e de qualidade da água na bacia (BICKNELL et al., 1996).

PRMS (Precipitation-Runoff Modeling System) - caracterizado como um modelo físico, de parâmetros distribuídos, sendo desenvolvido com o objetivo de avaliar os efeitos de diferentes combinações de precipitação, clima e uso do solo na bacia hidrográfica. Simula as respostas entre as variáveis do ciclo hidrológico de forma contínua ou de eventos (LEAVESLEY et al., 1983).

WEPP (Water Erosion Prediction Project) - modelo desenvolvido para ser aplicado a grandes bacias. É um modelo conceitual de base física, semidistribuído. A simulação da erosão é baseada na geração estocástica do clima, na teoria de infiltração, na física do solo, na ciência das plantas e na hidráulica e mecânica da erosão (FLANAGAN; NEARING, 1995).

TOPMODEL - modelo no qual os processos hidrológicos são representados utilizando relações físicas. Considerado um modelo semidistribuído, onde a discretização da bacia é em sub-bacias, mas a distribuição é em função de fator topográfico (topographic index) obtido através de mapas detalhados (BEVEN; KIRKBY, 1979).

SHE (System Hydrologic Europe) - Consiste num modelo de base física e parâmetros distribuídos, em que a bacia é discretizada por uma grade horizontal e vertical, sendo aplicado para diversos problemas hidrológicos. Porém, o modelo requer grande número de informações e uma dispendiosa estrutura computacional, o que pode inviabilizar a sua utilização para alguns seguimentos (ABBOTT, 1986; BATHURST, 1986).

ANSWERS (Areal Nonpoint Source Watersehed Environment Response Simulation) - aborda o conceito de parâmetros distribuídos para modelar os processos hidrológicos espacialmente variáveis de um único evento. É composto por dois componentes principais: hidrologia e resposta de erosão (BEASLEY; MONKE; HUGGINS, 1977). 
ANSWERS-Continuous (Areal Nonpoint Source Watersehed Environment Response Simulation Continuous) - tem a mesma finalidade do ANSWERS, no entanto, trabalha de forma contínua (BOURAOUI; BRAUD; DILLAHA, 2002).

HEC-HMS (Hydrologic Engineering Center's - Hydrologic Modeling System) - caracterizado como um modelo de base física, semidistribuídos, simula processos de chuva-vazão e tem capacidades para operação de reservatórios. $O$ modelo permite trabalhar com rotinas sub-diárias, onde 0 escoamento do evento é modelado pelo método SCS Curve Number o o método de infiltração de Green-Ampt (USACE, 1999).

QUAL2E - é um modelo de simulação da qualidade da água, aplicável a rios dendríticos e de boa mistura. Simula a concentração de oxigênio dissolvido associado a outras variáveis de qualidade de água, como a temperatura, clorofila-a, nitrogênio orgânico, nitrogênio amoniacal, nitrito, nitrato, fósforo, dentre outras (BROWN; BARNWELL, 1987).

SWAT - é um modelo conceitual, semidistribuído, contínuo, computacionalmente eficiente, sendo desenvolvido para auxiliar os gestores de recursos hídricos a prever e avaliar o impacto das alterações do uso e manejo do solo, em grandes bacias hidrográficas não monitoradas. É um modelo que vem sendo amplamente utilizado em diversos países (ARNOLD et al., 1998).

Neste trabalho foi utilizado o SWAT para a realização das simulações, devido as características do modelo e dos objetivos propostos.

\subsection{SWAT}

Os modelos hidrológicos de uma forma geral têm como limitação a quantidade e confiabilidade dos dados hidrológicos disponíveis, bem como a dificuldade de formular matematicamente alguns processos e simplificações do comportamento espacial de variáveis e fenômenos. 
O SWAT é um modelo em escala de bacia hidrográfica, desenvolvido no Departamento de Agricultura dos Estados Unidos (USDA) - Serviço de Pesquisas Agrícolas (ARS), criado para predizer o impacto de práticas de manejo da terra e da água, produção de sedimentos e agroquímicos em bacias hidrográficas (NEITSCH et al., 2005a).

Desde sua primeira versão, no começo da década de 90, o modelo vem sofrendo contínuas revisões e expansões de suas capacidades, sendo que o primeiro relato de aplicação na literatura científica foi de Engel et al. (1993).

A eficácia do SWAT na representação da distribuição espacial do uso e ocupação da terra, tipos de solo e declividade, aliado à diversidade de parâmetros capazes de controlar os processos que compõem o ciclo hidrológico, torna o modelo um dos mais utilizados no mundo (SILVA et al., 2013).

Como o SWAT é considerado um modelo semidistribuido, a bacia hidrográfica é dividida em sub-bacias, que podem ser subdivididas em unidades de resposta hidrológica (HRU's - Hydrologic Response Units), que consistem, basicamente, em áreas homogêneas de uso da terra, declividade e tipo de solo.

Os dados referentes aos solos no SWAT podem ser divididos em dois grupos: as características físicas e químicas do solo. As propriedades físicas regem o movimento de percolação da água e do ar pelo perfil estratigráfico do solo, e têm grande influência no ciclo hidrológico dentro da bacia. As características químicas, por outro lado, são usadas para definir os níveis iniciais dos diferentes componentes químicos que integram a estrutura do solo.

Para descrever a relação entre as variáveis de entrada e saída, o SWAT necessita de dados específicos, como o MDE, mapa de solo, mapa de uso e ocupação da terra, todos estes necessários para a formação das HRU's, e os dados climáticos. Os processos físicos associados ao movimento da água e dos sedimentos, crescimento de plantas, ciclagem de nutrientes e outros, como exemplo, são modelados diretamente pelo SWAT utilizando os dados de entrada mencionados (NEITSCH et al., 2005a). 
A componente hidrológica do modelo SWAT é composta por várias subrotinas, dentre elas: escoamento superficial, percolação, fluxo lateral subsuperficial, fluxo de retorno do aquífero raso e evapotranspiração (NEITSCH et al., 2005a).

As simulações de vazão utilizam séries históricas obtidas em estações fluviométricas utilizando dados diários e/ou mensais (FERRIGO, 2014; FERNANDES, 2012). É possível notar que a escolha da escala temporal da série de vazões (diária ou mensal), a ser utilizada nas simulações, considera alguns aspectos principais, como extensão da série, precisão e confiabilidade dos dados e número de falhas na série.

No Brasil, o SWAT vem sendo utilizado em uma série de trabalhos, como Oliveira e Medeiros (1999), Neves, Silva e Crestana (2006), Santos et al. (2006), Adriolo et al. (2008), Mercuri et al. (2009), Uzeika (2009), Marchioro et al. (2011), Fernandes, Galvíncio e Freire (2012), Malutta (2012), Salles (2012) e Castro (2013).

Oliveira e Medeiros (1999), realizaram uma pesquisa que tinha como objetivo principal, analisar o potencial da utilização do SWAT para a avaliação da bacia hidrográfica do Rio Joanes - BA em função das alterações no uso do solo. Sendo este, um dos primeiros trabalhos registrados que utilizou SWAT no Brasil.

Salles (2012) aplicou o modelo SWAT na bacia hidrográfica do ribeirão Pipiripau - DF para realizar simulações de vazão. O modelo foi calibrado manualmente em relação à vazão média mensal observada da estação fluviométrica FRINOCAP em um período de dez anos, no período de 1989 a 1998, e depois validado em uma série independente (1999 a 2008). Após a calibração do modelo, os resultados obtidos indicaram um bom ajuste entre a vazão média mensal da bacia hidrográfica simulada pelo modelo SWAT em relação aos dados observados. A simulação da vazão média mensal também foi satisfatória no período selecionado para verificação do modelo. 
No estudo de Castro (2013) foi realizado um teste com a simulação de vazões médias mensais e diárias na bacia do Alto Rio Jardim - DF, utilizando o modelo SWAT, a série histórica (julho de 2006 a junho de 2008) e dados físicos da área. A simulação não conseguiu representar a realidade de forma satisfatória sem a calibração dos parâmetros, porém, após a calibração, o modelo apresentou boa representatividade da vazão diária da bacia.

Esse modelo vem sendo aplicado como uma eficiente ferramenta no auxílio de profissionais que atuam em seguimentos conservacionistas em bacias hidrográficas. Diante de estudos promissores, a utilização do modelo SWAT em diversos locais do mundo torna-se um suporte para resultados e fundamentação científica, motivando discussões e propostas de soluções aos problemas ambientais em bacias hidrográficas (UZEIKA, 2009).

\subsection{Parâmetros de Análise de sensibilidade no SWAT}

Além dos dados de entrada já mencionados, as simulações no SWAT também requerem a definição prévia dos parâmetros a serem calibrados de acordo com a influência que exercem sobre o modelo no processo de predição de vazão na área de estudo.

O primeiro passo para o processo de calibração e verificação do modelo é a determinação dos parâmetros mais sensíveis para a bacia hidrográfica em estudo, que deve ser realizada com base em opinião especializada e/ou análise de sensibilidade (ARNOLD et al., 2012a).

A análise de sensibilidade é uma etapa importante no processo de calibração do modelo, pois identifica os parâmetros que levam a um melhor entendimento do modelo e do seu desempenho e, com isso são reduzidas as incertezas inerente ao processo de simulação (LENHART, 2002).

O usuário deve determinar quais parâmetros ajustar, bem como seus devidos intervalos de aplicação, tendo como objetivo avaliar a resposta do modelo. A delimitação dos intervalos de cada parâmetro pode ser determinada 
de acordo com a avaliação da variação fisicamente possível, quando disponível e retratado na literatura (ARNOLD et al., 2012a).

A escolha dos parâmetros é bastante relevante para a diminuição dos erros na modelagem, onde se busca compreender melhor o sistema modelado, identificando quais parâmetros de entrada apresentam maior efeito sobre as respostas do modelo. Tendo como objetivo uma melhoria na proximidade dos valores simulados em relação aos valores observados de vazão.

Santos (2016) fez uma compilação de diversos trabalhos realizados em bacias do Distrito Federal comparando os parâmetros mais sensíveis para a simulação no SWAT no Bioma Cerrado (Tabela 1).

Tabela 1: Parâmetros mais sensíveis para a simulação do SWAT feitas em Bacias do Distrito Federal, bioma Cerrado (Santos, 2016).

\begin{tabular}{|l|l|l|}
\hline Parâmetros mais sensíveis & Autor & Data \\
\hline $\begin{array}{l}\text { SURLAG, GWQMN, CN2, GW_REVAP, RCHRG_DP, } \\
\text { SOL_K }\end{array}$ & Sarmento & 2010 \\
\hline CN2, ALPHA_BF, CH_K2, ESCO, GW_DELAY,CH_N2 & Strauch & 2011 \\
\hline $\begin{array}{l}\text { ESCO, ALPHA_BF, GW_DELAY, SOL_Z, CHK2, BLAI, } \\
\text { SOL_AWC, FN2, SOL_K, GWQMN,SLOPE }\end{array}$ & 2011 \\
\hline $\begin{array}{l}\text { ALPHA_BF, CN2,GW_DELAY, GWQMN, GW_REVAP, } \\
\text { ESCO, FLSUBBSN }\end{array}$ & Ferrigo & 2012 \\
\hline $\begin{array}{l}\text { ESCO, ALPHA_BF, GW_QMN, SURLAG, GWREVAP, } \\
\text { CN2, CH_K2, SClles }\end{array}$ & 2012 \\
\hline $\begin{array}{l}\text { SURLAG, ALPHA_BF, CN2, GWQMN, SOL_K, CH_K2, } \\
\text { SLOPE, SLSUBBSN,BLAI E SOL_ALB }\end{array}$ & Castro & 2013 \\
\hline $\begin{array}{l}\text { CN2, SOL_K, ESCO, GW_DELAY, SURLAG, SOL_AWC, } \\
\text { SHALLST, Carvalho } \\
\text { RCHRGH_DP, GW_RE_, }\end{array}$ & 2014 \\
\hline $\begin{array}{l}\text { SOL_K, CN2, SOPL_AWC, SHALLST, ANION_EXCL, } \\
\text { REVAPMN, ESCO, ALPHA_BF, SOL_BD, DEEPST, } \\
\text { GW_REVAP, GWHT, GWQMN, GW_DELAY }\end{array}$ & Ferrigo & 2014 \\
\hline
\end{tabular}


Ao analisar os parâmetros mais utilizados para o Cerrado, destacam-se alguns que exercem influência direta no balanço hídrico e estão descritos na Tabela 2.

Tabela 2: Descrição dos principais parâmetros utilizados no Bioma Cerrado.

\begin{tabular}{|c|c|c|c|}
\hline Parâmetro & Definição & Unidade & Extensão \\
\hline $\mathrm{CN} 2$ & $\begin{array}{c}\text { Valor inicial de SCS curva número para condição de umidade II. A } \\
\text { curva SCS é função das caracteristicas de permeabilidade do solo, } \\
\text { uso e cobertura e condições prévias de umidade no solo. Desse modo, } \\
\text { as condições de deflúvio são dependentes do CN. }\end{array}$ & adimens. & .mgt \\
\hline ALPHA_BF & $\begin{array}{c}\text { Constante de recessão do escoamento de base. Representa um índice } \\
\text { direto da resposta do fluxo subterrâneo à variações na recarga. } \\
\text { Valores elevados indicam maiores recargas do aquifero e menor fluxo } \\
\text { de base. }\end{array}$ & adimens. &.$g w$ \\
\hline GW_DELAY & $\begin{array}{l}\text { Tempo de retardo do fluxo subterrâneo. Intervalo de tempo para a } \\
\text { recarga do aquífero. Dependente da formação geológica do solo. O } \\
\text { valores são inversamente proporcionais à taxa de recarga do aquifero. }\end{array}$ & dias &.$g w$ \\
\hline GWQMN & $\begin{array}{c}\text { Profundidade limite da água no aquifero raso necessária para que o } \\
\text { fluxo de retorno ocorra. Quanto maior o valor desse parâmetro, } \\
\text { maiores parcelas do fluxo de base são retardadas. }\end{array}$ & $\mathrm{mm} \mathrm{H} 2 \mathrm{O}$ &.$g w$ \\
\hline ESCO & $\begin{array}{c}\text { Fator de compensação da evaporação no solo. Representa um } \\
\text { percentual da capacidade de evaporação na camada superior do solo. } \\
\text { Valores elevados significam altas taxas de evaporação. }\end{array}$ & adimens. & bsn \\
\hline SOL_AWC & $\begin{array}{l}\text { Capacidade de água disponivel no solo. Utilizado para o cálculo do } \\
\text { tempo de percolação da água no solo. }\end{array}$ & $\begin{array}{c}\mathrm{mm} \\
\mathrm{H} 2 \mathrm{O} / \mathrm{mm} \\
\text { solo } \\
\end{array}$ & sol \\
\hline SOL_K & $\begin{array}{c}\text { Condutividade hidráulica saturada do solo. Relaciona a densidade do } \\
\text { fluxo e o gradiente hidráulico. Representa uma medida da facilidade } \\
\text { com que a água se movimenta pelo solo. }\end{array}$ & $\mathrm{mm} / \mathrm{hr}$ & sol \\
\hline CANMX & $\begin{array}{l}\text { Capacidade máxima de armazenamento de água da cobertura formada } \\
\text { pela vegetação. Influencia no escoamento superficial e na evoporação. }\end{array}$ & $\mathrm{mm} \mathrm{H} 2 \mathrm{O}$ & hru \\
\hline
\end{tabular}

Segundo Peterson e Hamlett (1998), CN2 é o parâmetro mais sensível no modelo SWAT, sendo o responsável pelo potencial do escoamento superficial. Sendo este um parâmetro adimensional e tem relação direta com a capacidade de infiltração, do tipo de solo, do uso do solo, e das condições antecedentes de umidade no solo.

O SOL_K é um parâmetro necessário para calcular o tempo de percolação da água de uma dada camada do solo para uma camada inferior. Este parâmetro 
interfere no fluxo de base, pois é responsável pelo fluxo horizontal na zona saturada, e isso pode ser determinante na simulação da vazão em épocas de estiagem. Devido as características do Cerrado, este parâmetro pode exercer influência na simulação do decaimento da vazão após o período chuvoso (NEITSCH et al. 2009).

O SOL_AWC representa a capacidade de armazenamento de água no solo e apresenta uma relação inversa com diversos componentes do balanço hídrico, ou seja, um aumento no valor de SOL_AWC diminui o fluxo de base e aumenta a infiltração (KANNAN et al., 2007).

O GWQMN tem influência direta no fluxo de base, sendo que para valores altos, uma considerável porção do fluxo de base é atrasada e armazenada no solo. Já para valores baixos desse parâmetro incidirá em um maior fluxo de base. Com esse efeito, esse parâmetro tem influência também na vazão.

Em relação ao ESCO, todos os componentes do balanço hídrico são afetados por uma mudança no fator de compensação de evaporação do solo, de forma geral, a predição da vazão torna-se próxima à vazão observada quando o valor de ESCO está próximo ao seu máximo (KANNAN et al., 2007).

A partir da realização de análises de sensibilidade, como as realizadas no software SWAT CUP, é possível determinar o grau de influência de cada parâmetro na modelagem.

O método de análise de sensibilidade pode ser local ou global. O método local visa a tendência do modelo em um dado ponto do espaço amostral, ou seja, para um determinado cenário de controle (SALTELLI; TARANTOLA; CHAN, 2000). A análise global avalia aleatória ou sistematicamente todo intervalo de valores que podem ser atribuídos a um parâmetro e as combinações que podem existir entre os diferentes parâmetros (SALLES, 2012).

$\mathrm{Na}$ análise global apresentada pelo SWAT CUP são apresentados o $t$-stat e o $P$-value. $O$ indicador $t$-stat é referente ao grau de sensibilidade, de forma que quanto maior for o seu valor absoluto, mais influente é o parâmetro. Já o $P$-value determina a significância da sensibilidade dos parâmetros, onde os valores 
próximos de zero apresentam maior influência na modelagem específica (ABBASPOUR, 2011).

\subsection{Indicadores Estatísticos}

Os indicadores estatísticos são a forma mais comum para a avaliação da eficiência de um modelo hidrológico, podendo revelar aspectos interessantes para compreensão das vantagens de uso, restrições e limitações do modelo (FRAGOSO Jr.; FERREIRA; MARQUES, 2009). Existem diversos indicadores estatísticos capazes de avaliar os mais diversos tipos de dados. Alguns autores, como Moriasi et al. (2007), sugerem a aplicações de alguns indicadores específicos para a análise dos resultados oriundos de simulações em bacias hidrográficas. No caso deste trabalho, foram analisados os modelos NSE (NashSutcliffe), porcentagem BIAS e RSR.

O coeficiente de eficiência NSE é recomendado por Moriasi et al. (2007) por ser comumente utilizado entre os usuários do SWAT no mundo inteiro, fato importante devido à grande quantidade de dados gerados nas análises. Além disso, é recomendado para a avaliação de modelos pela American Society of Civil Engineers (ASCE). Outros estudos mostram que o NSE é uma das melhores funções objetivo no ajuste de um hidrograma (SEVAT e DEZZETER, 1991). A Equação 1, apresenta a formulação matemática para o cálculo do NSE.

$$
N S E=1-\left[\frac{\sum_{i=1}^{n}\left(Y_{i}^{o b s}-Y_{i}^{s i m}\right)^{2}}{\sum_{i=1}^{n}\left(Y_{i}^{o b s}-Y_{i}^{\text {méd }}\right)^{2}}\right]
$$

Onde $Y_{i}^{\text {obs }}$ é o dado mensal observado para o mês $i, Y_{i}^{s i m}$ é o dado mensal simulado para o mês $i$ e $Y_{i}^{\text {méd }}$ refere-se à média dos valores da série observada.

O NSE é um indicador adimensional e varia entre - $\infty$ a 1, sendo que valores menores do que zero indicam que a média dos dados observados prevê 
melhor do que a simulação pelo modelo, enquanto valores próximos a um indicam um ajuste ótimo (FERRIGO, 2014).

O PBIAS considera a tendência média dos dados simulados em relação aos dados observados, sendo o valor ideal igual à zero, onde indicaria uma simulação exata do modelo. Os valores positivos apontam um viés de subestimação, enquanto os valores negativos indicam um viés de superestimação do modelo (GUPTA; SOROOSHIAN; YAPO, 1999). Na Equação 2 está apresentada a formulação para a determinação do PBIAS, que fornece um valor adimensional para este indicador.

$$
P B I A S=\left[\frac{\sum_{i=1}^{n}\left(Y_{i}^{o b s}-Y_{i}^{s i m}\right) *(100)}{\sum_{i=1}^{n}\left(Y_{i}^{o b s}\right)}\right]
$$

Este indicador foi escolhido por ser recomendado pela ASCE e apresentar bom desempenho na avaliação do modelo, levando em consideração período chuvoso e seco dentre os diferentes métodos de autocalibração (GUPTA; SOROOSHIAN; YAPO, 1999).

O RSR é um índice estatístico de erro bastante utilizado que contém um fator de escalonamento/normalização, de modo que as resultantes dos valores estatísticos descritos podem ser aplicadas a vários componentes. O índice varia de zero, o que corresponde a nenhuma variação residual do modelo (simulação perfeita), a um valor positivo. Quanto menor o valor, melhor o desempenho do modelo. A Equação 3 ilustra a formulação para o cálculo do RSR, que, assim como os anteriores, também fornece um valor adimensional para o indicador.

$$
R S R=\frac{\left[\sqrt{\sum_{i=1}^{n}\left(Y_{i}^{\text {obs }}-Y_{i}^{\text {sim }}\right)^{2}}\right]}{\left[\sqrt{\sum_{i=1}^{n}\left(Y_{i}^{\text {obs }}-Y_{i}^{\text {méd }}\right)^{2}}\right]}
$$


Alguns autores propuseram avaliações para os resultados dos indicadores estatísticos. Para o caso deste trabalho, optou por utilizar a classificação proposta por Moriasi et al. (2007), a qual é representada na Tabela 3:

Tabela 3: Indicadores estatísticos.

\begin{tabular}{|c|c|c|c|}
\hline CLASSIFICAÇÃO & NSE & PBIAS (\%) & RSR \\
\hline MUITO BOM & $0,75<\mathrm{NSE} \leq 1,00$ & PBIAS $< \pm 10$ & $0,00 \leq \mathrm{RSR} \leq 0,50$ \\
\hline BOM & $0,65<\mathrm{NSE} \leq 0,75$ & $\pm 10 \leq \mathrm{PBIAS}< \pm 15$ & $0,50<\mathrm{RSR} \leq 0,60$ \\
\hline SATISFATÓRIO & $0,50<\mathrm{NSE} \leq 0,65$ & $\pm 15 \leq \mathrm{PBIAS}< \pm 25$ & $0,60<\mathrm{RSR} \leq 0,70$ \\
\hline INSATISFATÓRIO & NSE $\leq 0,50$ & PBIAS $\geq \pm 25$ & $\mathrm{RSR}>0,70$ \\
\hline
\end{tabular}




\section{3 ÁREA DE ESTUDO}

A bacia hidrográfica do Rio Preto está compreendida na bacia do Rio Paracatu, que por sua vez, pertence à bacia do São Francisco, abrangendo parte do Distrito Federal e dos Estados de Goiás e Minas Gerais (Figura 2). Essa bacia ocupa aproximadamente $10.310 \mathrm{~km}^{2}$, possuindo grande importância na produção agropecuária regional.

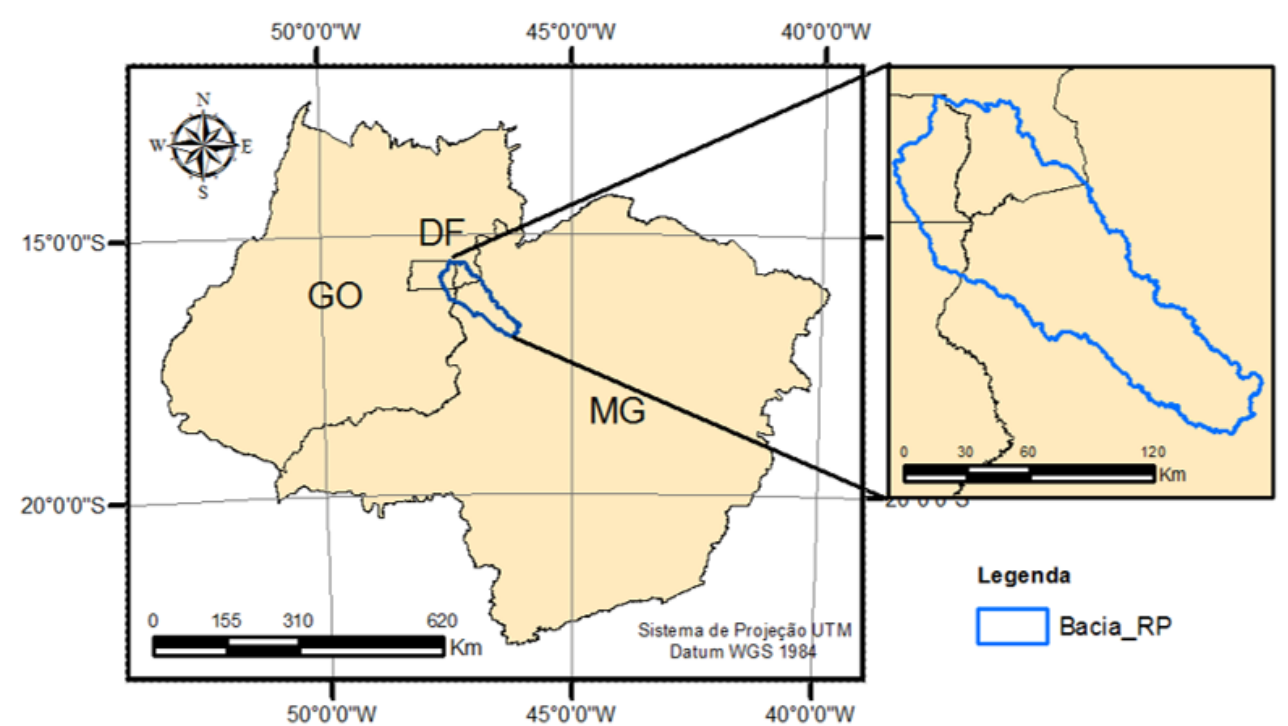

Figura 2 - Bacia hidrográfica do Rio Preto.

O clima da área é tropical, onde as variações térmicas são pequenas, com o regime pluviométrico caracterizado por máximas no verão e mínimas no inverno. A precipitação varia de 1600 a $1000 \mathrm{~mm}$ e estão concentradas nos meses de outubro a abril (PLANPAR, 1998).

A geologia da área é constituída pela Formação Vazante, Grupo Canastra, Grupo Paranoá, Subgrupo Paraopeba, pertencente ao Grupo Bambuí e pela cobertura detrito-laterítica do Terciário-Quaternário (SCHOBBENHAUS, 1984).

Planpar (1998) descreve a geomorfologia da bacia do Rio Preto nas seguintes unidades: Planalto do São Francisco, Cristas de Unaí e Depressão 
Sanfranciscana. Os planaltos são representados por superfícies tabulares ou chapadas. As cristas são alinhamentos orientados na direção NNW-SSE (nornoroeste/su-sudeste), entre as quais se intercalam zonas rebaixadas e aplainadas com feições cársticas. A Depressão Sanfranciscana é uma área rebaixada e aplainada com cotas variando entre 400 e $600 \mathrm{~m}$. As paisagens cársticas da região são típicas e apresentam um sistema hidrológico predominantemente subterrâneo de característica criptorreica e com formação de cavernas (BIGARELLA; BECKER; PASSOS, 1996).

Historicamente, a ocupação territorial da bacia do Rio Preto tem sido reservada para a implementação da agropecuária (FROTA, 2006), a qual ocupa, principalmente, as áreas planas que estão localizadas na porção superior e inferior da bacia, com o cultivo de grãos como feijão, soja, milho, sorgo, algodão, cítricos, café, além disso, criação de gado, aves e suínos, dentre outros usos. $\mathrm{Na}$ bacia, as áreas preservadas estão localizadas principalmente nas porções íngremes do relevo, onde existem limitações para a produção em grandes escalas, no Campo de Treinamento do Exército Brasileiro e no município de Formosa - GO (FREITAS et al., 2007). 


\section{METODOLOGIA}

O modelo SWAT exige uma diversidade de informações para ser executado, sendo necessário dados de entrada que são correlacionados com características físicas da bacia hidrográfica para que o modelo possa caracterizar e equacionar: o ciclo hidrológico, o método curva número, a vazão de pico de escoamento superficial, o retardo de escoamento superficial, a percolação, o escoamento lateral, o fluxo de água subterrânea, a evapotranspiração, a produção de sedimentos, a propagação do fluxo de água, a análise de sensibilidade, a calibração e a verificação do modelo.

O modelo já possui uma base de dados (default) referente aos parâmetros de solo e vegetação referentes as bacias estudadas nos Estados Unidos da América (EUA), que em grande parte dos casos não se adequam a outras realidades. No Brasil, as informações com maior nível de detalhamento são escassas ou de difícil acesso de uma forma em geral.

A proposta metodológica (Figura 3) apresentada neste trabalho foi dividida nos tópicos: Dados de entrada, que inclui os subtópicos tratamento do MDE, mapa de uso e cobertura do solo, mapa de tipos de solos, dados climáticos e dados de vazão; Processamento SWAT, incluindo simulação SWAT, calibração SWAT CUP, verificação; Simulações, subdivididas em primeira, segunda e terceira etapa; e Análise estatística. 


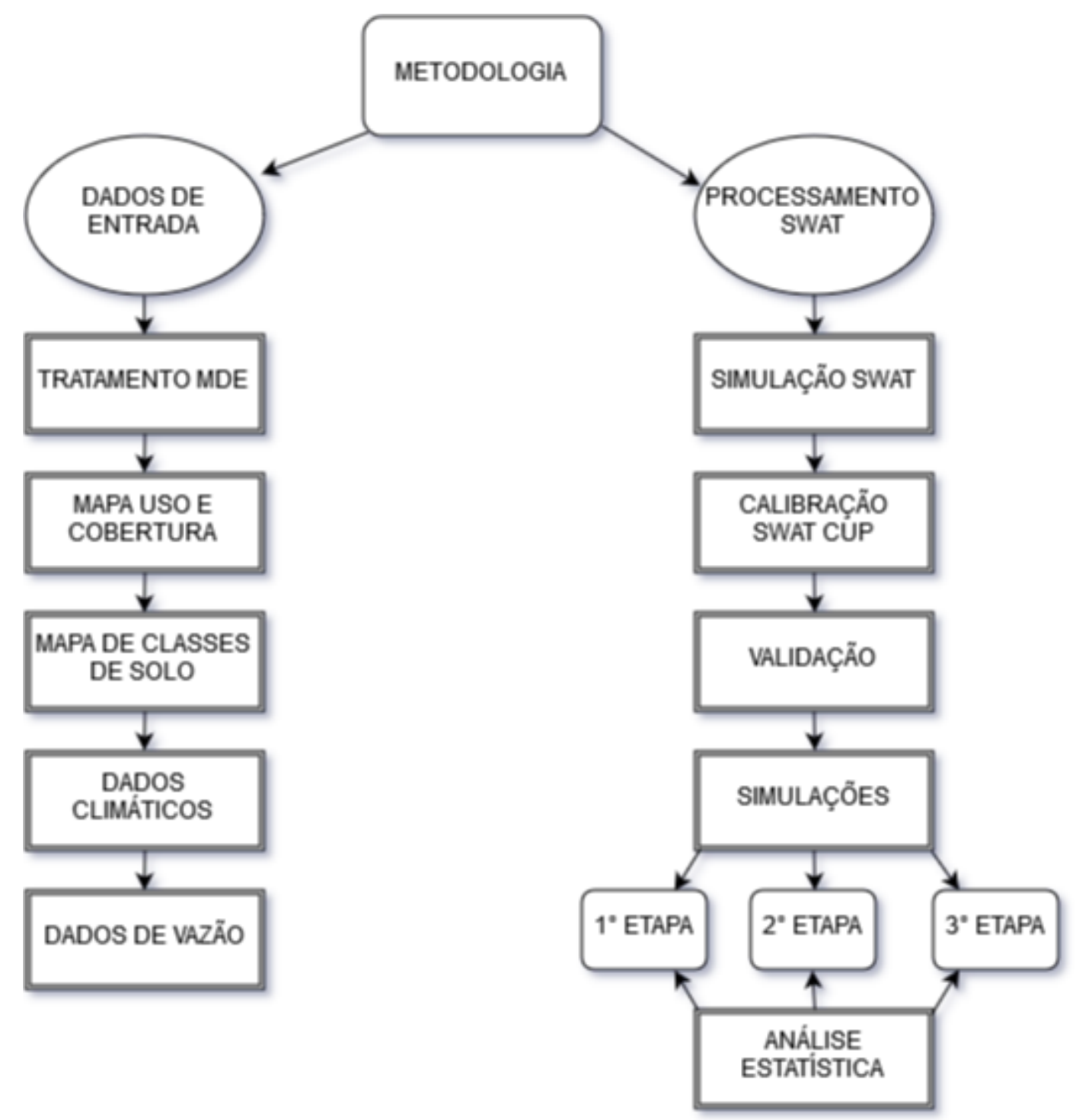

Figura 3: Esquema metodológico aplicado ao trabalho.

\subsection{Dados de entrada}

O modelo requer dados básicos de entrada, como: MDE, mapa de uso e ocupação da terra, mapa de classe de solo, séries temporais de precipitação, radiação solar, velocidade do vento, evaporação, temperatura máxima e mínima do ar, dentre outros. 
Dessa forma, uma das etapas do trabalho foi a aquisição e organização dos dados de entrada necessários para suprir o modelo, de acordo com a realidade da bacia analisada para que a modelagem possa ser realizada de forma consistente.

Os dados referentes às características de uso e cobertura da terra, bem como as classes de solos presentes na área de estudo, foram inseridos no SWAT por meio de tabelas de atributos que incluem uma série de parâmetros físicos dos solos e dos tipos de vegetação necessários para a realização das simulações. Neste trabalho, optou-se por utilizar as informações de parâmetros de solo e uso e ocupação da terra caracterizados pela pesquisadora Sara Ferrigo (FERRIGO, 2014), tendo em vista a similaridade das áreas de estudo e que a obtenção desses parâmetros estava fora do escopo do presente estudo. A escolha do banco de dados também levou em consideração as classes de uso e ocupação da terra e tipo de solo que não estavam presentes no default do SWAT e são característicos da área analisada, como vegetação cerrado. Vale ressaltar que os valores dos parâmetros inseridos no banco de dados foram obtidos por meio compilação de dados de diferentes trabalhos realizados no Bioma Cerrado.

\subsubsection{Tratamento do MDE}

O MDE utilizado no trabalho é o Shuttle Radar Topography Mission (SRTM), que foi uma missão topográfica por radar interferométrico, desenvolvido pela NASA (National Aeronautics and Space Administration) e NGA (National Geospatial-Intelligence Agency) dos Estados Unidos, no ano de 2000. A missão adquiriu dados topográficos de $80 \%$ da superfície da terra entre as latitudes $60^{\circ} \mathrm{N}$ e $57^{\circ} \mathrm{S}$ em apenas 11 dias no ano 2000 (RABUS et al., 2003).

As imagens SRTM utilizadas no trabalho possuem resolução espacial de aproximadamente 30 metros e foram necessárias 4 imagens para compor 0 mosaico que compreende a área da bacia disponível no USGS (United States Geological Survey) Eros Data Center no site: http://earthexplorer.usgs.gov/. 
Os erros encontrados nos modelos digitais de elevação são, em geral, em função do método de obtenção dos dados utilizados e do tipo de modelagem utilizada em sua confecção. Nesse contexto, várias metodologias têm sido desenvolvidas com intuito de se obter MDEs que representem melhor a superfície terrestre.

As simulações desenvolvidas nesse trabalho foram realizadas com os dados com e sem "tratamento", com o objetivo de analisar a sensibilidade do modelo quanto aos dados altimétricos para a área em estudo. $\mathrm{O}$ termo em "tratamento" refere-se a um conjunto de etapas para o processamento da imagem, visando, entre outros objetivos, a correção de ruídos (falhas na matriz de dados) e de demais erros grosseiros na imagem.

O procedimento aplicado ao MDE neste trabalho, consistiu basicamente em: aplicação de filtros de mediana com janela 7x7; Criação e aplicação de máscara identificando as variações superiores a 5 metros; Exclusão dos valores superiores a 5 metros; e interpolação de pixels por meio do algoritmo TOPOGRID (SILVA, 2013).

Por sua vez, o MDE sem "tratamento" não passou pelo procedimento definido anteriormente. Nesse contexto, as imagens SRTM disponibilizadas no website do USGS foram utilizadas diretamente no SWAT.

\subsubsection{Mapa de Uso e Cobertura da terra}

O mapa de uso e cobertura do solo utilizado no trabalho foi oriundo do TerraClass Cerrado, um dos maiores esforços técnicos já realizados para especificar as condições do bioma Cerrado, o qual ocupa aproximadamente dois milhões de $\mathrm{km}^{2}$ ou $24 \%$ do território brasileiro. O estudo envolveu 1.389 municípios de onze estados e mais o Distrito Federal.

Participaram do trabalho aproximadamente 50 cientistas e técnicos de cinco instituições, sendo elas: Empresa Brasileira de Pesquisa Agropecuária (Embrapa), Instituto Nacional de Pesquisas Espaciais (INPE), Instituto Brasileiro 
do Meio Ambiente e dos Recursos Renováveis (Ibama); Universidade Federal de Goiás (UFGO) e Universidade Federal de Uberlândia (UFU) sob coordenação do Ministério do Meio Ambiente (MMA). Os pesquisadores fizeram o estudo a partir de 121 cenas processadas digitalmente do satélite Landsat 8. O préprocessamento e segmentação foram realizados em cada cena isoladamente, gerando um banco de dados geográficos. A área mínima mapeável teve resolução espacial de 6,25 hectares, o que permitiu separar doze classes de uso e cobertura no território: agricultura anual e perene, corpos d'água, mineração, área urbana, pastagens, silvicultura, solo exposto, natural florestal, savânico, campestre e mosaico de ocupação.

O mapa possui uma escala de 1:250.000 (Figura 4) e está disponível no site do Sistema de Observação e Monitoramento da Agricultura no Brasil (Soma Brasil) e no site do Instituto Nacional de Pesquisas Espaciais (INPE) e pode ser baixado por meio do endereço eletrônico: http://www.dpi.inpe.br/tccerrado/download.php.

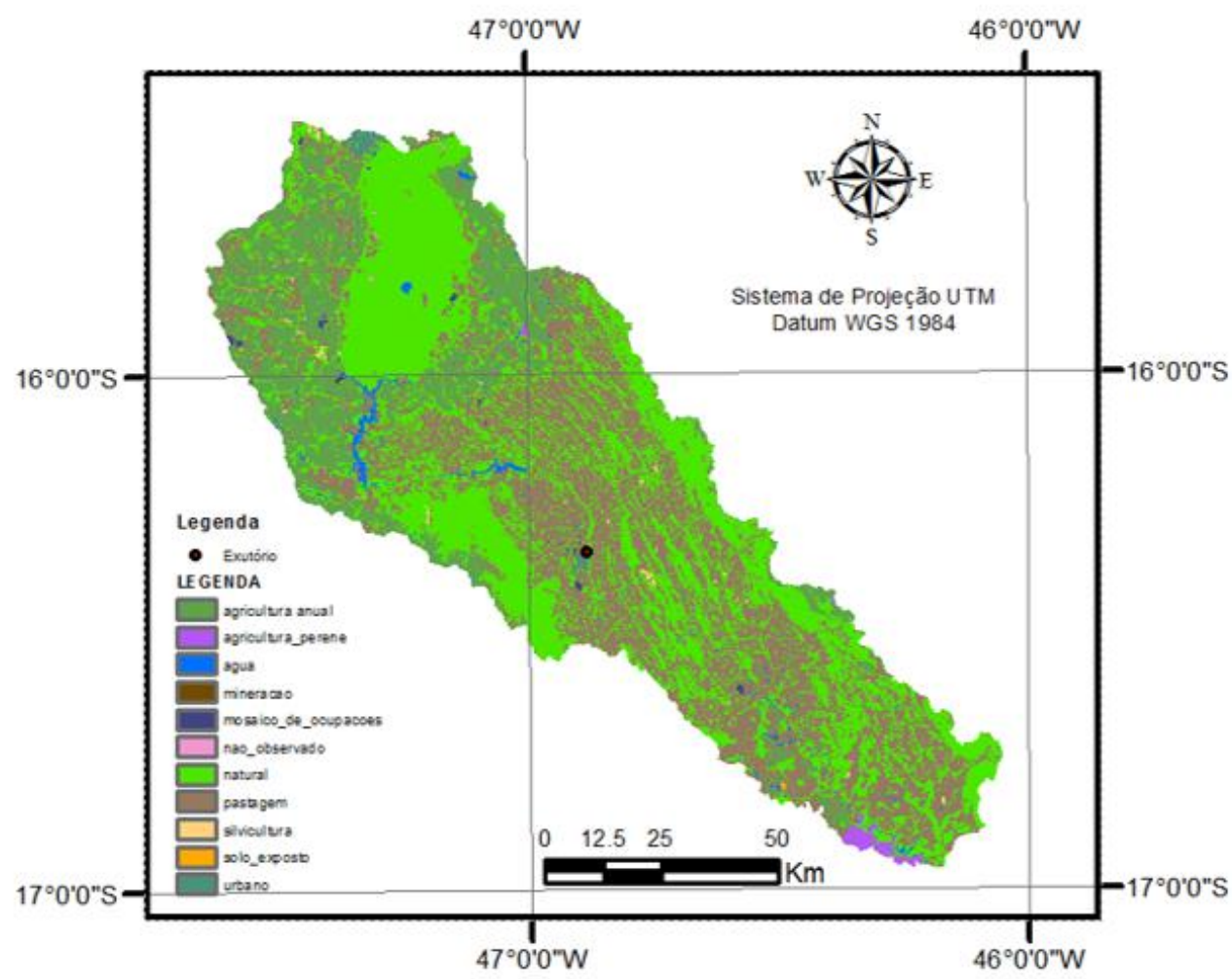

Figura 4 - Mapa de Uso e Cobertura da Bacia do Rio Preto. 
Para a entrada dos dados de uso e cobertura, foram feitas correspondências entre as classes de uso e cobertura do mapeamento do Terraclass, com os disponibilizados pelo SWAT e com o banco de dados de Ferrigo (2014), que estão sendo apresentados na Tabela 4 a seguir. Esse banco de dados foi utilizado devido à indisponibilidade de informações específicas sobre características físicas dos tipos de solo e uso e ocupação presentes na área de estudo. Sendo assim, optou-se por utilizar o mesmo banco de dados para a entrada de informações no SWAT pela similaridade das áreas estudadas neste trabalho e na pesquisa da Sara Ferrigo.

Tabela 4: Classes de Uso e Cobertura da Bacia do Rio Preto.

\begin{tabular}{|c|c|c|}
\hline CLASSE DE USO (TERRA CLASS) & CORRESPONDENCIA SWAT & PERCENTUAL DA ÁREA \\
\hline Agricultura Anual & AGRL (Agricultural Land-Generic) & 16.54 \\
\hline Agricultura Perene & AGRC (Agricultural Land-Close-Grown) & 0.54 \\
\hline Água & WATR (Water) & 0.82 \\
\hline Mineraçao & URHD (Residential-High Density) & $\sim 0$ \\
\hline Mosaico de ocupações & URBN (Residential) & 0.26 \\
\hline Não observado & URMD (Residential-Medium Density) & 0.02 \\
\hline Natural & CERR (Cerrado) & 44.44 \\
\hline Pastagem & PAST (Pasture) & 36.61 \\
\hline Silvicultura & FRST (Forest-Mixed) & 0.28 \\
\hline Solo exposto & URHD (Residential-High Density) & $\sim 0$ \\
\hline Urbano & URMD (Residential-Medium Density) & 0.50 \\
\hline
\end{tabular}

\subsubsection{Mapa de Tipos de Solo}

O mapa de solos utilizado na pesquisa foi elaborado pela Diretoria de Geociências do IBGE, através do Departamento de Recursos Naturais e Divisões de Geociências juntamente com a Embrapa - Centro Nacional de Pesquisas de Solos. O trabalho deu-se a partir de compilações, conversão para o meio digital e de levantamentos de solos produzidos pelo Projeto RADAMBRASIL e está disponível no endereço eletrônico: http://mapas.cnpm.embrapa.br/somabrasil/webgis.html. 
No mapeamento foram catalogadas cinco classes de solos. Como o modelo requer informações detalhadas das características físicas de cada classe, algumas considerações foram realizadas para que fosse possível a utilização do banco de dados já citado. Outro fator importante foi a dificuldade de acesso a dados mais detalhados, fator determinante para a escolha da base de dados utilizada. Contudo, levando-se em conta as considerações feitas (banco de dados) e por se tratar de uma bacia hidrográfica de mesoescala, os dados não necessitam de um alto grau de detalhamento, o mapa está representado na Figura 5.

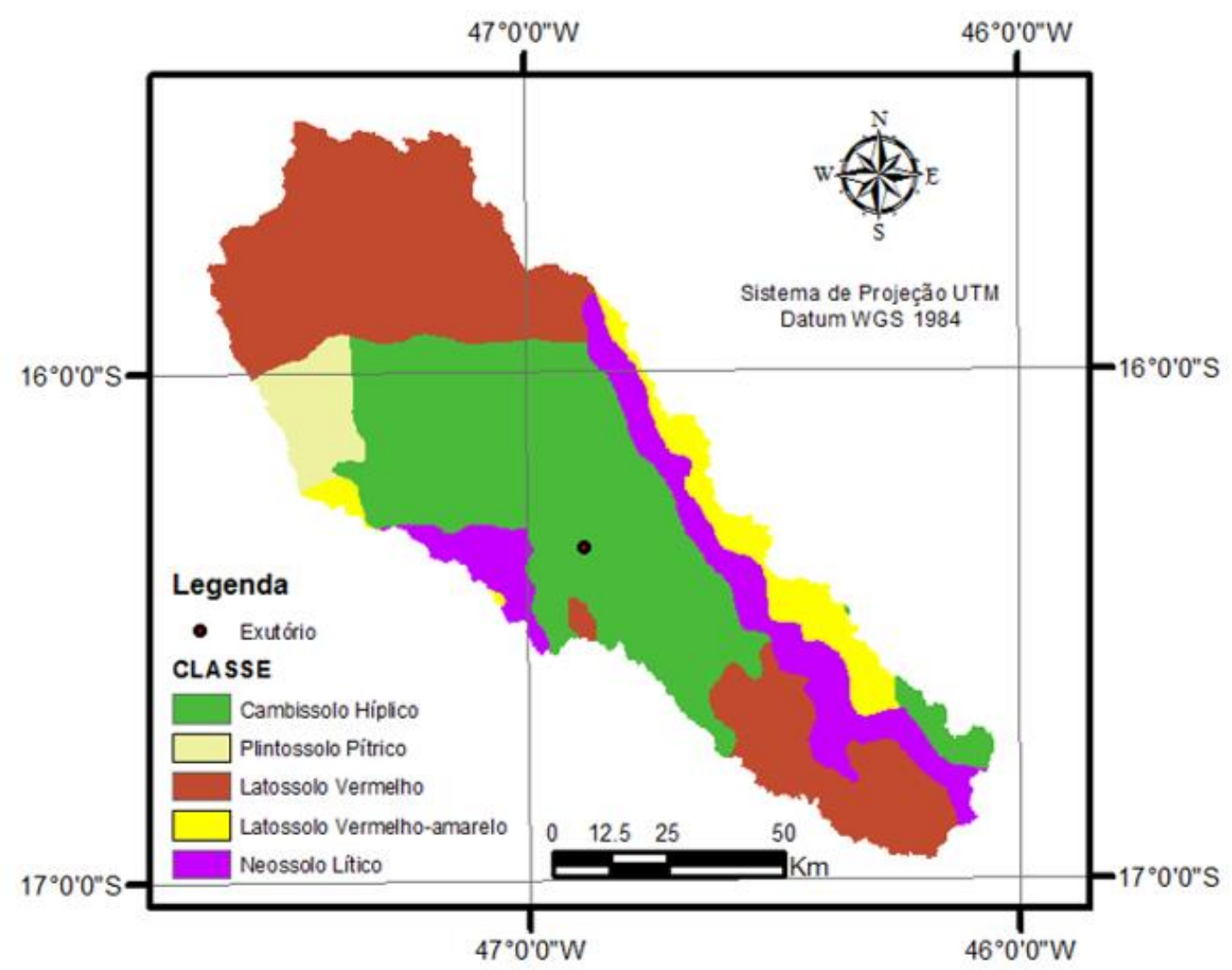

Figura 5 - Mapa de Solos da Bacia do Rio Preto.

Em função da indisponibilidade dos tipos de solo FF (Plintossolo Pítrico Concrecionário) e RL (Neossolo Lítico Distrófico) no banco de dados utilizado (FERRIGO, 2014), estes foram substituídos pelos solos mais próximos em 
termos de características físicas, sendo eles o FX (Plintossolo Híplico Distrófico) e RQ (Neossolo Quartzarênico Hidromórfico) ), respectivamente. Segue tabela referente às classes de solo (Tabela 5).

Tabela 5: Classes de solos da Bacia do Rio Preto.

\begin{tabular}{|c|c|c|}
\hline CLASSE MAPA DE SOLO & CORRESPONDENCIA SWAT & $\sim$ ÁREA \% \\
\hline Cambissolo Hiplico & Cambissolo Hiplico & 37.69 \\
\hline Latossolo Vermelho-amarelo & Latossolo Vermelho-amarelo & 6.78 \\
\hline Neossolo Lítico Distrófico & Neossolo Quartzarênico Hidromórfico & 12.61 \\
\hline Plintossolo Pítrico Concrecionário & Plintossolo Hiplico Distrófico & 4.58 \\
\hline Latossolo Vermelho & Latossolo Vermelho & 36.73 \\
\hline
\end{tabular}

\subsubsection{Dados climáticos}

O modelo requer dados climáticos de precipitação diária, temperatura máxima-mínima do ar, radiação solar, velocidade do vento e umidade relativa do ar. Os dados de clima utilizados pelo componente de gerador de tempo no modelo foram calculados conforme recomendação do manual Input/Output (ARNOLD et al., 2012b).

Foram utilizados dados referentes às estações climatológicas de Brasília, Formosa e Unaí. Apesar da estação de Brasília não se encontrar dentro da área de estudo, o mecanismo de regionalização do SWAT permite que sub-bacias que estejam mais próximas à estação, comparativamente às demais, sejam utilizadas na estimativa dos dados climáticos. Isso permite que estações próximas das sub-bacias possam ser empregadas para fornecer séries de dados climáticos, mesmo as que não se localizem dentro da área analisada. A Figura 6 apresenta a disposição das estações climatológicas na região. 


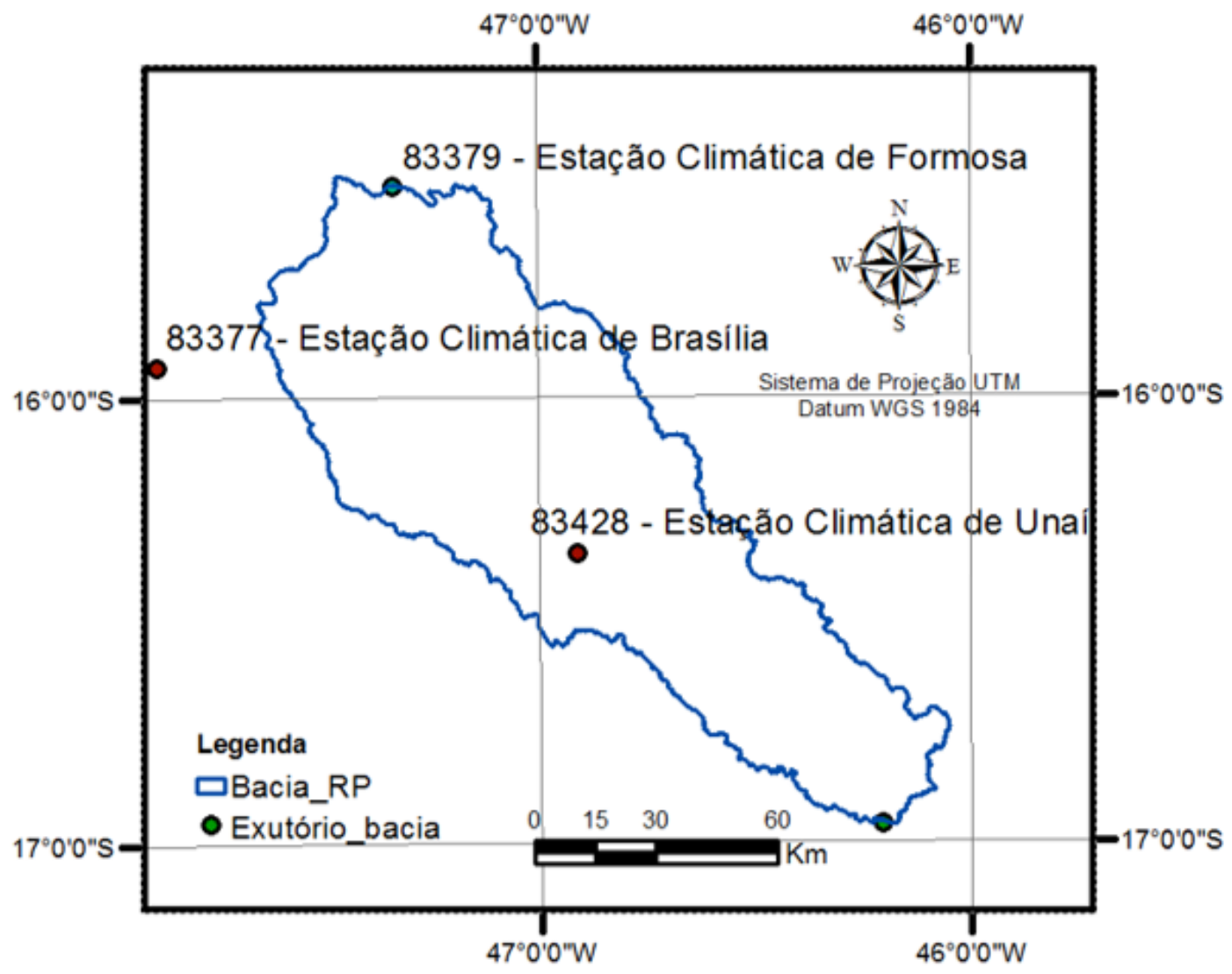

Figura 6 - Estações Climatológicas.

A seleção das estações climatológicas considerou, entre outros aspectos, a disponibilidade e confiabilidade dos dados das estações, a extensão do período de coleta de informações, a quantidade de falhas (ausência de dados ao longo da série) e a proximidade quanto à sub-bacia estudada.

A série histórica utilizada nas simulações compreende o período de janeiro de 1981 a novembro de 2010. Os dados foram oriundos de estações climatológicas do Projeto Chuva-Vazão (Avaliação dos impactos das projeções de mudanças climáticas globais sobre os recursos hídricos do bioma Cerrado) realizado pela Embrapa Cerrados e foram disponibilizados como dado de entrada para a pesquisa devido a parceria com a UnB. Foi escolhido o intervalo de 30 anos da série histórica porque era o período máximo com disponibilidade de dados observados e de maior confiabilidade das informações. 


\subsubsection{Dados de vazão}

Os dados de vazão foram catalogados da base de dados HIDROWEB, sob gestão da ANA (Agência Nacional das Águas). Dentro da área de estudo tem-se 8 estações fluviométricas, sendo a estação Porto dos Poções a mais próxima do exutório da bacia, na confluência com o Rio Paracatu conforme a Figura 7.

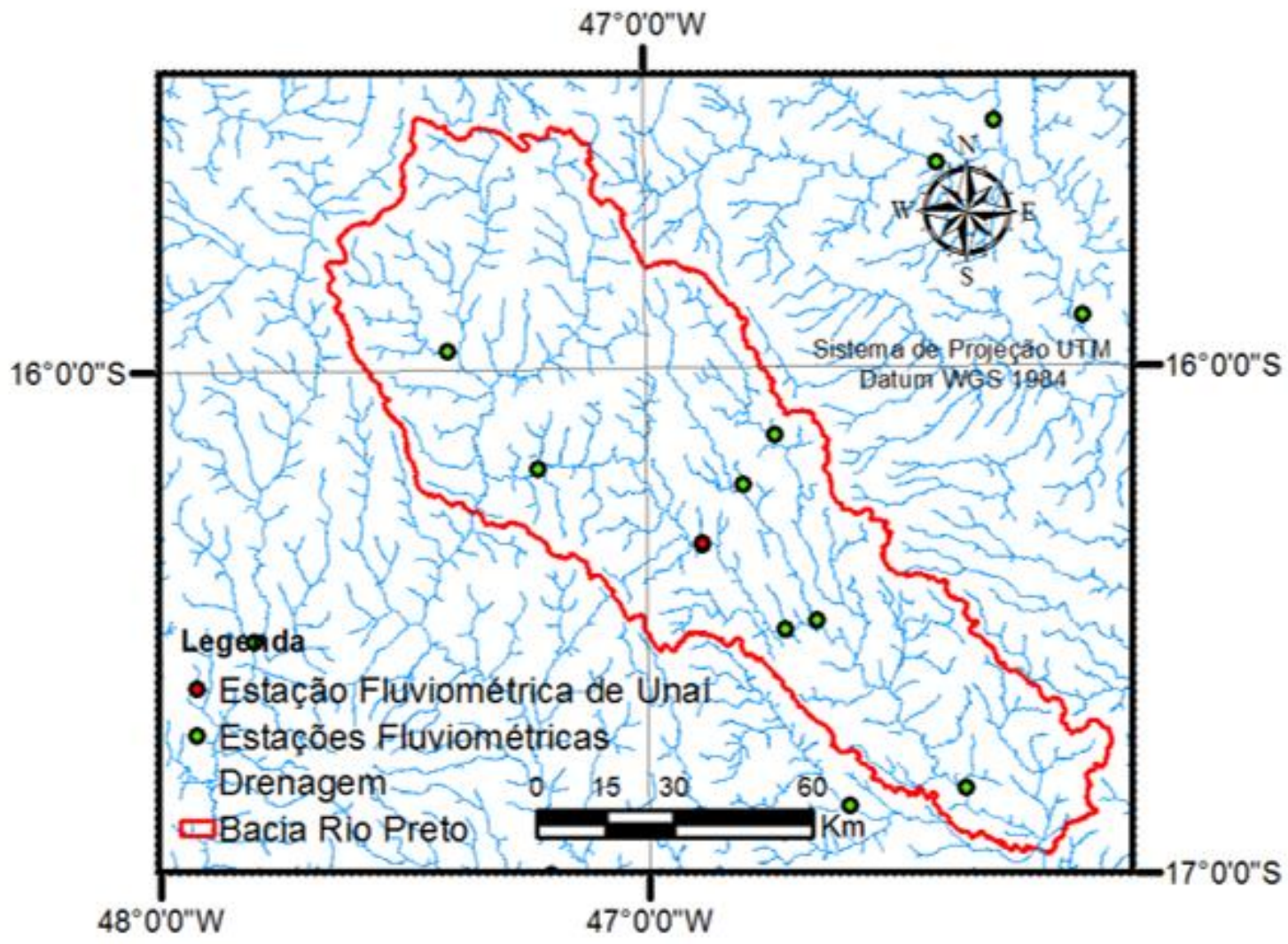

Figura 7 - Estações Fluviométricas da ANA.

Os dados de vazão diária disponibilizados das 8 estações foram baixados e analisados. A ANA disponibiliza os dados com o status de bruto e consistido hidrologicamente, porém independente da consistência, os dados foram submetidos a correções e reamostragens a fim de facilitar a análise e minimizar erros. As principais correções foram referentes a erros de digitação e repetição 
de dados. A importância desse processo se deve à produção de uma série de dados mais confiáveis que sejam capazes de reproduzir com fidelidade a série histórica de vazões na estação fluviométrica.

Com os dados tratados, as hidrógrafas foram traçadas por meio de análise gráfica. Essas análises se deram a cada ano e entre os anos. Para a caracterização da vazão, os dados foram organizados com base em medições diárias, em médias mensais e anuais.

Após analisar todas as estações em relação à quantidade de tempo de monitoramento e disponibilização dos dados observados e em relação à consistência, a estação de referência para calibração e verificação seria Porto dos Poções, por ser a mais próxima do exutório e por ter uma série mais longa e com período de consistência maior. Contudo, ao analisar a caracterização da vazão mensal e anual das 8 estações, foi proposta como estação de referência a estação fluviométrica de Unaí, pelo fato de apresentar uma série que caracteriza melhor as variações de vazão, tendo dados medidos de 1964 a 2014.

Foi utilizada a escala mensal para as simulações, tendo como intervalo os meses entre janeiro de 1981 a novembro de 2010, totalizando 359 dados de vazão. A série compreende o mesmo período que se tinha disponibilidade de dados climáticos. Para a estação de Unaí houve uma falha de 16 meses sem média de dados, enquanto a estação de Porto dos Poções foram 42 meses sem médias mensais. Conforme já descrito neste trabalho, é possível realizar simulações tanto em escala diária como mensal. Nesse caso, em função da disponibilidade de dados, da extensão da série histórica e da dimensão da região analisada, optou-se por realizar as simulações com base na escala mensal de dados.

\subsection{Processamento SWAT}

\subsubsection{Simulação SWAT}

A primeira etapa desenvolvida no SWAT consistiu na utilização do MDE do terreno que compreende a área em estudo para que sejam definidas as sub- 
bacias. O SWAT determinou o traçado das sub-bacias considerando uma área de acumulação de fluxo de 1.000 ha para todas as simulações. Este valor, escolhido pelo usuário, foi proposto considerando-se uma estimativa da área de acumulação necessária para produzir um fluxo contínuo em sub-bacias do Bioma Cerrado. Na delimitação das sub-bacias pelo software, a área de acumulação determina as dimensões das micro-bacias e as extensões de suas respectivas linhas de drenagem.

Ao final desta etapa foram criadas as subdivisões da bacia hidrográfica, apresentando as especificações quanto a possível drenagem, bem como 0 caminho mais longo percorrido pela água em relação ao exutório de cada subbacia.

$\mathrm{Na}$ etapa seguinte, de definição das Unidades de Resposta Hidrológica (HRU), foram utilizados os mapas de uso e cobertura da terra e tipo de solos apresentados anteriormente, bem como o mapa de declividade criado pelo próprio SWAT, com base em especificações de classes propostas pelo usuário. O mapa de declividade é gerado para agrupar, em poucas classes, todas as declividades que se encontram na área, de modo a reduzir o tempo de processamento dos dados e permitir a produção das HRUs. Neste caso, o mapa de declividade foi proposto com 5 classes: 0-2, 2-5, 5-10, 10-20 e 20-9999, valores dados em porcentagem. A escolha dos intervalos das classes levou em consideração o perfil topográfico do terreno, o qual dispunha de extensas regiões com declividade suave e, portanto, seria necessário um maior número de classes com intervalos pequenos de declividade para que o mapa produzido pelo SWAT representasse melhor a região. Ao final do processo, acionou-se o comando de sobreposição das três camadas para a determinação de polígonos com mesmas características de uso e ocupação/solo/declividade.

Para a definição das HRUs é necessário que se considere um limite mínimo de área da característica (uso e cobertura da terra, classes de solo e declividade) para que as frações menores que esses valores mínimos sejam anexados à outra fração maior que esteja circundando a mesma. Isso evita que áreas muito pequenas sejam consideradas na definição das HRUs, o que 
implicaria em uma grande quantidade de combinações únicas de unidades de resposta hidrológica.

Vale ressaltar, que não há interação entre as HRUs, apenas entre as subbacias, ou seja, as cargas (escoamento, sedimentos, nutrientes, etc) não são transmitidas de uma HRU para outra dentro de cada sub-bacia. As cargas por HRU são calculadas separadamente e depois somadas para determinar as cargas totais da sub-bacia, que a partir dessa são transpostas à sub-bacia conseguinte. Esse cálculo de cargas aumenta a precisão dos valores referentes a diversidade da cobertura vegetal, do crescimento e do desenvolvimento das espécies pode tornar muito mais preciso o valor líquido das cargas de cada subbacia (FERRIGO, 2013).

Para a criação das HRU's deve-se levar em consideração o tamanho da área de estudo e o nível de detalhamento dos mapas de uso e cobertura da terra, classes de solo e declividade, tendo em vista a capacidade e tempo de processamento.

Chaves (2016), tinha como área de estudo a bacia do córrego Sarandi DF com área de drenagem de aproximadamente $30 \mathrm{~km}^{2}$. Na modelagem não suprimido nenhum percentual das classes de uso e cobertura da terra, classes de solo e declividade, obtendo um total de $261 \mathrm{HRU}$ 's.

Ferrigo (2014), modelou na bacia hidrográfica do lago Descoberto - DF, subdividindo-a em sub-bacias para realizar as simulações. Na Sub-bacia do Rio Descoberto que tem como área de drenagem 114 km², também não suprimiu nenhum percentual das classes necessárias para formação das HRU's e gerou simulações com 1435 HRU's.

Fernandes (2015), trabalhou na bacia hidrográfica do Rio São Francisco, devido ao tamanho da área de estudo subdividiu trabalho em seis projetos, visando a capacidade de processamento. Para tanto, trabalhou com supressão de áreas menores que $2 \%$ do total nos dados de uso e cobertura da terra, classes de solo e declividade. 
Com o objetivo de avaliar a sensibilidade do modelo na utilização de diferentes percentuais de supressão de uso e cobertura da terra, classes de solo e declividade, para este trabalho, foram propostos diferentes limites de supressão de área de cada característica. A definição dos valores levou em consideração o nível de detalhamento dos mapas, para tanto, somente para o mapa de classes de solo que não foi suprimido nenhuma área devido seu detalhamento ser menor em relação as outras classes. Já para as classes de uso e cobertura da terra e declividade foram geradas simulações com supressão de $00 \%, 10 \%$ e $20 \%$ de área. Desse modo, o número total de HRUs, bem como o tempo de processamento requerido pelas simulações, foi significativamente reduzido.

Retomando a sequência, é necessário que o usuário forneça os dados climáticos diários de precipitação, radiação solar, temperatura, umidade relativa e velocidade média do vento das estações climatológicas próximas à bacia analisada.

Finalmente, com todas as informações inseridas, o usuário pode executar uma simulação no SWAT para o período correspondente a série histórica de dados climáticos definido na etapa anterior. Mello et al., (2008) relatam que no início da simulação ocorrem grandes incertezas, devido ao desconhecimento das condições iniciais, com isso, o modelo nos permite a utilização de um período de aquecimento, também conhecido como warmup. Fato que possibilita que as variáveis estudadas estejam livres da influência das condições iniciais. Em todas as simulações, foram considerados 3 anos de aquecimento, compreendendo os anos de 1978 a 1980.

Em seguida, foram realizadas as simulações para o período de calibração, compreendendo os anos de 1981 a 2000. Nesta primeira fase, o software fornece uma estimativa da vazão no exutório de cada sub-bacia. A sequência cronológica simplificada está apresentada na figura a seguir (Figura 8). 


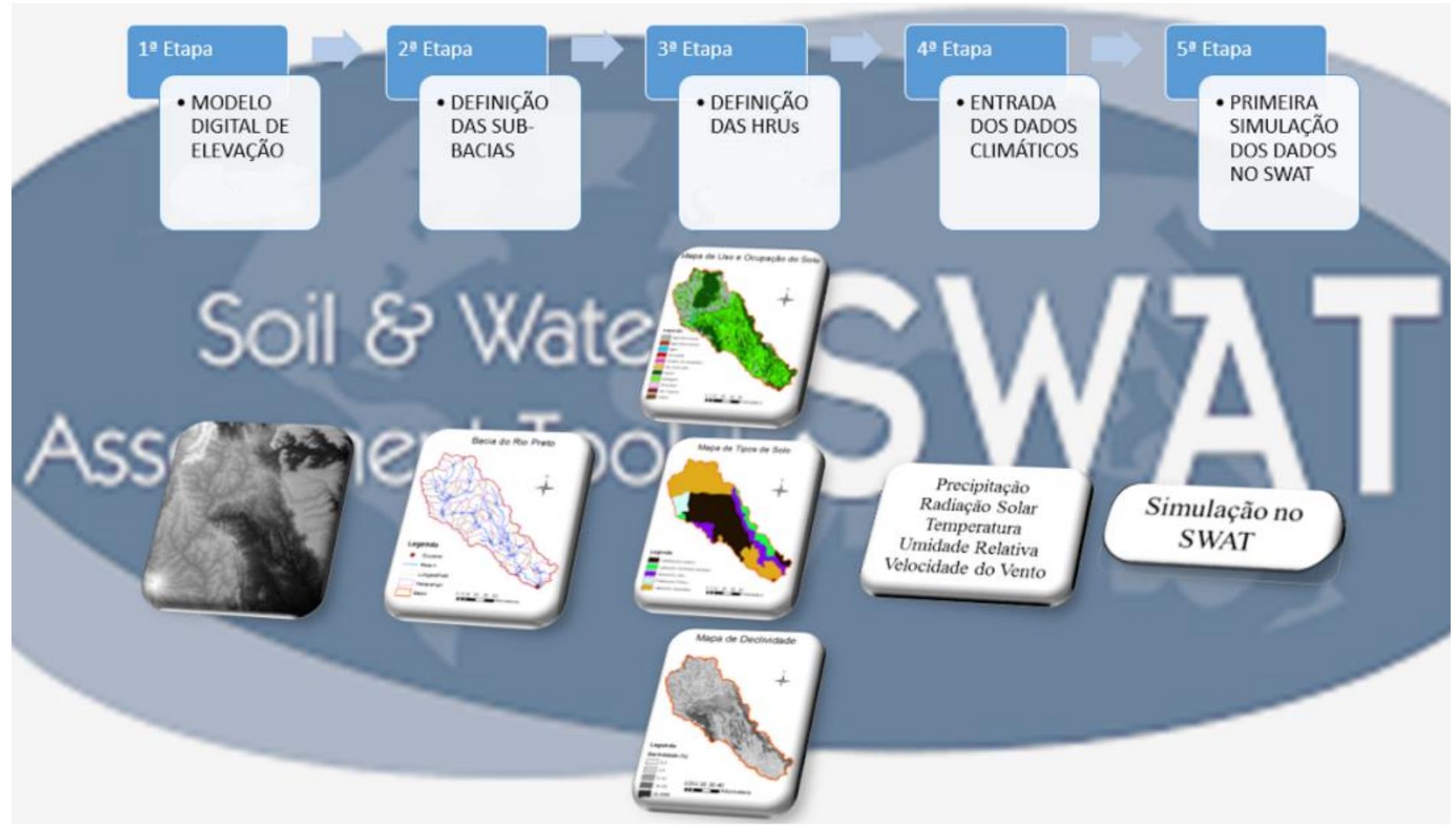

Figura 8 - Processamento SWAT.

\subsubsection{Calibração SWAT CUP}

Finalizada a simulação inicial no SWAT, a etapa seguinte baseou-se na calibração do modelo utilizando o software SWAT CUP.

O SWAT CUP nos possibilita a escolha entre cinco métodos de calibração (Glue, ParaSol, Sufi2, MCMC e PSO) descritos de forma detalhada no trabalho publicado por Abbaspour e Srinivasan (2009b, 2011). O método escolhido foi o Sequential Uncertainty Fitting (Sufi2), comumente empregado nesse tipo de calibração de dados hidrológicos.

No Sufi2 são consideradas para a análise de incerteza todas as suas fontes, como a incerteza em variáveis de entrada, o conceitual do modelo e as incertezas nos parâmetros e nos dados medidos. O grau para o qual todas as incertezas são contabilizadas e quantificadas por uma medida é referida como o fator-p, que é a percentagem dos dados medidos e delimitadas pela incerteza de 
predição de 95\% (95PPU). Outra medida que busca quantificar a eficácia de uma análise de calibração e incerteza é o fator-r, que é a espessura média da banda 95PPU dividida pelo desvio padrão dos dados medidos (ABBASPOUR, 2011).

Definido o arquivo no SWAT CUP, o próximo passo foi estabelecer quais parâmetros seriam utilizados no processo de calibração. Para tanto, a análise de sensibilidade foi realizada com parâmetros que o modelo utiliza nos cálculos de estimativa de vazão diretamente ou indiretamente, permitindo identificar quais parâmetros influenciam significativamente na dinâmica hidrológica.

Em função de certa variabilidade nos resultados dos autores, a decisão quanto aos parâmetros e seus respectivos intervalos também se levaram em consideração a experiência prévia e opinião especializada de pesquisadores da área.

No caso deste trabalho foi proposto o uso dos parâmetros e os devidos intervalos, apresentados na tabela a seguir (Tabela 6):

Tabela 6: Parâmetros e intervalos utilizados para a modelagem da vazão no modelo SWAT para a área de estudo.

\begin{tabular}{|c|c|c|c|}
\hline \multirow{2}{*}{ Parâmetro } & \multirow{2}{*}{ Método } & \multicolumn{2}{|c|}{ Intervalo utilizado } \\
\cline { 3 - 4 } & & Mínimo & Máximo \\
\hline CN2 & Relativo & -0.5 & 0.2 \\
\hline ALPHA_BF & Substituição & 0 & 0.2 \\
\hline GW_DELAY & Substituição & 30 & 180 \\
\hline GWQMN & Substituição & 0 & 6000 \\
\hline ESCO & Substituição & 0.8 & 1 \\
\hline SOL_AWC & Substituição & 0 & 0.22 \\
\hline SOL_K & Substituição & 0 & 3000 \\
\hline CANMX & Absoluto & 0 & 20 \\
\hline
\end{tabular}


Em seguida, determinou-se a quantidade de iterações que foram realizadas, levando em consideração os parâmetros e seu range de variação. $O$ número de iterações tem influência direta nas chances de se atingir valores ótimos para os parâmetros analisados. Quanto maior o número de iterações, maiores as chances de alcançar um conjunto de parâmetros que produzam as condições de vazão observada para o rio.

Um dos fatores importantes nesta etapa e que deve ser levado em consideração é o tempo de processamento dos dados, fato este que está diretamente relacionado à quantidade de iterações. Abbaspour (2015) aponta que 500 simulações para cada iteração é, em geral, suficiente para calibrar o modelo.

Tendo em vista os objetivos deste trabalho, a quantidade de iterações realizadas no SWAT CUP para cada parâmetro foi um dos elementos variáveis nas simulações. Para uma primeira simulação, foram utilizadas 150 iterações, as quais casadas com outros dados variáveis de entrada demandaram um tempo de processamento de aproximadamente 23 horas. Num segundo instante, optouse para a realização de 300 iterações, sendo necessário 40 horas de processamento aproximadamente. Ressaltando que o tempo de processamento é aproximado, pelo fato de se ter influência do conjunto de dados variáveis, bem como da capacidade de processamento do hadware.

Levando em conta o tempo de processamento desta etapa e a quantidade de simulações propostas para este trabalho de acordo com os objetivos específicos, optou-se por realizar simulações com 150 e 300 iterações. Tendo em vista que a realização de um número maior de iterações no processo de calibração, não garantem necessariamente um melhor resultado das simulações. Ferrigo (2014), calibrou automaticamente 14 parâmetros por meio de 1020 iterações e depois calibrou com 1200 iterações, no entanto, os coeficientes estatísticos avaliados foram iguais ou muito similares aos encontrados na simulação anterior.

Após todo este processo, o programa fornece uma série de informações, dentre elas a análise de sensibilidade, conjunto ótimo de parâmetros, gráficos e 
uma série com a melhor simulação, sendo esta última fornecida pelo software e feita por meio da comparação entre os resultados de indicadores estatísticos, como o NSE, PBIAS e RSR. A simulação que obtiver os resultados mais satisfatórios é considerada a melhor simulação. O processamento realizado no SWAT CUP está apresentado na imagem abaixo (Figura 9):

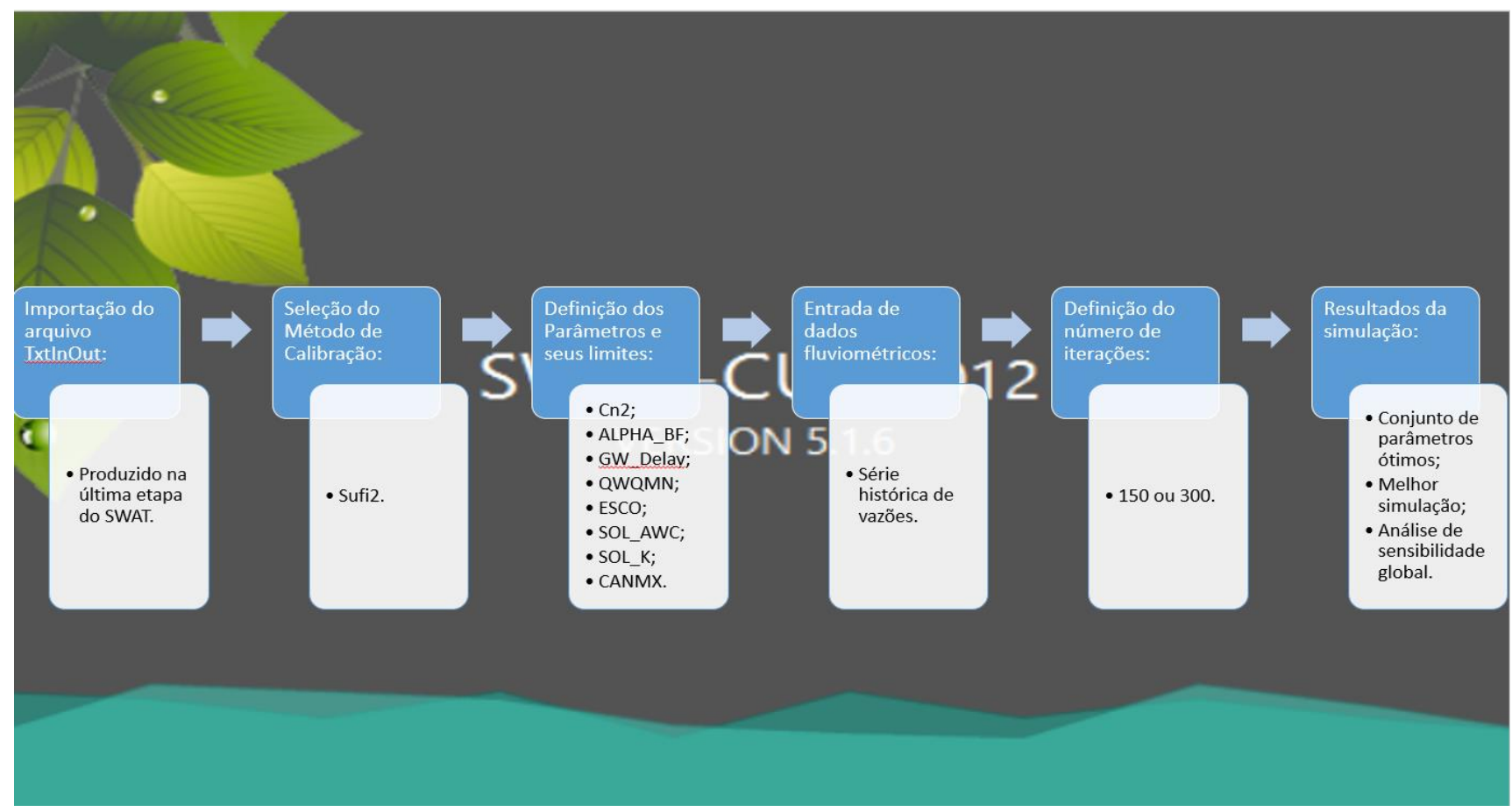

Figura 9 - Calibração SWAT CUP.

\subsubsection{Verificação}

Após o processo de calibração no SWAT CUP e com as informações geradas referentes ao conjunto ótimo de parâmetros estabelecidos, o projeto no ARC SWAT foi retomado. Nesta etapa, manualmente, cada parâmetro foi alterado de uma maneira, sendo adicionado, multiplicado ou substituído pelo valor inicial do parâmetro contido no banco de dados utilizado. Em seguida, foi feita uma nova simulação no SWAT para o período de verificação, o qual compreendeu o intervalo entre janeiro de 2001 e novembro de 2010, gerando uma série de vazão para o período, tal fato que permitiu realizar análises 
estatísticas referentes aos dados simulados e observados para a verificação do modelo. Sendo assim, segue esquema metodológico aplicado (Figura 10):

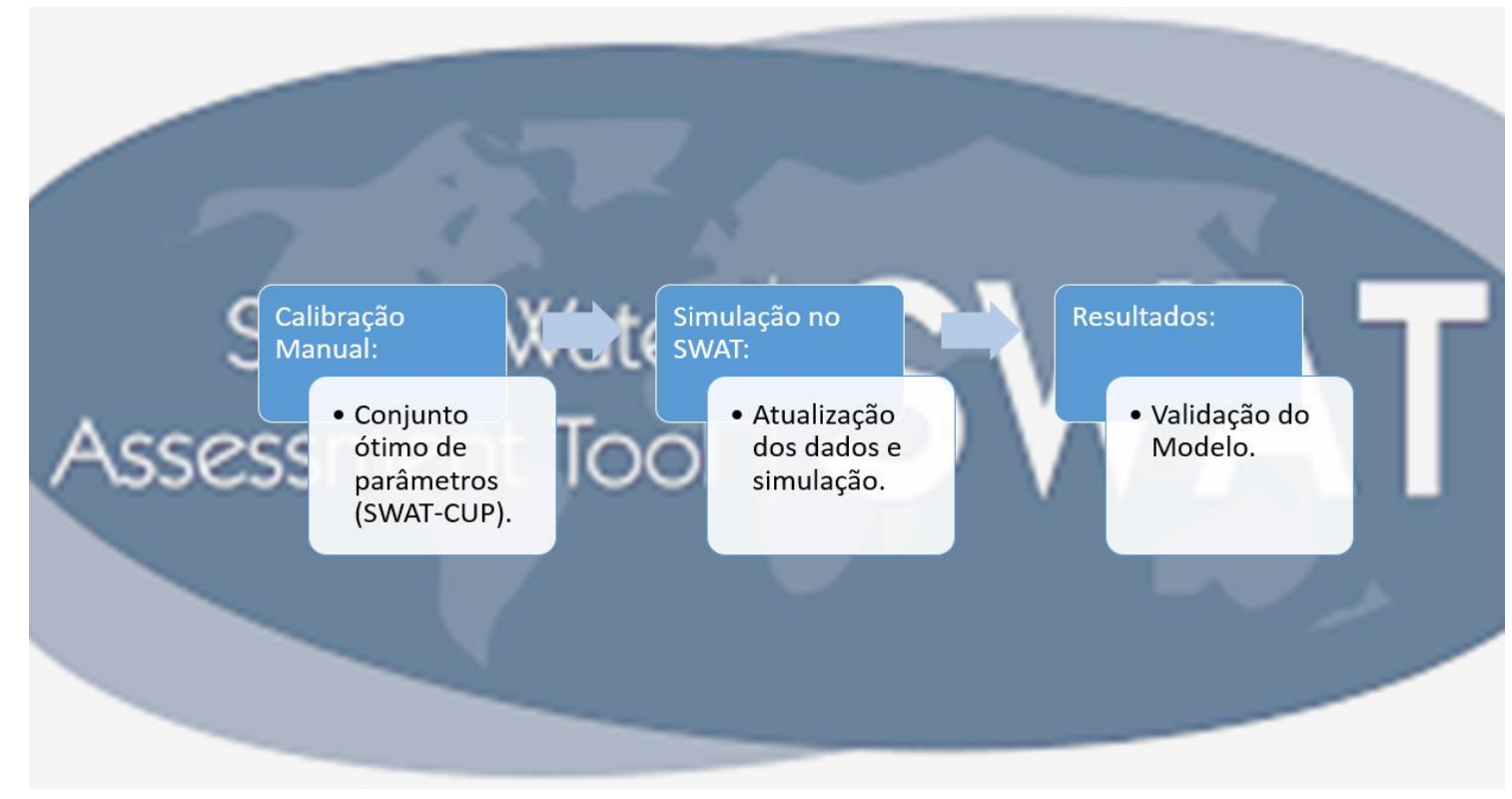

Figura 10 - Verificação SWAT.

\subsection{Simulações}

Com o objetivo de avaliar a influência dos dados de entrada, estações de referência e quantidade de iterações no SWAT CUP em relação aos resultados das simulações, foi proposto um cenário dispostos em três etapas. Em cada etapa foram definidas as estações climatológicas e fluviométricas a serem utilizadas, um MDE (tratado ou não), uma porcentagem de supressão na definição de HRUs e quantidade de iterações na etapa de calibração. Cada simulação recebeu um nome (combinação X).

A segmentação do tópico simulações em três etapas foi proposta visando comparar os resultados de cada combinação. Os dados de entrada das melhores simulações da primeira etapa foram utilizados na segunda etapa. Em seguida, os dados referentes a segunda etapa, foram utilizados na terceira. O princípio 
desse processo foi avaliar quais combinações de fatores apresentariam melhores resultados nas simulações.

Na Figura 11 está representado o fluxo com as variáveis utilizadas em todas as simulações realizadas.

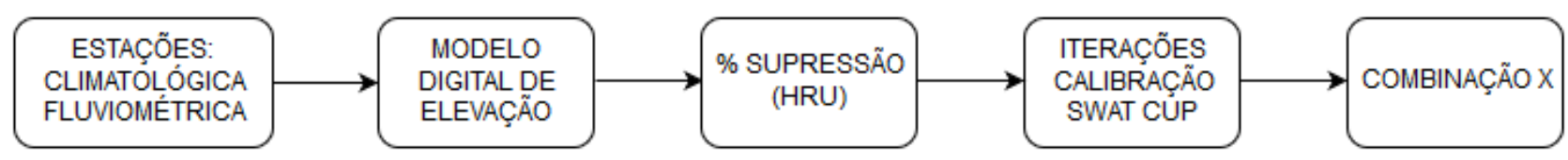

Figura 11 - Fluxo com as variáveis utilizadas em todas as simulações realizadas.

\subsection{Análise estatística}

Para a análise estatística, nos períodos de calibração e verificação do modelo foram empregados três indicadores estatísticos quantitativos com o intuito de se obter uma melhor análise do desempenho do modelo, sendo eles recomendados por Moriasi et al. (2007) (Tabela 1), que avaliou diversos modelos para a quantificação sistemática da acurácia em simulações de bacias hidrográficas. Os indicadores são: Nash-Sutcliffe (NSE), porcentagem BIAS (PBIAS) e o RSR. 


\section{RESULTADOS E DISCUSSÃO}

\subsection{Análise de Sensibilidade}

Na Figura 12 é apresentado como exemplo o conjunto de parâmetros referente a uma das simulações, combinação 3 , devido à grande quantidade de dados gerados e suas similaridades. Esta etapa foi realizada juntamente com o processo de calibração e é apresentada no SWAT CUP de forma global e individual para cada parâmetro.
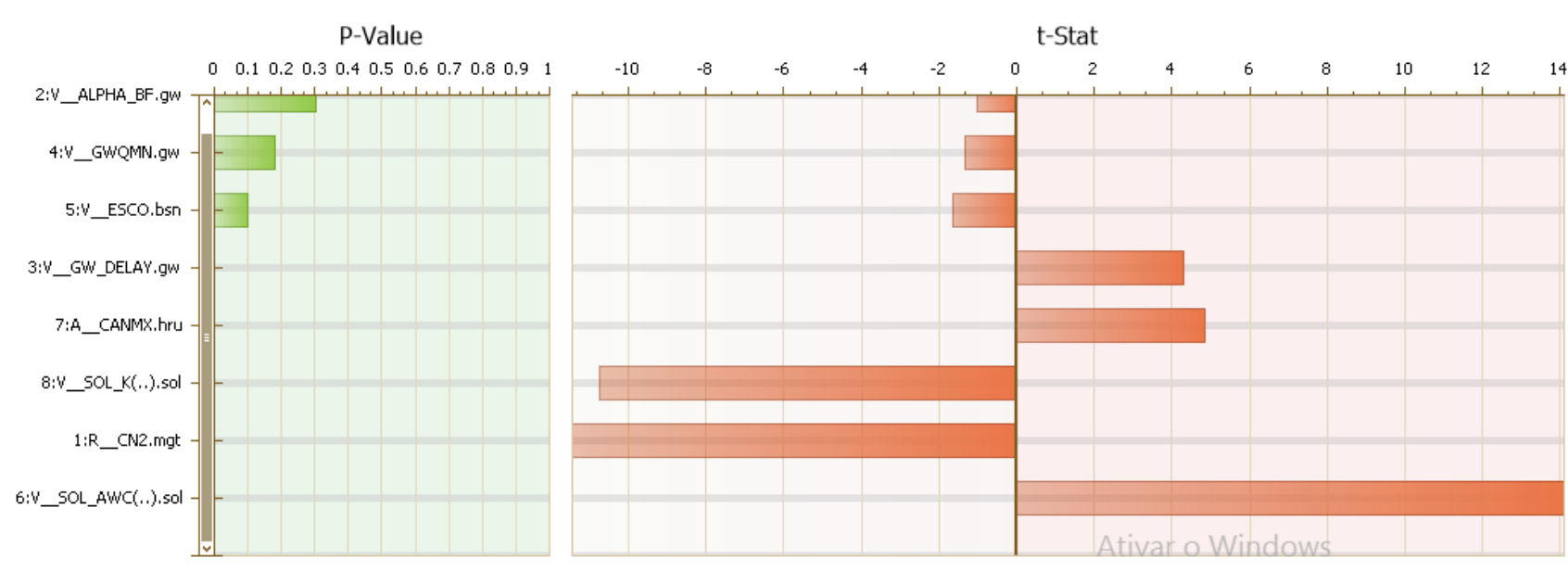

Figura 12 - Análise de sensibilidade global.

De acordo com a análise acima, a ordem dentre os parâmetros que apresentaram maiores níveis de sensibilidade ( $t$-stat) foi a mesma da significância da sensibilidade ( $P$-value), obedecendo a seguinte ordem crescente: SOL_AWC, CN2, SOL_K, A_CANMX, GW_DELAY, ESCO, GWQMN e ALPHA_BF. Os valores atribuídos a cada parâmetro podem ser observados na Tabela 7. 
Tabela 7: Níveis de sensibilidade dos parâmetros.

\begin{tabular}{|l|r|r|}
\hline Parameter Name & t-Stat & P-Value \\
\hline 2:V_ALPHA_BF.gW & -1.031609635 & 0.304021278 \\
\hline 4:V_GWQMN.gW & -1.341664068 & 0.181861715 \\
\hline 5:V_ESCO.bsn & -1.660671903 & 0.099001514 \\
\hline 3:V_GW_DELAY.gW & 4.313408854 & 0.000030044 \\
\hline 7:A_CANMX.hru & 4.824580645 & 0.000003597 \\
\hline 8:V_SOL_K(..).sol & -10.761270913 & 0.000000000 \\
\hline 1:R_CN2.mgt & -11.450591124 & 0.000000000 \\
\hline 6:V_SOL_AWC(..).sol & 14.104317694 & 0.000000000 \\
\hline
\end{tabular}

Para a análise de sensibilidade individual, o SWAT CUP apresenta gráficos de dispersão de cada parâmetro em relação à distribuição do valor atribuído para a respectiva resposta na função objetivo, sendo isso considerado a sensibilidade do modelo ao parâmetro. Nas figuras 13 e 14 são apresentados os parâmetros SOL_AWC (mais sensível) e o do ALPHA_BF (menos sensível).

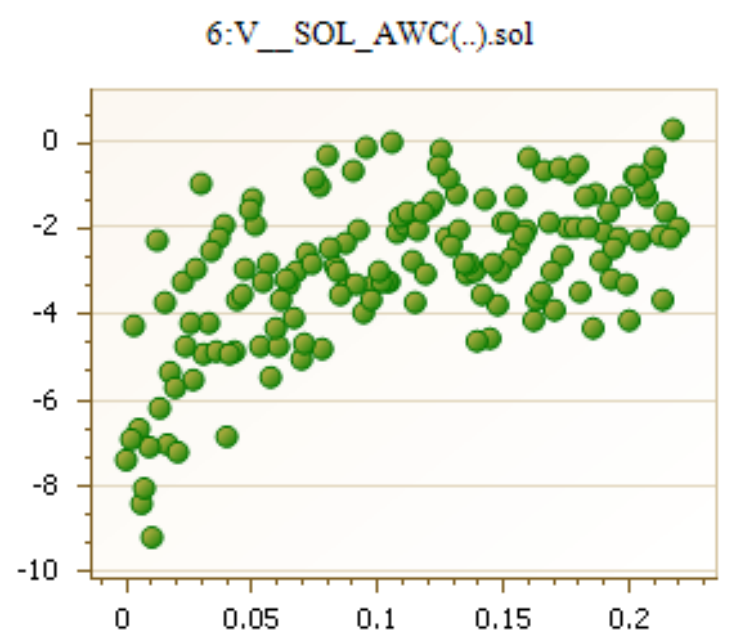

Figura 13 - Análise individual SOL_AWC. 


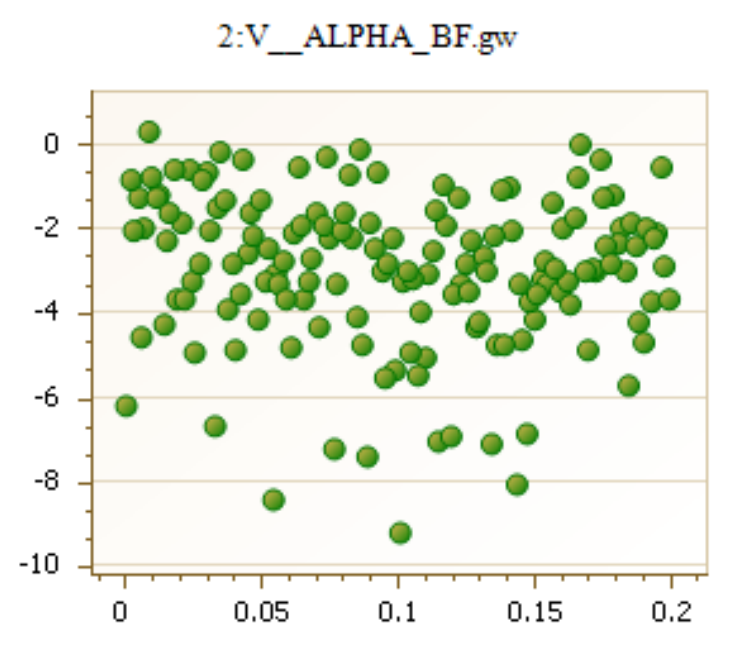

Figura 14 - Análise individual ALPHA_BF.

Comparando o gráfico do parâmetro SOL_AWC (mais sensível) com o do ALPHA_BF (menos sensível), pode-se observar que os pontos do SOL_AWC são menos dispersos e apresentam certa tendência, enquanto que os pontos do ALPHA_BF são mais dispersos. No entanto, isso ocorre por conta da interdependência dos parâmetros avaliados em relação aos outros.

Após todo o processo de calibração no SWAT CUP, o programa apresenta um conjunto ótimo de parâmetros, sendo este baseado na análise de sensibilidade e quantidade de iterações escolhidas. Na Tabela 8 podem-se observar os valores de cada parâmetro para a referida simulação: 
Tabela 8: Conjunto ótimo de parâmetros.

\begin{tabular}{|c|c|c|}
\hline PARÂMETRO & MÉTODO & VALOR \\
\hline r_CN2.mgt & Relativo & -0.13367 \\
\hline v_ALPHA_BF.gw & Substituição & 0.16733 \\
\hline v_GW_DELAY.gw & Substituição & 159.50000 \\
\hline v_ESCO.bsn & Substituição & 0.82200 \\
\hline v_GWQMN.gw & Substituição & 3700.00000 \\
\hline v_SOL_AWC().sol & Substituição & 0.16793 \\
\hline v__SOL_K().sol & Substituição & 50.00000 \\
\hline a_CANMX.hru & Absoluto & 14.06667 \\
\hline
\end{tabular}

Os resultados da análise de sensibilidade obtidos neste trabalho, estão de acordo com trabalhos utilizando o SWAT que promulgam quais os parâmetros são mais relevantes para o Bioma Cerrado, como os de Salles (2012), Castro (2013), e Ferrigo (2014).

\subsection{Primeira Etapa}

Na primeira etapa todas as simulações tiveram como referência a estação de Unaí, tanto climatológica quanto fluviométrica. Sendo assim, foram realizadas nove simulações, dentre as combinações de MDE USGS (original) e tratado, quantidade de HRU's (supressão de áreas de 00\%, 10\% e 20\% nas classes de uso e ocupação da terra e declividade, valores propostos) e quantidade de iterações no SWAT CUP. O número de simulações e as porcentagens das áreas de supressão foram obtidos em tentativas prévias de simulação do modelo. Antes de serem definidos, foram testadas outras possíveis combinações até que os valores apresentados neste trabalho fossem alcançados, sendo estes apresentados na Tabela 9. 
Tabela 9: Combinações geradas na primeira etapa.

\begin{tabular}{|c|c|c|c|c|}
\hline ESTAÇÕES & MODELO & HRU SUPRESSÃO & ITERAÇÕES & NOME \\
\hline \multirow{9}{*}{$\begin{array}{l}\frac{\text { CLIMATOLÓGICA }}{\text { UNAÍ }} \\
\frac{\text { FLUVIOMÉTRICA }}{\text { UNAÍ }}\end{array}$} & \multirow{4}{*}{ MDE } & \multirow{2}{*}{$10 \% 2.210$ HRU's } & \begin{tabular}{|l|}
150 \\
\end{tabular} & COMBINAÇÃO 1 \\
\hline & & & 300 & COMBINAÇÃO 2 \\
\hline & & \multirow{2}{*}{$20 \% 1.217$ HRU's } & 150 & COMBINAÇÃO 3 \\
\hline & & & 300 & COMBINAÇÃO 4 \\
\hline & \multirow{5}{*}{ MDE TRATADO } & $0 \% 4.162$ HRU's & 150 & COMBINAÇÃO 5 \\
\hline & & \multirow{2}{*}{$10 \% 2.070$ HRU's } & 150 & COMBINAÇÃO 6 \\
\hline & & & 300 & COMBINAÇÃO 7 \\
\hline & & \multirow{2}{*}{$20 \% 1.152$ HRU's } & 150 & COMBINAÇÃO 8 \\
\hline & & & 300 & COMBINAÇÃO 9 \\
\hline
\end{tabular}

No delineamento automático da bacia hidrográfica, tendo o MDE como base, foi gerada uma bacia com área de drenagem de $5.892 \mathrm{~km}^{2}$ composta por 265 sub-bacias, tendo como exutório a de número 260. O MDE tratado apresentou resultados bem próximos, com uma área total de $5.889 \mathrm{~km}^{2}$ e 258 sub-bacias com exutório a de número 250.

Em relação à quantidade de HRU's geradas, os valores variaram de acordo com o percentual suprimido referente às classes de uso e ocupação e das classes de declividade. Foi gerada uma simulação sem supressão apenas para o MDE tratado, o qual resultou num total de 4.162 HRU's. Com supressão de $10 \%$ das referidas classes, foram geradas $2.210 \mathrm{HRU}$ 's com o MDE, enquanto que com o MDE tratado foram geradas 2.070 HRU's. Já com a supressão de $20 \%$ obteve-se um total de 1.217 HRU's no MDE e 1.152 no MDE tratado. Essa diferença de percentuais de supressão permitiu que fosse realizada uma análise do comportamento do modelo quanto à variação da quantidade de HRU's, sendo quase $50 \%$ de diferença entre as variações.

Outra análise realizada foi a avaliação quanto à quantidade de iterações (150 e 300) aplicadas a cada simulação no período de calibração, com o intuito de avaliar os resultados das diferentes combinações.

Após todas as combinações possíveis, foram gerados gráficos para analisar a melhor simulação para o período de calibração (1981 a 2000) e 
verificação (2000 a 2010) em relação aos dados observados. Devido às similaridades entre as séries geradas, os gráficos foram gerados em dois grupos, os quais estão representados nas figuras 15 (calibração) e 17 (verificação) para as combinações 1, 3, 5, 6 e 8 e nas figuras 16 (calibração) e 18 (verificação) para as combinações 2, 4, 7 e 9 .

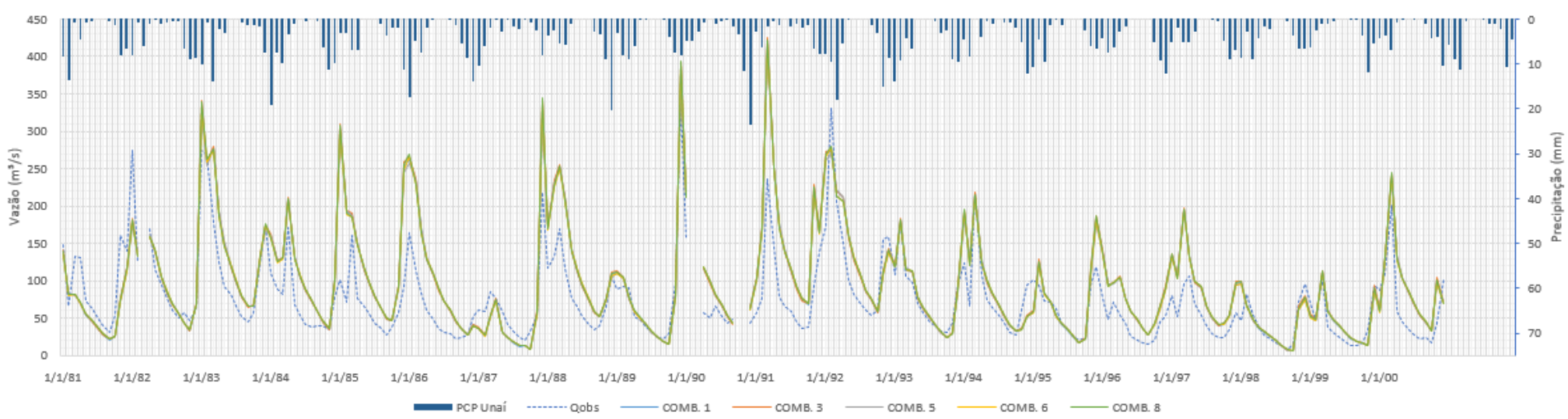

Figura 15 - Comparação entre dados de chuva com as vazões simuladas e observadas no período de calibração das combinações 1, 3, 5, 6 e 8 (Tabela 9).

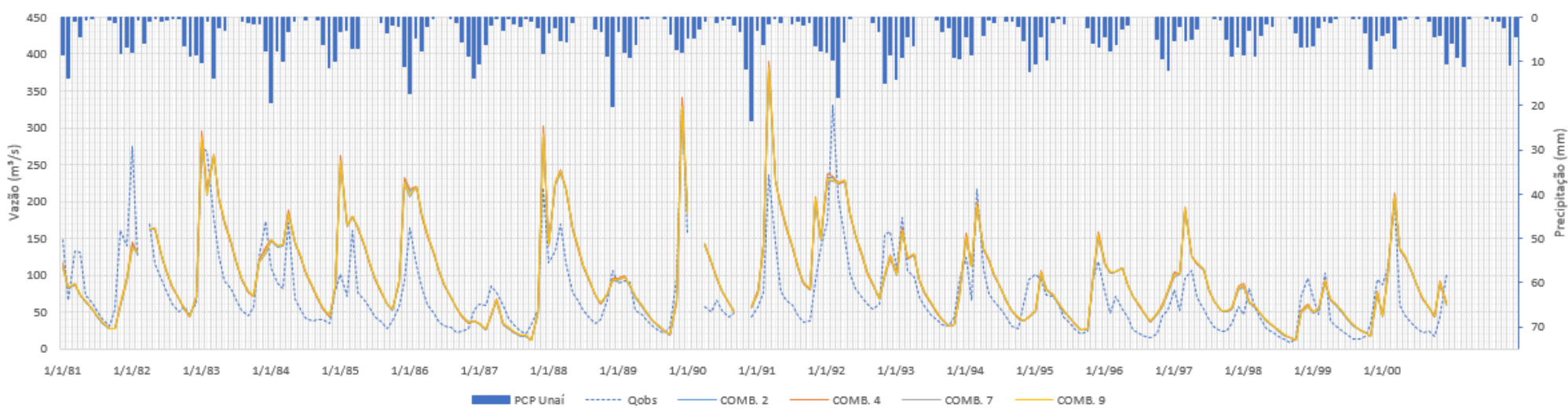

Figura 16 - Comparação entre dados de chuva com as vazões simuladas e observadas no período de calibração das combinações 2, 4, 7 e 9 (Tabela 9). 


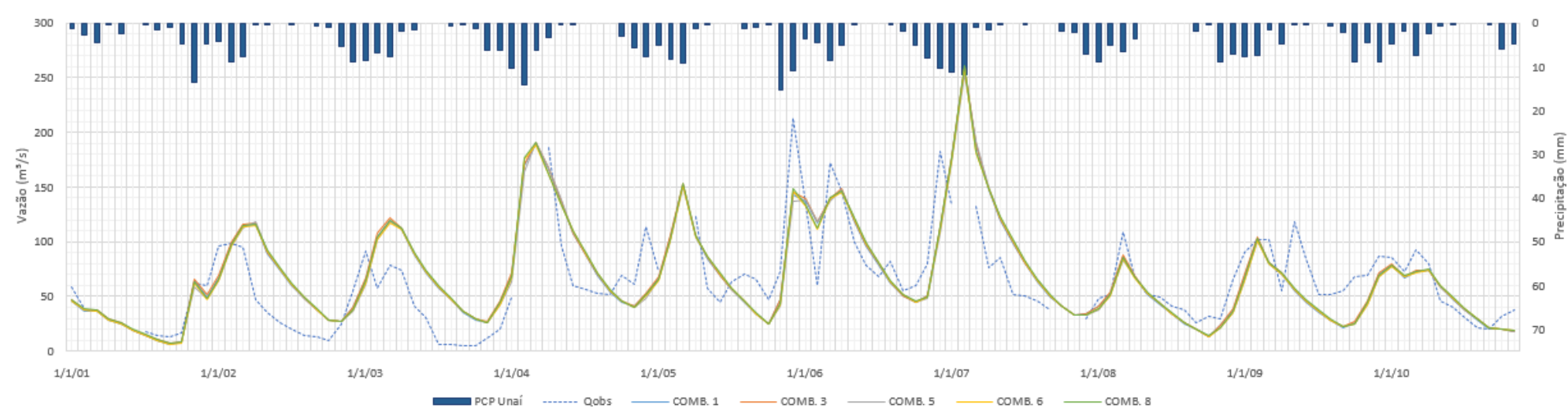

Figura 17 - Comparação entre dados de chuva com as vazões simuladas e observadas no período de verificação das combinações 1, 3, 5, 6 e 8 (Tabela 9).

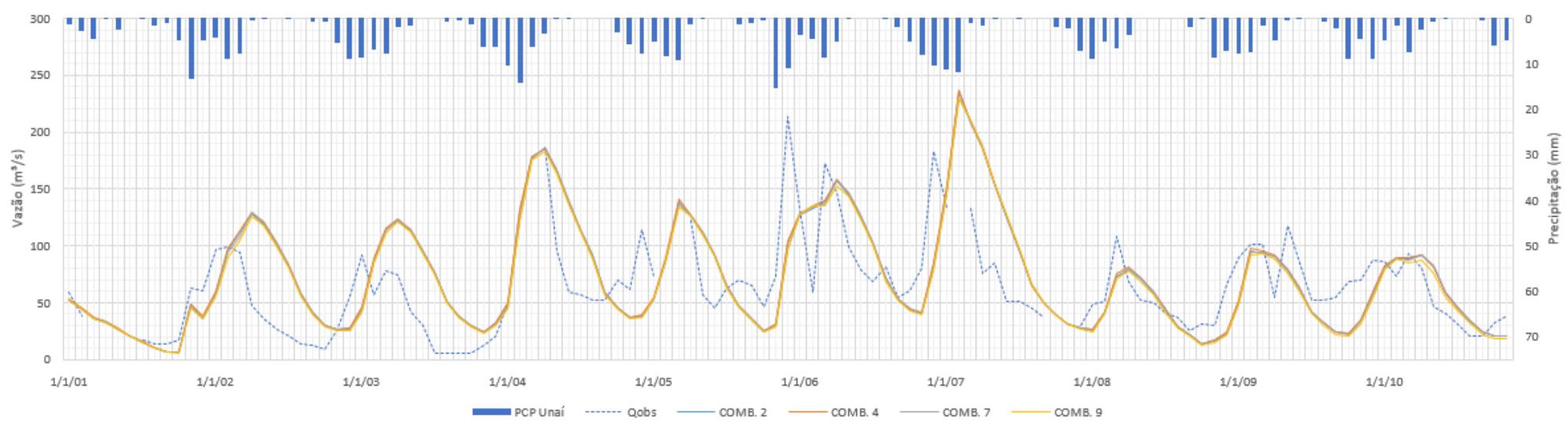

Figura 18 - Comparação entre dados de chuva com as vazões simuladas e observadas no período de verificação das combinações 2, 4, 7 e 9 (Tabela 9).

Ao analisar os gráficos para o período de calibração e de verificação, observou-se que as combinações 1, 3, 5, 6 e 8 se aproximam mais das vazões observadas. Em ambos os grupos de simulações, o período de calibração apresentou melhores resultados em relação ao período de verificação. No entanto, é possível observar que os picos foram superestimados de uma forma geral, do mesmo modo que ocorreu um retardamento sistemático na fase de recessão das vazões.

Para o período de verificação, observou-se que o fluxo de base simulado até o ano de 2004 esteve acima do observado e nos anos seguintes ficou abaixo do observado em grande parte do período. 
$\mathrm{Na}$ Tabela 10 observa-se todas as simulações realizadas na primeira etapa do trabalho de forma esquematizada, bem como os resultados dos coeficientes estatísticos aplicados para o período de calibração e verificação.

Tabela 10: Resultados estatísticos para a definição da melhor combinação de dados e procedimentos para modelar a vazão na bacia do Rio Preto com base no MDE, HRU's e número de iterações.

\begin{tabular}{|c|c|c|c|c|c|c|}
\hline NOME & NSE CAL & NSE VAL & PBIAS CAL & PBIAS VAL & RSR CAL & RSR VAL \\
\hline COMBINAÇÃO 1 & 0.64 & 0.43 & -29.45 & -4.23 & 0.60 & 0.76 \\
\hline COMBINAÇÃO 2 & 0.52 & 0.22 & -30.81 & -11.42 & 0.70 & 0.89 \\
\hline COMBINAÇÃO 3 & 0.63 & 0.43 & -30.70 & -5.64 & 0.60 & 0.75 \\
\hline COMBINAÇÃO 4 & 0.52 & 0.22 & -32.06 & -12.63 & 0.69 & 0.88 \\
\hline COMBINAÇÃO 5 & 0.63 & 0.40 & -28.99 & -3.82 & 0.61 & 0.78 \\
\hline COMBINAÇÃO 6 & 0.64 & 0.41 & -29.24 & -3.78 & 0.60 & 0.77 \\
\hline COMBINAÇÃO 7 & 0.50 & 0.19 & -30.61 & -11.47 & 0.71 & 0.90 \\
\hline COMBINAÇÃO 8 & 0.63 & 0.42 & -30.45 & -5.07 & 0.60 & 0.76 \\
\hline COMBINAÇÃO 9 & 0.50 & 0.19 & -31.84 & -8.92 & 0.71 & 0.90 \\
\hline
\end{tabular}

O MDE não foi um fator de grande influência para os resultados nesta área de estudo, tendo em vista a similaridade das simulações com ambos os modelos utilizados. O tratamento para minimizar os ruídos não foi justificado, tendo em vista que este exige tempo considerável de processamento de dados e não influiu significativamente nos resultados finais. Desse modo, nas etapas seguintes optou-se por utilizar somente o MDE USGS (original).

A quantidade de HRU's definidas pelo percentual de supressão não influenciou diretamente nos resultados das modelagens, este fato pode ser observado quando se compara a combinação 5 com a combinação 8, onde se utilizou toda a área das classes (4.162 HRU's) e suprimiu-se $20 \%$ das referidas classes (1.152 HRU's), respectivamente. Essa diferença de HRU's tem influência direta no tempo de processamento, visto que na combinação 5 tem-se aproximadamente 3,6 vezes mais HRU's em relação a combinação 8 , fato que não gerou melhores resultados em relação a outra simulação. Neste contexto, e 
considerando ainda o requerimento de maiores períodos demandados para o processamento quando maiores quantidades de HRU's fossem produzidas, para as simulações das etapas seguintes, optou-se por realizá-las com supressão de $20 \%$ para geração das HRU's.

De uma forma geral, os resultados mostraram uma grande similaridade entre as combinações 1, 3, 5, 6 e 8, assim como para as combinações 2, 4, 7 e 9, sendo que a variável comum entre elas foi a quantidade de iterações realizadas na calibração para cada simulação, sendo respectivamente 150 e 300 iterações (Tabela 9). A partir da análise comparativa, foi observado que mesmo aumentando a quantidade de iterações no processo de calibração, não se obteve melhores resultados em relação aos coeficientes estatísticos aplicados, neste caso, portanto, vale ressaltar que o resultado foi divergente do esperado.

Por se tratar de uma bacia de mesoescala e devido à grande quantidade de simulações realizadas, o que acarreta em muitos dados processados e extensos períodos para se executar o modelo, foi levado em conta o resultado ter sido inferior quando se realizou mais iterações. Desse modo, nas simulações seguintes a calibração foi realizada com somente 150 iterações.

Os resultados do NSE foram melhores no período de calibração em relação ao período de verificação, sendo que em todas as simulações foram obtidos valores superiores à zero. Comparativamente ao uso da média dos dados observados, este é um melhor resultado, o qual representa um dos fatores que justificam o uso do modelo.

Segundo Moriasi et al. (2007), para a calibração mensal, os valores de NSE acima de 0,5 são considerados "satisfatórios", acima de 0,65 "bons", e superiores a 0,75 "muito bons". Assim como, para os autores Santhi et al. (2001) e Van Liew, Arnold e Garbrecht (2003) consideram também que valores maiores que 0,5 são "aceitáveis".

O NSE nas combinações $1,3,5,6$ e 8, os resultados variaram de 0.63 a 0.64 no período de calibração e de 0.40 a 0.43 para o período de verificação. Já nas combinações 2, 4,7 e 9, os valores variam de 0,50 a 0,52 na calibração e de 
0,19 a 0,20 na verificação. Sendo assim, os resultados foram "satisfatórios" na calibração e "insatisfatórios" na verificação.

O PBIAS apresentou menor diferença entre as simulações para o período de calibração, variando entre -28.99 e -32.06. Já na verificação, a diferença foi de -3.82 a -11.47. De acordo com a classificação Moriasi et al. (2007), o período de verificação apresentou melhores resultados, classificando-se como "muito bom" para as combinações 1, 3, 5, 6, 8 e 9 e "bom" para as combinações 2, 4, e 7.

Para o RSR, os resultados variaram de "bom" para as combinações 1, 3, 6 e 8 a "satisfatório" para as combinações 2, 4, 5, 7 e 9 no período de calibração. E na calibração todas as simulações apresentaram resultado como "insatisfatório".

\subsection{Segunda Etapa}

Na segunda etapa foi gerada apenas à simulação referente à combinação 10. Foram levados em consideração os apontamentos realizados na etapa anterior referente aos dados de entrada necessários ao modelo. Para tanto, utilizou-se o MDE USGS (original) com uma combinação de $20 \%$ de supressão de classes para geração das HRU's (total de 1.217) e optou-se pela realização de 150 iterações na calibração no SWAT CUP, conforme apresentado na Tabela 11. Esses critérios propostos levaram em consideração os resultados estatísticos gerados na primeira etapa, bem como o tempo requerido de processamento. 
Tabela 11: Combinação gerada na segunda etapa.

\begin{tabular}{|c|c|c|c|c|}
\hline ESTAÇÕES & MODELO & HRU SUPRESSÃO & ITERAÇÕES & NOME \\
\hline $\begin{array}{c}\text { CLIMATOLÓGICA: } \\
\text { UNAÍ/BSB/FORMOSA } \\
\text { FLUVIOMÉTRICA: UNAí }\end{array}$ & MDE & $20 \% 1.217$ HRU's & 150 & COMBINAÇÃO 10 \\
\hline
\end{tabular}

Como os dados físicos de entrada do modelo não foram alterados, não se teve variação da área de drenagem, sub-bacias e quantidades de HRU's nesta etapa em relação à primeira. A combinação 10 somente divergiu da combinação 3 (realizada na primeira etapa) em relação a entrada dos dados climáticos. $\mathrm{Na}$ primeira etapa foram utilizados somente os dados da estação de Unaí, enquanto que nesta etapa, também foram utilizados os dados das estações climáticas de Brasília e Formosa. A estação fluviométrica de referência continuou sendo a de Unaí. Desse modo, foi possível avaliar as diferenças entre as etapas em relação a componente climática.

Ao analisar os gráficos referentes à simulação da combinação 10, Figuras 19 e 20, pode-se observar um melhor ajuste dos valores simulados com os dados observados, tanto no período de calibração quanto de verificação.

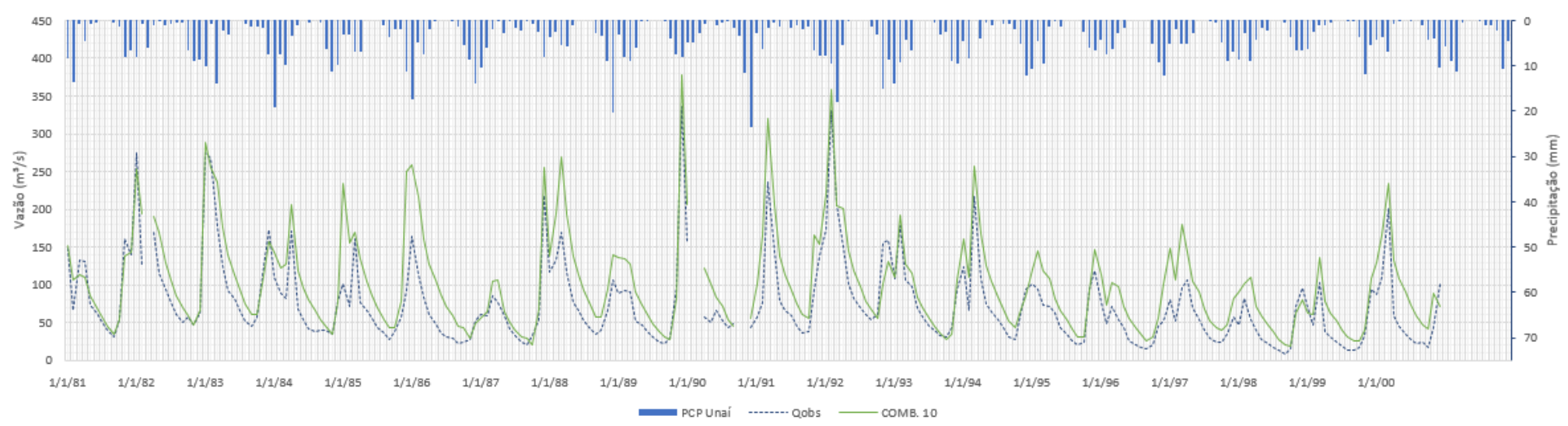

Figura 19 - Comparação entre dados de chuva com as vazões simuladas e observadas no período de calibração da combinação 10 (Tabela 11). 


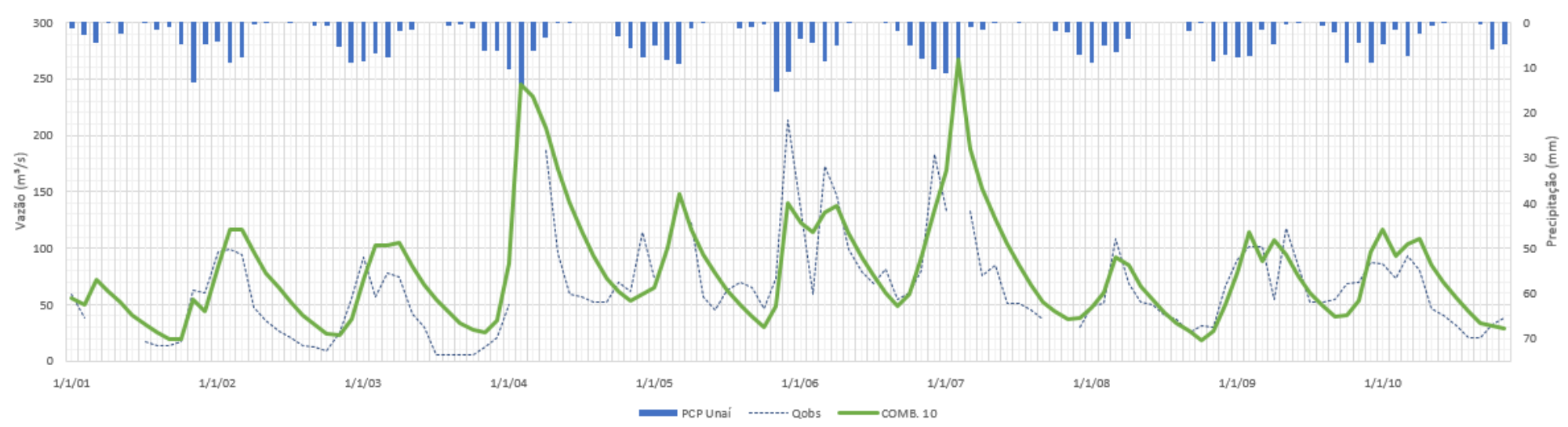

Figura 20 - Comparação entre dados de chuva com as vazões simuladas e observadas no período de verificação da combinação 10 (Tabela 11).

A série da calibração, visivelmente, mostrou-se melhor do que a da verificação. Pela análise visual dos gráficos pode-se observar uma diminuição na superestimação dos picos, na retardação sistêmica e na recessão das vazões em grande parte da série histórica, bem como, uma melhor representação do fluxo de base.

Para o período de verificação, ainda pode-se observar o retardo da recessão de vazão, porém, em menor intensidade em relação ao da etapa anterior. Em relação ao fluxo de base, o modelo apresentou um melhor ajuste nesta etapa.

$\mathrm{Na}$ Tabela 12 são apresentados os resultados dos coeficientes estatísticos referente à combinação 10 .

Tabela 12: Resultados estatísticos para a definição da melhor combinação de dados e procedimentos para modelar a vazão na bacia do Rio Preto com dados climáticos de três estações climatológicas.

\begin{tabular}{|c|c|c|c|c|c|c|}
\hline NOME & NSE CAL & NSE VAL & PBIAS CAL & PBIAS VAL & RSR CAL & RSR VAL \\
\hline COMBINAÇÃO 10 & 0.70 & 0.48 & -35.88 & -17.55 & 0.55 & 0.72 \\
\hline
\end{tabular}


O NSE da combinação 10 em relação à combinação 3 apresentou melhores resultados na calibração e na verificação dos dados, sendo eles 0.70 na calibração e 0.48 na verificação para a combinação 10 e de 0.63 na calibração e 0.43 na verificação para a combinação 3 (Tabela 9). Nesse contexto, e assumindo os critérios definidos por Moriasi et al, (2007), o resultado obtido foi considerado bom na calibração e insatisfatórios na verificação.

Levando-se em conta que quanto mais próximo de zero for o valor do coeficiente PBIAS, mais próximos são os resultados da simulação com os valores observados, então, percebeu-se que os resultados da combinação 3 já foram melhores que os da combinação 10 para ambos os períodos de análise. Para a combinação 3 foram obtidos os valores -30.70 para a calibração e -5.64 para a verificação, enquanto que, para a combinação 10 , os valores foram -35.88 e -17.55 para calibração e verificação, respectivamente. Portanto, na calibração, o resultado é insatisfatório, já para o período de verificação é satisfatório. Outro ponto a ser observado sobre o PBIAS nesta etapa é que o modelo continua superestimando quanto à vazão, visto que os valores apresentados são negativos.

Em relação ao coeficiente RSR que varia de 0 a $\infty$, os resultados desta etapa foram melhores comparativamente aos resultados da etapa anterior. Os valores obtidos foram de 0.55 na calibração (classificação boa) e 0.72 na verificação (classificação insatisfatória), enquanto que na anterior os valores foram de 0.60 e 0.75 para calibração e verificação, respectivamente.

Os resultados estatísticos desta etapa apresentaram melhor desempenho em dois dos três coeficientes avaliados (NSE e RSR). Mesmo não sendo muito grande esta diferença, pode-se dizer que o modelo apresentou melhorias com a entrada dos dados climáticos das outras duas estações, fato que pode estar relacionado com a melhor espacialização e regionalização de tais variáveis. 


\subsection{Terceira Etapa}

Um dos objetivos desta fase da pesquisa foi avaliar o comportamento do modelo quanto à mudança da estação de referência de dados fluviométricos para a estação de Porto dos Poções. Visto isto, no delineamento da bacia foi gerada uma área de drenagem de $10.445 \mathrm{~km}^{2}$ subdividida em 491 sub-bacias, sendo a de número 491 correspondente ao exutório e, com isso, a mais próxima da confluência com o Rio Paracatu, afluente do Rio São Francisco.

Foram geradas duas simulações com os mesmos dados de entrada, onde foram levados em consideração os resultados das etapas anteriores. Para tanto, foi utilizado o MDE USGS (original) com uma combinação de $20 \%$ de supressão de classes para geração das HRU's, resultando em 2.562. As combinações geradas nesta etapa estão representadas na Tabela 13.

Tabela 13: Combinações geradas na terceira etapa.

\begin{tabular}{|c|c|c|c|c|c|}
\hline \multirow{3}{*}{$\begin{array}{c}\text { ESTAÇõES } \\
\text { CLIMATOLÓGICA: } \\
\text { UNAII/BSB/FORMOSA } \\
\text { FLUVIOMÉTRICA: }\end{array}$} & MODELO & HRU SUPRESSÃO & ITERAÇÕES & PARÂMETROS & NOME \\
\hline & \multirow{2}{*}{ MDE } & \multirow{2}{*}{$20 \% 2.562$ HRU's } & \multirow{2}{*}{150} & UNAÍ & COMBINAÇÃO 11 \\
\hline & & & & $\begin{array}{l}\text { PORTO DOS } \\
\text { POCCÕES }\end{array}$ & COMBINAÇÃO 12 \\
\hline
\end{tabular}

O principal objetivo desta etapa foi avaliar o comportamento do modelo em uma simulação em que não ocorreria a calibração automática no SWAT CUP. Para tanto, foi proposto o uso do conjunto de parâmetros ótimos calibrados para estação de Unaí, na etapa 2 (Tabela 11), a fim de avaliar a similaridade dos dados físicos por meio dos parâmetros da bacia, em nível de uma regionalização, tendo como resultado a simulação de número 11.

Em seguida, o modelo foi calibrado e validado para a estação de Porto dos Poções. Foram realizadas 150 iterações para a geração dos parâmetros ótimos, resultando na combinação 12, o que proporcionou a análise dos 
resultados na mesma estação de referência, porém, com um conjunto de parâmetros ótimos calibrados e validados na estação de Porto dos Poções.

No gráfico abaixo, Figura 21, está representada a simulação da combinação 12 para o período de calibração.

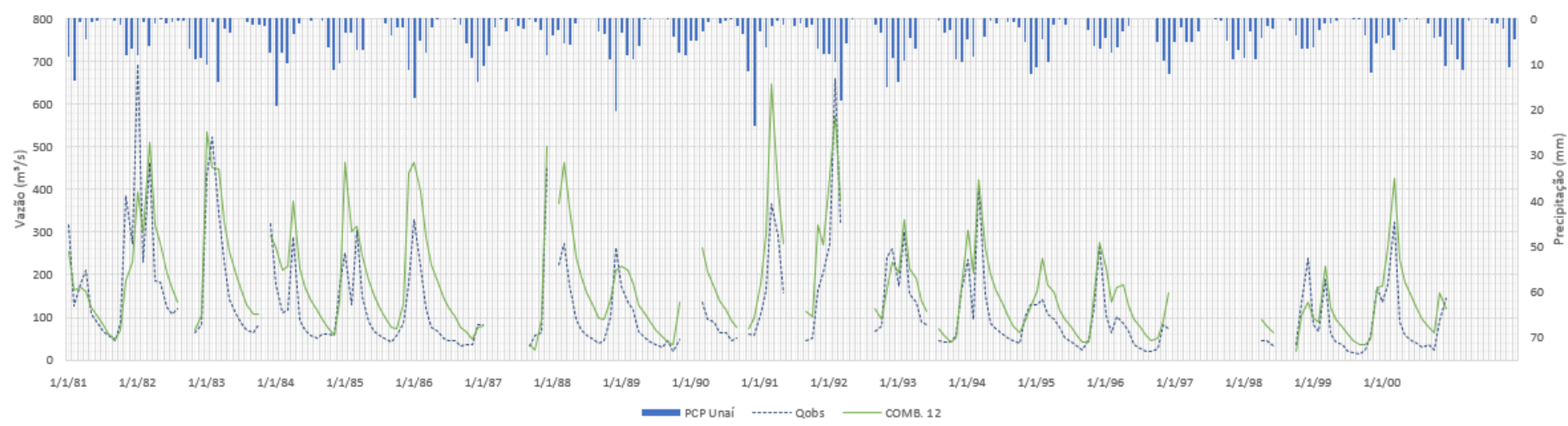

Figura 21 - Comparação entre dados de chuva com as vazões simuladas e observadas no período de calibração da combinação 12 (Tabela 13).

$\mathrm{Na}$ Figura 21, pode-se observar que o modelo apresentou bons resultados, sendo visível uma menor superestimação em grande parte dos picos de vazão. O fluxo de base está bem representado, porém deslocado, devido a um retardo sistêmico da série de vazão.

Na Figura 22 está representado a série de vazão das combinações 11 e 12 , comparadas com a vazão observada para o período de verificação. 


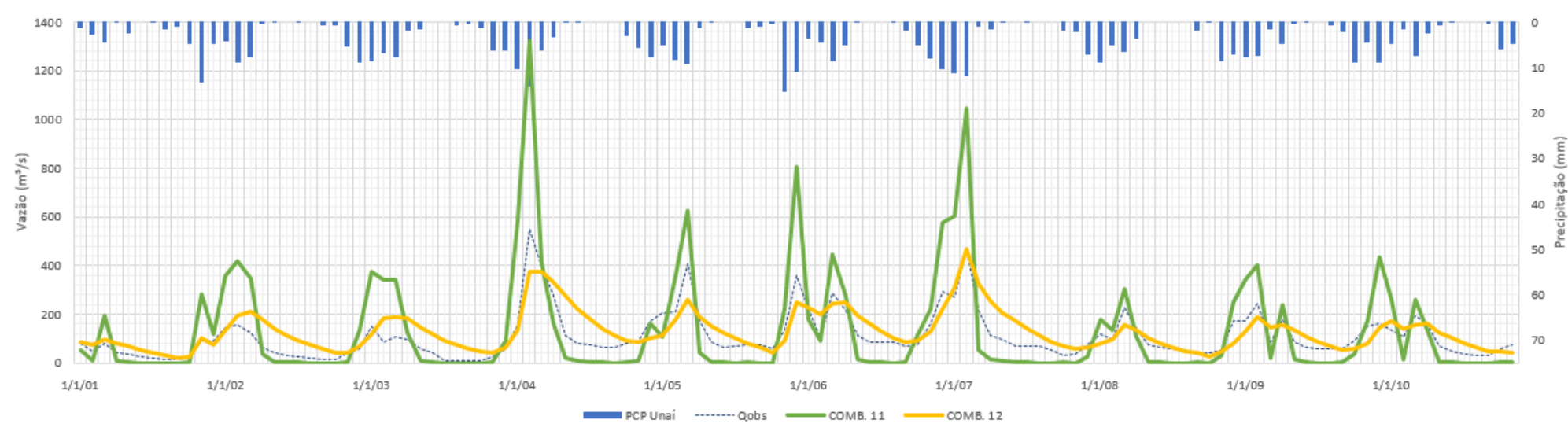

Figura 22 - Comparação entre dados de chuva com as vazões simuladas e observadas no período de verificação da combinação 11 e 12 (Tabela 13).

Para o período de verificação, figura 22, fica visível a diferença na escala quando se compara a simulação da combinação 11 (parâmetros da estação de Unaí) com a combinação 12 (parâmetros de Porto dos Poções). O modelo apresentou uma melhor série na combinação 12 do que na combinação 11. Em ambas, pode-se observar que o modelo continuou superestimando os picos.

Na combinação 11, o fluxo de base simulado está muito abaixo do fluxo de base observado, chegando a valores próximos de zero. Já na combinação 12, fica visível um retardo sistêmico da série de vazão.

$\mathrm{Na}$ Tabela 14 está representada as simulações e seus referidos resultados estatísticos.

Tabela 14: Resultados estatísticos das combinações da estação de referência de Porto dos Poções com parâmetros calibrados para a estação de Unaí e da estação de Porto dos Poções.

\begin{tabular}{|c|c|c|c|c|c|c|}
\hline NOME & NSECALUNAÍ & NSEVAL PAR UNÁl & PBIAS CAL UNAí & PBIAS VAL_PAR UNÁ & RSR CALUNAí & RSR VAL PAR UNÁl \\
\hline COMBINAÇÃO 11 & . & 0.57 & - & -18,34 & - & 0.66 \\
\hline & NSECAL PORTO POCONOES & NSE VAL PORTO POÇOES & PBIASCAL PORTO POÇOES & PBIAS VAL PORTO POÇOEES & RSR CAL PORTO POÇOEES & RSR VAL PORTO POCONOES \\
\hline COMBINAÇÃO 12 & 0.61 & 0.31 & $-40,81$ & -20.29 & 0.63 & 0.83 \\
\hline
\end{tabular}


Analisando os coeficientes estatísticos, o primeiro ponto a ser observado é que a simulação 11 apresentou os melhores resultados para os coeficientes NSE e RSR no período de verificação em relação a todas as combinações do trabalho, onde ambos foram classificados como satisfatórios. O PBIAS não apresentou diferença significativa entre as combinações, sendo também classificado como satisfatório, ressaltando que a verificação foi realizada com o conjunto de parâmetros ótimos gerados na combinação 10 (Tabela 11), fato que pode justificar certa similaridade físicas e uma regionalização dos dados de componentes de uma mesma bacia hidrográfica.

$\mathrm{Na}$ combinação 12, os resultados foram inferiores em relação à combinação 11 para este caso, sugerindo que a calibração não gerou um bom conjunto de parâmetros ótimos para a estação de Porto dos Poções. Fato que pode estar ligado a quantidade de falhas encontradas nos períodos em análise para a estação de Porto dos Poções em relação à estação de Unaí, o que explica a escolha da estação de referência ser a de Unaí.

\subsection{Balanço Hídrico}

O modelo utiliza a equação do balanço hídrico para o cálculo da fase terrestre do ciclo hidrológico, sendo esta a responsável por todo o restante que ocorre na bacia hidrográfica (NEITSCH et al., 2005a).

Para o período compreendido entre janeiro de 2001 a novembro de 2010 (verificação), foi realizada uma comparação entre as estimativas dos parâmetros médios relativos ao ciclo hidrológico calculado pelo modelo.

Como foram realizadas muitas simulações e os resultados não apresentaram diferenças relevantes, optou-se por fazer uma análise somente das combinações 3 e 8 (primeira etapa, Tabela 9), combinação 10 (segunda etapa, Tabela 11) e combinação 12 (terceira etapa, Tabela 13). 
A Tabela 15 lista os resultados das simulações e a Tabela 16 algumas das relações entre estas variáveis consideradas para o ciclo hidrológico.

Tabela 15: Parâmetros médios do ciclo hidrológico.

\begin{tabular}{|l|c|c|c|c|}
\hline \multicolumn{1}{|c|}{ Variável (mm) } & Combinação 3 & Combinação 8 & Combinação 10 & Combinação 12 \\
\hline Capilaridade & 29,52 & 29,47 & 29,24 & 29,21 \\
\hline Descarga do Aquifero & 438,04 & 457,67 & 469,12 & 444,15 \\
\hline Escoamento Subsuperficial & 134,71 & 113,70 & 140,19 & 163,49 \\
\hline Escoamento Superficial & 220,97 & 213,25 & 208,74 & 188,97 \\
\hline Evapotranspiração & 580,80 & 589,90 & 574,20 & 588,30 \\
\hline Percolação & 491,90 & 512,55 & 524,19 & 497,88 \\
\hline Precipitação & $1.425,30$ & $1.425,30$ & $1.443,90$ & $1.436,10$ \\
\hline Recarga do Aquifero Profundo & 24,59 & 25,63 & 26,21 & 24,89 \\
\hline
\end{tabular}

Tabela 16: Relações do ciclo hidrológico.

\begin{tabular}{|l|c|c|c|c|}
\hline \multicolumn{1}{|c|}{ Relações do Balanço Hidrico } & Combinação 3 & Combinação 8 & Combinação 10 & Combinação 12 \\
\hline Deflúvio/Precipitação & 0,56 & 0,55 & 0,57 & 0,55 \\
\hline Fluxo de Base/Vazão Total & 0,72 & 0,73 & 0,74 & 0,76 \\
\hline Escoamento Superficial/Vazão Total & 0,28 & 0,27 & 0,26 & 0,24 \\
\hline Percolação/Precipitação & 0,35 & 0,36 & 0,36 & 0,35 \\
\hline Recarga do Aquifero Profundo/Precipitação & 0,02 & 0,02 & 0,02 & 0,02 \\
\hline Evapotranspiração/Precipitação & 0,41 & 0,41 & 0,40 & 0,41 \\
\hline
\end{tabular}

De uma forma geral, as simulações apresentaram valores muito próximos em praticamente todos os parâmetros em análise do ciclo hidrológico. A Tabela 17 dispõe uma comparação entre os resultados das variáveis hidrológicas obtidas por diversos autores no Bioma Cerrado. 
Tabela 17: Comparação entre as variáveis hidrológicas.

\begin{tabular}{|c|c|c|c|c|}
\hline Referência & $\begin{array}{c}\text { Silva e Oliveira } \\
(1999)\end{array}$ & Lima (2010) & Lima (2010) & Silva (2016) \\
\hline Ano Hidrológico & $1996 / 1997$ & $1998 / 1999$ & $2007 / 2008$ & $2015 / 2016$ \\
\hline Bacia Hidrográfica & Capetinga, DF & Capetinga, DF & Alto Jardim, DF & Rio Preto \\
\hline $\begin{array}{c}\text { Área da Bacia } \\
\text { (km²) }\end{array}$ & 10.00 & 10.00 & 104.86 & 10310.00 \\
\hline Variável & $\%$ & $\%$ & $\%$ & $\%$ \\
\hline Precipitação & 100.00 & 100.00 & 100.00 & 100.00 \\
\hline Evapotranspiração & 71.53 & 78.49 & 70.71 & 40.00 \\
\hline $\begin{array}{c}\text { Escoamento } \\
\text { Superficial }\end{array}$ & 3.01 & 1.42 & 2.94 & 14.00 \\
\hline $\begin{array}{c}\text { Escoamento de } \\
\text { Base }\end{array}$ & 25.46 & 26.86 & 26.35 & 46.00 \\
\hline Escoamento Total & 28.47 & 28.28 & 29.29 & 60.00 \\
\hline
\end{tabular}

Percebe-se que, comparativamente aos trabalhos desenvolvidos pelos autores mencionados, houveram discrepâncias em termos das porcentagens resultantes para cada variável hidrológica. De forma geral, a evapotranspiração foi subestimada, enquanto os escoamentos superficial, de base e total foram superestimados em aproximadamente $30 \%$.

Os valores entre as variáveis do ciclo hidrológico estão diretamente relacionados as características da área de estudo. Dados observados mostram que em análises relacionadas à razão entre evapotranspiração e precipitação em nível global, os valores variam entre 60 a 65\% (TATEISH; AHN, 1996). Neves (2007), na estimativa do balanço hídrico de uma bacia do Amapá, encontrou valores entre a evapotranspiração e a precipitação na região de 0,41 . Já para estudo em bacias do Bioma Cerrado, Lima (2010) achou valores que demonstraram uma relação de $78 \%$. Silva e Oliveira (1999) obtiveram uma relação de $72 \%$.

Para trabalhos que utilizaram o SWAT, os valores de evapotranspiração tendem a ser subestimados. Salles (2012), encontrou uma relação entre evapotranspiração e precipitação de $49 \%$ utilizando o SWAT. Castro (2013), modelando na bacia hidrográfica do Alto Jardim (DF), encontrou valores em torno de $56 \%$, enquanto que para o mesmo período, Lima (2010) encontrou valores de $71 \%$ com dados medidos. 
É possível que esse distanciamento seja decorrente das dimensões da bacia estudada, da escala dos mapas de uso e cobertura da terra e tipo de solo, do número de HRUs produzido para a simulação e/ou na quantidade de iterações realizadas. 


\section{CONCLUSÃO}

O estudo permitiu comparar o efeito de diferentes variáveis de entrada, dentre as propostas na metodologia. $\mathrm{O}$ tratamento empregado ao MDE não se justificou, tendo em vista a similaridade dos resultados encontrados nas simulações com ambos os modelos. Os diferentes percentuais de supressão de área das classes de uso e cobertura e de declividade utilizados para a geração das HRU's também não se mostraram como uma variável de grande influência, visto que as simulações com maiores quantidades de HRU's não apresentaram resultados superiores em relação às simulações com menos quantidades. $A$ variável que apresentou maior influência nos resultados foi a quantidade de iterações realizadas no processo de calibração do modelo, onde observou-se que as simulações com 300 iterações apresentaram resultados inferiores às simulações com 150 iterações.

Em relação à análise de sensibilidade, aos parâmetros escolhidos para a calibração do modelo apresentaram a mesma ordem de sensibilidade ( $t$-stat) e de significância da sensibilidade ( $P$-value), sendo o mais influente o SOL_AWC e o menos influente ALPHA_BF.

As análises gráficas em conjunto com os coeficientes estatísticos utilizados, mostraram que os resultados do período de calibração foram melhores que o período de verificação. Em praticamente todas as simulações o modelo superestimou os picos e apresentou um retardo sistêmico na fase de recessão das vazões, no entanto obteve melhores resultados no fluxo de base.

O modelo apresentou melhores resultados estatísticos quando foram utilizadas mais estações climatológicas. Em relação à estação fluviométrica de referência, quando se utilizou a de Porto dos Poções, o modelo apresentou resultados melhores para a simulação com o conjunto de parâmetros da estação de Unaí em relação à simulação com os parâmetros da mesma estação. Num contexto geral, de acordo com a classificação utilizada, as simulações variaram de "satisfatória" a "insatisfatória".

As variáveis do balanço hídrico para o período de verificação do modelo apresentaram resultados coerentes com os as características físicas da área de 
estudo. Porém, para o cálculo do balanço hídrico, o escoamento superficial e de base foram superestimados e a evapotranspiração foi subestimada em relação aos trabalhos semelhantes.

Considerando a dificuldade de estudos hídricos em grande escala que apresentem resultados satisfatórios, espera-se que a metodologia empregada no presente trabalho possa ser replicada para outras áreas de estudo e que possam servir de subsídio para diferentes fins que visem elaboração de políticas públicas com foco na gestão dos recursos naturais. 


\section{REFERÊNCIAS BIBLIOGRÁFICAS}

ABBASPOUR, K.C. SWAT-CUP2009: SWAT Calibration and Uncertainty Programs - a user manual. Department of Systems Analysis, Integrated Assessment and Modelling (SIAM), Eawag, Swiss Federal Institute of Aquatic Science and Technology, Duebendorf, Switzerland, 95 p, 2011.

ABBOTT, M. B. An introduction to the European Hydrological System - Système Hydrologique Européen, 'SHE' - 2: Structure of a Physically-Based, Distributed Modelling System. Journal of Hydrology, v. 87, p. 61-77, 1986.

ADRIOLO, M.V.; SANTOS, I.; GIBERTONI, R.C.; CAMARGO, A.S.G. Calibração do modelo SWAT para a produção e transporte de sedimentos. In: VI Simpósio Brasileiro sobre Pequenas e Médias Centrais Hidrelétricas. Belo Horizonte - Minas Gerais, Brasil, 2008.

ANA - AGÊNCIA NACIONAL DAS ÁGUAS. Disponibilidade e demandas de recursos hídricos no Brasil. Caderno de recursos hídricos. ANA-CDOC, 2005. Disponível em: <http://www2.ana.gov.br/Paginas/imprensa/artigos.aspx>. Acesso em: 15 de out. de 2013.

ARNOLD, J.G.; ALLEN, P.M. Estimating hydrologic budgets for three Illinois watersheds. Journal of Hydrology, n. 176, p. 57-77, 1996.

ARNOLD, J.G.; MORIASI, D.N.; GASSMAN, P.W.; ABBASPOUR, K.C.; WHITE, M.J.; SRINIVASAN, R.; SANTHI, C.; HARMEL, R.D.; VAN GRIENSVEN, A.; VAN LIEW, M.W.; KANNAN, N.; JHA, M.K. SWAT: Model Use, Calibration, and Validation. Transactions of the ASABE - American Society of Agricultural and Biological Engineering, v. 55, n. 4, p. 1491-1508, 2012a.

ARNOLD, J.G.; KINIRY, J.R.; SRINIVASAN, R.; WILLIAMS, J.R.; HANEY, E.B.; NEITSCH, S.L. Soil and Water Assessment Tool - Input/Output 
Documentation: Version 2012. College Station, Texas Water Resources Institute, p. 650, 2012b.

ARNOLD, J.G.; SRINIVASAN, R.; MUTTIAH, R.S.; WILLIAMS, J.R. Large area hydrologic modeling and assessment part I: Model development. Journal of the American Water Resources Association, v. 34, n. 1, p. 1-17, 1998.

BATHURST, J.C. Physically-Based Distributed Modelling of an Upland Catchment using the Système Hydrologique Européen. Journal of Hydrology, v. 87, p. 79-102, 1986.

BEASLEY, D.B.; MONKE, E.J.; HUGGINS, L.F. ANSWERS: A model for watershed planning. Transactions of the ASABE - American Society of Agricultural and Biological Engineering, v. 23 n 4, p. 938-944, 1977.

BEVEN, K.J.; KIRKBY, M.J. A physically based, variable contributing area model of basin hydrology. Hydrological Sciences-Bulletin-des Sciences Hydrologiques, v 24, p. 43-69, 1979.

BICKNELL, B.R.; IMHOFF, J.C.; KITTLE, J.L.; DONIGIAN, A.S.; and JOHANSON, R.C. Hydrologic simulation program - FORTRAN user's manual, v.11, Athens, GA., USEPA, 1996.

BIGARELLA, J.J.; BECKER, R.D.; PASSOS, E. Paisagem cárstica. In: Estrutura e origem das paisagens tropicais e subtropicais, Florianópolis, Santa Catarina, v.1, p. 242-308, 1996.

BOURAOUI, F.; BRAUD, I.; DILLAHA, T.A. ANSWERS: A nonpoint-source pollution model for water, sediment, and nutrient losses. Chapter 22 in Mathematical Models of Small Watershed Hydrology and Applications, 833882. V. P. Singh and D. K. Frevert, eds. Highlands Ranch, Colo.: Water Resources Publications, 2002. 
BROWN, L.C.; T.O. BARNWELL. The enhanced stream water quality models QUAL2E and QUAL2E - UNCAS: documentation and user manual. Env. Res. Laboratory. US EPA, EPA /600/3-87/007, Athens, GA, p. 189, 1987.

CARNEIRO, P.J.R.; MALDANER, V.I.; ALVES, P.F.; QUEIRÓS, I.A.de; MAURIZ, T.V.; PACHECO, R.J. Evolução do uso da água na bacia do rio Preto no Distrito Federal. Espaço \& Geografia, v. 10, n. 2, p. 47-76, 2007.

CASTRO, K.B. Avaliação do modelo SWAT na simulação da vazão em bacia agrícola do Cerrado intensamente monitorada. Dissertação de Mestrado em Geociências, Universidade de Brasília, Brasília, 2013.

$\mathrm{CECH}, \mathrm{T}$. Principles of Water Resources: History, Development, Management, and Policy. 3. ed., 546 p, 2009.

CHAVES, T. A. Integração de modelos hidrológico e econômico para a avaliação dos custos internos da erosão na agricultura em bacias hidrográficas. Tese de Doutorado, Curso de Pós-Graduação em Geografia, Universidade de Brasília, Brasília, 140 p. 2016.

CORREIA, E.F.G.; RIBEIRO, G.P.; BAPTISTA, A.C. Modelagem hidrológica da bacia hidrográfica do rio Bengalas, Nova Friburgo, RJ, utilizando o potencial de geotecnologias na definição de áreas de risco à inundação. Revista Brasileira de Cartografia, n. 67/6, p. 1183-1202, 2015.

CRAWFORD, N.H.; LINSLEY JR, R.K. Digital simulation in hydrology: Stanford Watershed Model IV. Department of Civil Engineering, Stanford University, Stanford, CA, n. 39, 1966.

DOOGE, J.C.I. Linear theory of hydrologic sistems. Technical Bulletin, n. 1948, p. $327,1973$. 
ENGEL, B.A.; SRINIVASAN, R.; ARNOLD, J.G.; REWERTS, C.; BROWN, S.J. Nonpoint-source (NPS) pollution modeling using models integrated with geographic information systems (GIS). Water Science and Technology, v. 28., p. 685-690, 1993.

ENGMAN, E.T. Remote sensing applications to hydrology. Future Impact. Hydrology Sciencies Journal, v. 41, n. 4, p. 637-647, 1996.

FAYAL, M.A. de A. Previsão de vazão por redes neurais artificiais e transformada. Dissertação de Mestrado em Engenharia Elétrica, Pontifícia Universidade Católica do Rio de Janeiro, Rio de Janeiro, 2008.

FERNANDES, J. G. Estimativa de vazão e produção de sedimentos na Bacia Hidrográfica do Rio São Francisco, utilizando o modelo SWAT. Recife, 186 p., 2015.

FERNANDES, J.G.; GALVÍNCIO, J.D.; FREIRE, M.B.G. dos S. O Modelo SWAT e suas Possibilidades de Aplicações em APL Agrícolas. Revista Brasileira de Geografia Física, p. 115-126, 2012.

FERRIGO, S.; MINOTTI, R.; ROIG, H.L.; KOIDE S. Avaliação da utilização de diferentes métodos na calibração automatizada do modelo SWAT In: XX Simpósio Brasileiro de Recursos Hídricos, Bento Gonçalves, 2013.

FERRIGO, Sara. Análise de consistência dos parâmetros do modelo SWAT obtidos por calibração automática - estudo de caso da bacia do Lago Descoberto - DF. Dissertação de Mestrado em Tecnologia Ambiental e Recursos Hídricos, Universidade de Brasília, Brasília, 2014.

FLANAGAN, D.C.; NEARING, M.A. USDA-Water Erosion Prediction Project: Hillslope Profile and Watershed Model Documentation. USDA-ARS National Soil Erosion Research Laboratory, West Lafayette, Indiana, 1995. 
FRAGOSO Jr. C.R.; FERREIRA, T.F.; MARQUES, D.M. Modelagem Ecológica em Ecossistemas Aquáticos. São Paulo: Oficina Textos. 304p. 2009.

FREITAS, L.F.; CARVALHO Jr, O.A.; GUIMARÃES, R.F.; GOMES, R.A.T.; MARTINS, E.S.; GOMES-LOEBMANN, D. Determinação do potencial de erosão a partir da utilização da EUPS na bacia do rio Preto. Espaço \& Geografia, v. 10, n. 2, p. 431-452, 2007.

FROTA, P.V. Propostas para gestão integrada dos recursos hídricos na bacia hidrográfica do rio Jardim - DF. Dissertação de Mestrado, Centro de Desenvolvimento Sustentável, Universidade de Brasília, Brasília, p. 145, 2006.

GUPTA, H.V.; SOROOSHIAN, S.; YAPO, P.O. Status of automatic calibration for hydrologic models: comparison with multilevel expert calibration. Journal of Hydrologic Engineering, v. 4, n. 2, p. 1-9, 1999.

HORTON, R.E. The role of infiltration on the hydrologic cycle. Transactions of American Geophysics Union, v. 145, p. 446-460, 1933.

IBGE - INSTITUTO BRASILEIRO DE GEOGRAFIA E ESTATÍSTICA. Mapa de biomas do Brasil, 2004. Disponível em: <www.mapas.ibge.gov.br/biomas2/viewer.htm>. Acesso em: 22 de fev. de 2013.

KANNAN, N.; WHITE, S.M.; WORRALL, F. WHELAN, M.J. Sensitivity analysis and identification of the best evapotranspiration and runoff options for hydrological modelling in SWAT-2000. Journal of Hydrology, v. 332, p. 456466, 2007.

LEAVESLEY, G.H.; LICHTY, R.W.; TROUTMAN, B.M.; SAINDON, L.G. Precipitation-Runoff Modelind System: User's Manual. Water-Resources Investigations Report. Denver, Colorado (EUA), 214 p. 1983. 
LENHART, T.; ECKHARDT, K.; FOHRER, N.; FREDE, H. G. Comparison of two different approaches of sensitivity analysis. Physics and Chemistry of the Earth. v. 27, p. 645-654, 2002.

LIMA, J.E.F.W.; SILVA, E.M. da. Estimativa da contribuição hídrica superficial do Cerrado para as grandes regiões hidrográficas brasileiras. In: XVII Simpósio Brasileiro de Recursos Hídricos, São Paulo. Anais do XVII Simpósio Brasileiro de Recursos Hídricos, Porto Alegre, 2007.

LIMA, J.E.F.W. Modelagem numérica do fluxo da água no solo e do escoamento de base em uma bacia experimental em área agrícola no Cerrado. Dissertação de Doutorado, Universidade de Brasília, Brasília, 312 p., 2010.

LIMA, J.E.F.W.; MONTENEGRO, S.M.G.L; MONTENEGRO, A.A.A.; KOIDE, S. Comparative hydrology: relationships among physical characteristics, hydrological behavior, and results of the SWAT model in diferente regions of Brazil. Revista Brasileira de Geografia Física, v. 7, n. 6, pp. 1187-1195, 2014.

MALDANER, V.I. Análise dos conflitos do uso da água na bacia hidrográfica do rio Preto no DF. Dissertação de Mestrado, Universidade Católica de Brasília, Brasília, 2003.

MALUTTA, S. Estudo hidrossedimentológico da bacia hidrográfica do rio negrinho - SC com o modelo SWAT. Dissertação de Mestrado, Instituto de Engenharia Ambiental, Universidade Federal de Santa Catarina, p. 126, 2012.

MARCHIORO, E.; FERNANDES, N.F.; MACEDO, J.R.de; BHERING, S.B.; GONÇALVES, A.O.; CAIADO, M.A.C. Modelagem da produção de sedimentos no noroeste fluminense como subsídio ao planejamento ambiental: um estudo de caso da bacia do córrego Santa Maria. Revista Brasileira de Geomorfologia, v. 12, p. 29-38, 2011. 
MELLO, C.R.; VIOLA, M.R.; NORTON, L.D.; SILVA, A.M.; ACERBI JÚNIOR, F.W. Development and application of a simple hydrologic model simulation for a Brazilian head water basin. Catena, v. 75, p. 235-247, 2008.

MERCURI, E.G.F.; DEPPE, F.; LOHMANN, M.; SIMÕES, K. Metodologia da geração de dados de entrada e aplicação do modelo SWAT para bacias hidrográficas brasileiras. In: XIV Simpósio Brasileiro de Sensoriamento Remoto, Natal, Rio Grande do Norte, Brasil, 2009.

MORIASI D.N; ARNOLD J.G; VAN LIEW M.W; BINGER R.L; HARMEL R.D; VEITH T. Model evaluation guidelines for systematic quantification of accuracy in watershed simulations. Transactions of the ASABE - American Society of Agricultural and Biological Engineering, v. 50, p. 885-900, 2007.

MULVANY, T.J. On the use of self registering rain and flood gouges. Proceedings of the Institution of Civil Engineers, v. 4, n. 2, p. 1-8, 1850.

NEITSCH, S.L.; ARNOLD, J.R.; KINIRY, J.R.; WILLIAMS, J.J. Soil and water assessment tool: theoretical documentation - version 2005. SERVICE, GS.A.W.R.L. - A. R, Texas USA, p. 525, 2005a.

NEITSCH, S. L.; ARNOLD, J. G.; KINIRY, J.R.; WILLIAMS, J.R. Soil and water assessment tool - Theoretical documentation version 2009. Temple, Blackland Research Center, Texas Agricultural Experiment Station, 654p, 2009.

NEVES, F.F.; SILVA, F.G.B.; CRESTANA, S. Uso do modelo AVSWAT na avaliação do aporte de nitrogênio $(\mathrm{N})$ e fósforo $(\mathrm{P})$ aos mananciais de uma microbacia hidrográfica contendo atividade avícola. Engenharia Sanitária e Ambiental, v. 11, n. 4, p. 311-317, 2006.

NEVES, D. G. Estimativa do balanço Hídrico Normal para o Município de Oiapoque localizado no setor costeiro do Amapá. In: VIII WORKSHOP ECOLAB (Ecossistema Costeiro Amazônico), Macapá, 2007. 
OLIVEIRA, M. Q. C.; MEDEIROS, Y. D. P. Aplicação do modelo SWAT na avaliação de impactos decorrentes da modificação no uso do solo em baciashidrográficas. In: XIII Simpósio Brasileiro de Recursos Hídricos, Belo Horizonte, Minas Gerais, Brasil, 1999.

PLANPAR - PLANO DIRETOR DE RECURSOS HÍDRICOS DA BACIA DO RIO PARACATU. Relatório de inventário dos recursos hídricos, 1998. In: Sistema de Informação de recursos hídricos. Disponível em: <http://www.ana.gov.br/AcoesAdministrativas/CDOC/docs/planos_diretores/Bac iaRioParacatu/plano_diretor2.asp>. Acesso em: 18 de jun. de 2012.

PETERSON, J. R.; HAMLETT, J. M. Hydrologic calibration of the SWAT model in a watershed containing fragipan soils. Journal of the American Water Resources Association, n. 34, p. 531-544, 1998.

RABUS, B.; EINEDER, M.; ROTH, R.; BAMLER, R. The Shuttle Radar Topography Mission-a new class of digital elevation models acquired by spaceborne radar. ISPRS Journal of Photogrammetry \& Remote Sensing, v.57, p.241-262, 2003.

REBOUÇAS, A.C.; BRAGA, B.; TUNDISI, J.G. Águas doces no Brasil: capital ecológico, uso e conservação.Academia Brasileira Científica, p. 717, 1999.

RENNÓ, C.D.; SOARES, J.V. Modelos hidrológicos para gestão ambiental. Programa de Ciência e Tecnologia para Gestão de Ecossistemas - Relatório técnico parcial. São José dos Campos: INPE, p. 60, 2000.

SALLES, L.A. Calibração e verificação do modelo Swat para a predição de vazões na Bacia do Ribeirão Pipiripau. Dissertação de Mestrado em Ciências Florestais - Universidade de Brasília, Brasília, 2012. 
SALTELLI, A.; TARANTOLA, S.; CHAN, K. A quantitative, model independent method for global sensitivity analysis of model output. Technometrics, v. 41, n. 1, p. 39-56, 2000.

SANTHI, C.; ARNOLD, J.G.; WILLIANS, J.R.; DUGAS, W.A.; SRINIVASAN, R.; HAUCK, L.M. Validation of the SWAT model on a large river basin with point and nonpoint sources. Journal of the American Water Resources Association, v. 37, n. 5, 2001.

SANTOS, I.; ANDRIOLO, M.V.; GIBERTONI, R.C.; PEREIRA FILHO, D.L; NISHIDA, E.; SILVA, R.C. Simulação com modelo SWAT das condições hidrológicas e de produção e transporte de sedimentos na bacia do rio Apucaraninha - PR. In: VI Simpósio Nacional de Geomorfologia Geomorfologia Tropical e Subtropical: processos, métodos e técnicas. Goiânia Goiás, Brasil, 2006.

SANTOS, R.C. Classificação textural aplicada à cobertura do solo de uma bacia hidrográfica usando sensoriamento remoto. Dissertação de Mestrado, Instituto de Engenharia Civil, Universidade Federal do Rio de Janeiro, Rio de Janeiro, p. 153, 2002.

SANTOS, R.F. Análise da produção da carga líquida na bacia do ribeirão do Gama-DF através do modelo SWAT. Dissertação de Mestrado do Departamento de Geografia, Universidade de Brasília, Brasília, p. 144, 2016.

SCHOBBENHAUS, C. As faixas de dobramentos Brasília, Uruaçu e Paraguai- Araguaia e o Maciço Mediano de Goiás. In: SCHOBBENHAUS, C. (coord.). Geologia do Brasil - texto explicativo do mapa geológico do Brasil e da área oceânica adjacente incluindo depósitos minerais, escala 1:2500000. Cap. VI. Brasília. Departamento Nacional de Produção Mineral, p. 251-29, 1984.

SETTI, A.A; LIMA, J.E.F.; CHAVES, A.G.M.; PEREIRA, I.C. Introdução ao Gerenciamento de Recursos Hídricos. Agência Nacional da Água, Brasília, p. 225, 2001. 
SHERMAN, L.K. Stream flow from rainfall by the Unit-Graph method. Engineering News-Record., v. 108, p. 501-505, 1932.

SILVA, C.L.; OLIVEIRA, C.A.S. Runoff measurement and prediction for a watershed under natural vegetation in central Brazil. Revista Brasileira de Ciência do Solo, v. 23, p. 695-701, 1999.

SILVA, F.D.M. Análise comparativa de Modelos Digitais de Elevação obtidos a partir de sensores orbitais: estudo de caso da Bacia Experimental do Alto Rio Jardim. Monografia de Curso de Bacharel em Gestão Ambiental, Universidade de Brasília Campus Planaltina, Brasília, p. 22, 2013.

SILVA, J.M.C; BATES, J.M. Biogeographic Patterns and Conservation in the South American Cerrado: A Tropical Savanna Hotspot. Bioscience, v. 52, p. 225-234, 2002.

SILVA, R.M., SANTOS, C.A.G., SILVA, V.C.L.; SILVA, L.P. Erosivity, surface runoff, and soil erosion estimation using GIS-coupled runoff-erosion model in the Mamuaba catchment, Brazil. Environmental Monitoring and Assessment, v. 185, n. 8, p. 8977-8990, 2013.

TATEISH, R.; AHN, C.H., Mapping Evapotranspiration and water balance for global land surfaces. ISPRS Journal of Photogrametry \& Remote ensisng, v. 51, p $209-215,1996$.

TUCCI, C.E.M.; CLARKE, R.T. Impacto das mudanças da cobertura vegetal no escoamento: Revisão. ABRH- Associação Brasileira de Recursos Hídricos, v. 2, n. 1, p. 135-152, 1997.

TUCCI, C.E.M. Modelos Hidrológicos. Porto Alegre: Ed. Universidade/UFRGS: ABRH- Associação Brasileira de Recursos Hídricos, p. 652, 1998. 
TUCCI, C.E.M. Modelos Hidrológicos. Porto Alegre: Ed. Universidade/UFRGS: ABRH- Associação Brasileira de Recursos Hídricos, 2. ed., p. 679, 2005.

TUCCI, C.E.M. Hidrologia: Ciência e aplicação. Editora da Universidade Federal do Rio Grande do Sul - ABRH. Porto Alegre: Ed. Universidade/UFRGS: ABRHAssociação Brasileira de Recursos Hídricos, 4. ed., p. 943, 2009.

TUCCI, C.E.M. Hidrologia: ciência e aplicação. Porto Alegre: Editora da UFRGS/ABRH. 4. ed., p. 943, 2012.

USACE. GeoHEC - HMS user's manual (Draft). Hydrologic Engineering Center, Davis, CA, 1999.

UZEIKA, T. Aplicabilidade do modelo SWAT (Soil and Water Assessment Tool) na simulação da produção de sedimentos em uma pequena bacia hidrográfica rural. Dissertação de Mestrado, Instituto de Recursos Hídricos e Saneamento Ambiental, Universidade Federal do Rio Grande do Sul, p. 130, 2009.

VAN LIEW, M.W.; ARNOLD, J.G.; GARBRECHT, J.D. Hydrologic simulation on agricultural watersheds: Choosing between two models. Transactions of the ASABE - American Society of Agricultural and Biological Engineering, v. 46, p. 1539-1551, 2003. 